Portland State University

PDXScholar

\title{
Conceptualizing and Measuring the Self in Chronic Illness and its Relationship to Adjustment
}

Jessica Marie Morea

Portland State University

Follow this and additional works at: https://pdxscholar.library.pdx.edu/open_access_etds

Part of the Psychology Commons

Let us know how access to this document benefits you.

\section{Recommended Citation}

Morea, Jessica Marie, "Conceptualizing and Measuring the Self in Chronic Illness and its Relationship to Adjustment" (2006). Dissertations and Theses. Paper 4308.

https://doi.org/10.15760/etd.6195

This Thesis is brought to you for free and open access. It has been accepted for inclusion in Dissertations and Theses by an authorized administrator of PDXScholar. Please contact us if we can make this document more accessible: pdxscholar@pdx.edu. 


\section{THESIS APPROVAL}

The abstract and thesis of Jessica Marie Morea for the Master of Science in

Psychology were presented on May 26,2006, and accepted by the thesis committee and the department.

COMMITTEE APPROVALS:
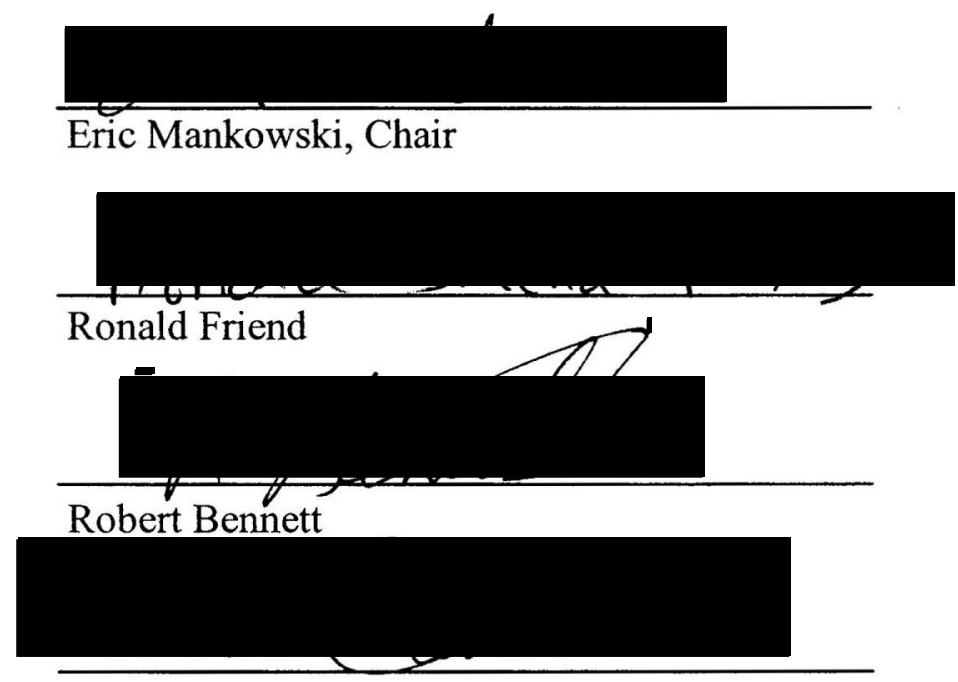

Victoria Cotrell

Representative of the Office of Graduate Studies

DEPARTMENT APPROVAL:

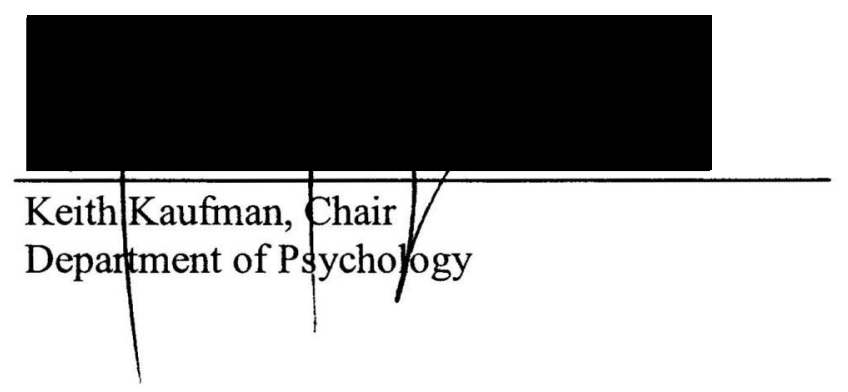




\begin{abstract}
An abstract of the thesis of Jessica Marie Morea for the Master of Science in Psychology presented May 26, 2006.
\end{abstract}

Title: Conceptualizing and Measuring the Self in Chronic Illness and its Relationship to Adjustment

This research sought to clarify the role of the self in chronic illness by developing and evaluating several new constructs, which intend to describe the extent to which illness permeates the self-concept. Following the works of Lewin and Asch, the concepts of central and peripheral regions of the self were elaborated to describe the state of illness within the self, termed "illness self-concept".

Three subsidiary constructs were introduced to further depict illness selfconcept: directionality, pervasiveness, and illness self-consciousness. Directionality refers to whether illness drives the self or self drives illness. Pervasiveness refers to whether illness affects many or few regions of the self. Illness self-consciousness refers to the degree of preoccupation with illness. A 23-item scale was developed to assess illness self-concept $(\alpha=.94)$, with items addressing each construct. A 14-item scale measuring "illness self-concept support" (ISC Support, $\alpha=.89$ ) was 
developed to assess whether family and friends reinforce illness as central or peripheral to the self.

I hypothesized that illness self-concept relates to adjustment such that the more illness is peripheral to the self, the better the adjustment. My second hypothesis was that personal, interpersonal, and illness-related factors would influence illness selfconcept. The third hypothesis was that illness self-concept would predict additional variance in adjustment after controlling for each of these factors.

Fibromyalgia patients $(n=109)$ completed measures of illness self-concept, optimism, ISC support, illness intrusiveness, and functional status. Results supported hypothesis one, indicating that illness self-concept significantly predicted quality of life $\left(\mathrm{R}^{2} \Delta=.39\right)$ and depression $\left(\mathrm{R}^{2} \Delta=.24\right)$. Results supported hypothesis two, indicating that ISC support, optimism, illness intrusiveness and functional status each contribute to illness self-concept. Results supported hypothesis three, indicating that illness self-concept predicted substantial variance in adjustment even after controlling for personal, interpersonal, and illness-related factors.

All three hypotheses were strongly supported, indicating that illness selfconcept is an important predictor of adjustment in chronic illness. This study demonstrated that the extent to which illness permeates the self-concept has implications for adjustment in fibromyalgia, and may be an important variable in improving psychological adjustment in other chronic illnesses. 
CONCEPTUALIZING AND MEASURING THE SELF IN CHRONIC ILLNESS AND ITS RELATIONSHIP TO

ADJUSTMENT

by

JESSICA MARIE MOREA

A thesis submitted in partial fulfillment of the

requirements for the degree of

MASTER OF SCIENCE

in

PSYCHOLOGY

Portland State University

2006 


\section{ACKNOWLEDGEMENTS}

I would first and foremost like to thank Dr. Ronald Friend, who introduced me to this area of study and who has mentored me beyond my expectations. I would like to thank Dr. Robert Bennett, who graciously offered us his expertise and access to patients, and who gave me the opportunity to work with fibromyalgia patients, which has been an invaluable experience. I would also like to thank Dr. Eric Mankowski for chairing this committee and seeing the thesis through to its finish. I would like to extend my appreciation and gratitude to Susan and Nick Morea, Brandon Irvine, and Toni Dancu for their unconditional support during this process. 


\section{TABLE OF CONTENTS}

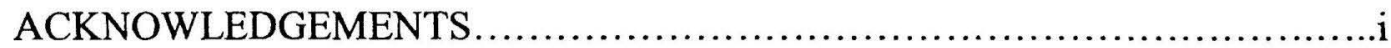

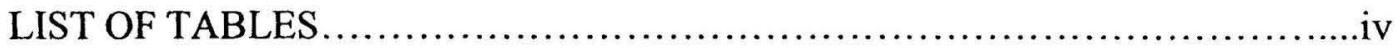

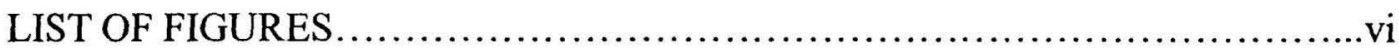

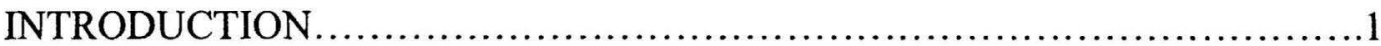

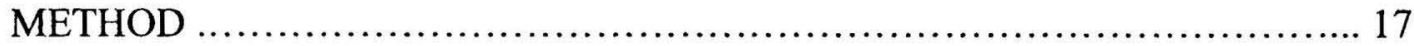

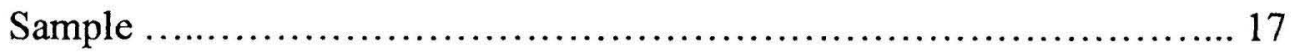

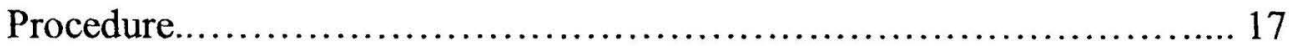

Measures........................................................... 18

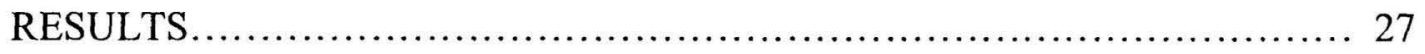

Psychometric Properties of the Illness Self-Concept Scale............... 27

Psychometric Properties of the ISC Support Scale...................... 33

Hypothesis One............................................. 44

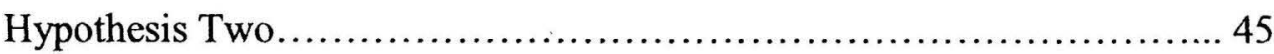

Hypothesis Three.................................................. 49

Additional Analyses.......................................... 55

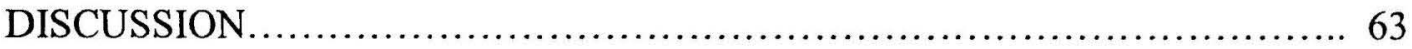

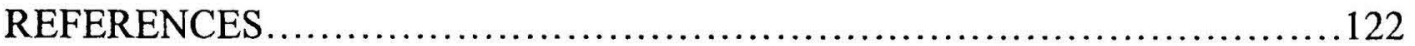

Appendix A: Illness Self-Concept Scale...............................134

Appendix B: ISC Support Scale.................................... 135 
Appendix C: Illness Intrusiveness Ratings Scale.

Appendix D: Fibromyalgia Impact Questionnaire (FIQ).

Appendix E: Life Orientation Test-Revised (LOT-R)

Appendix F: Marlowe-Crowne Social Desirability Scale. 140

Appendix G: Quality of Life. 141

Appendix H: Beck Depression Inventory (BDI) 142 


\section{LIST OF TABLES}

Table 1: Illness Self-Concept Scale ........................................ 82

Table 2: Illness Self-Concept Scale: Items reflect illness as central to self .............83

Table 3: Illness Self-Concept Scale: Items reflect illness as peripheral to self ............84

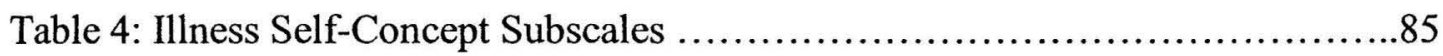

Table 5: Correlation Between Subscales and Study Variables ........................86

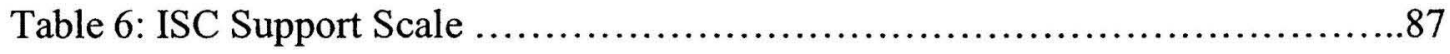

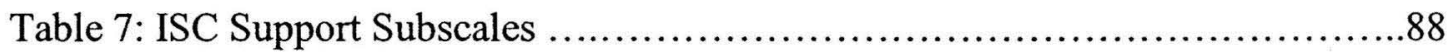

Table 8: Correlation Between ISC Subscales and Study Variables ....................89

Table 9: Correlation Between Study and Demographic Variables ...................90

Table 10: Correlations and Descriptive Statistics of Study Variables ................91

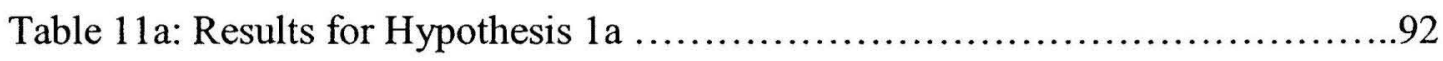

Table 11b: Results for Hypothesis 1b .........................................93

Table 12a: Results for Hypothesis 2a .......................................94

Table 12b: Results for Hypothesis $2 b$.....................................95

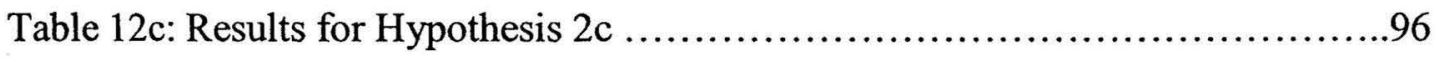

Table 12d: Results for Hypothesis 2d .......................................97

Table 13: Additional Analysis for Hypothesis $2 \ldots \ldots \ldots \ldots \ldots \ldots \ldots \ldots \ldots \ldots \ldots \ldots$

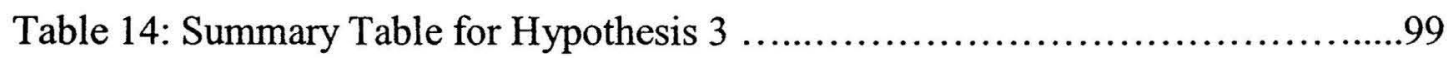




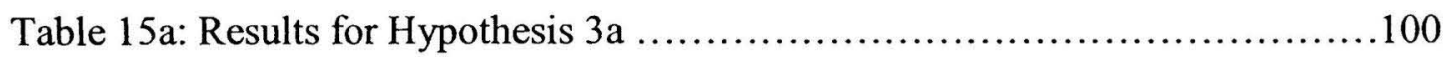

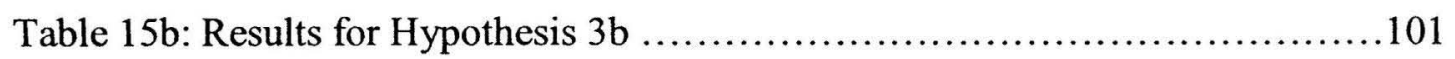

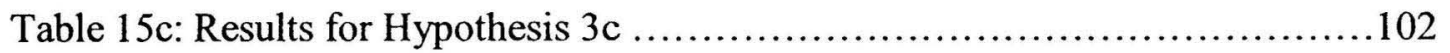

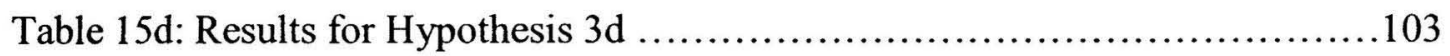

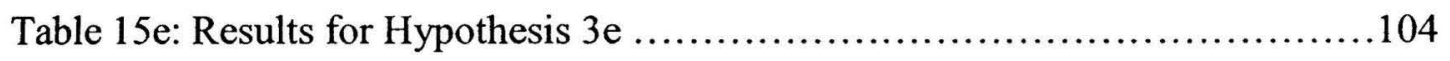

Table 15f: Results for Hypothesis $3 f$......................................... 105

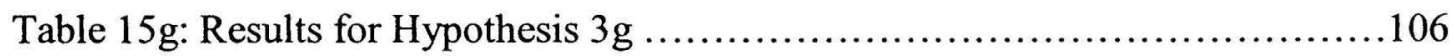

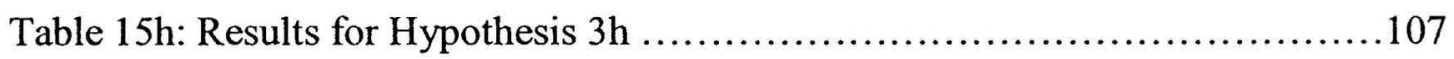

Table 16a: Additional Analysis for Hypothesis 3 with Quality of Life ..............108

Table 16b: Additional Analysis for Hypothesis 3 with Depression ...................109

Table 17a: Additional Analysis with Quality of Life \& Control over Symptoms .....110

Table 17b: Additional Analysis with Depression \& Control over Symptoms .........111

Table 18: Additional Analysis Controlling for Depression ........................112

Table 19a: Additional Analysis with Quality of Life \& Self-Esteem ...............113

Table 19b: Additional Analysis with Depression \& Self-Esteem ..................114

Table 20a: Additional Analysis with Quality of Life \& Victimization ..............115

Table 20b: Additional Analysis with Depression \& Victimization ...................116 


\section{LIST OF FIGURES}

Figure 1: Illustration of Proposed Framework ................................117

Figure 2: Box \& Whisker Plot of the Illness Self-Concept Scale .................118

Figure 3: Distribution of the Illness Self-Concept Scale ..........................119

Figure 4: Box \& Whisker Plot of the ISC Support Scale ........................120

Figure 5: Distribution of the ISC Support Scale ...............................121 


\section{Introduction}

The onset and course of a chronic illness often result in disruptions in the lives of those who suffer. Individual reactions to these interferences vary and can have important consequences for the self. Such interferences in valued activities and important life domains have been labeled as illness intrusiveness (Devins, Yitzchak, et al., 1983). Many studies have shown that illness intrusiveness has a negative impact on depression and quality of life in a variety of chronic illnesses, including end-stage renal disease, rheumatoid arthritis, multiple sclerosis, asthma and diabetes (Devins, Armstrong, et al., 1990; Devins, Edworthy, Seland et al., 1993; Devins, Mandin, et al., 1990; Devins, Mann, et al., 1990; Devins, Seland, et al., 1993; Devins, Yitzchak, et al., 1983-84; Eitel, Hatchett, Friend, Griffin, \& Wadhwa, 1995; Littlefield, et al., 1996; Mullens, Chaney, Balderson, \& Hommel, 2000; Peterson et al., 1991; Talbot, Nouwen, Gingras, Belanger, \& Audet, 1999). A related but broader concept, illness effects, is concerned with how illness and treatment disrupt somatic, psychological and interpersonal life domains (Greenberg \& Peterson, 1997). The primary purpose of this research is to conceptualize the self in the course of chronic illness. A secondary purpose is to describe how illness intrusiveness and other personal and interpersonal variables are related to illness self-concept and adjustment to chronic illness.

To the extent that a person's self-concept is defined in terms of their goals, activities, and major life domains, it follows that disruptions to these may challenge the self-concept. Two studies have attempted to establish a relationship between the degree of illness disruption and the self-concept (Beanlands et al., 2003; Devins, 
Beanlands, Mandin, \& Paul, 1997). Beanlands et al. used the semantic differential technique to obtain a measure of participants' self-concept. Participants assessed a typical bone marrow transplant patient (BMT) and "myself as I am now" on three major dimensions: evaluation (good-bad, kind-cruel), potency (strong-weak, hardsoft), and activity (active-passive, rash-cautious). If the difference scores between a participant's assessment of a BMT patient and "myself as I am now" was great, the self-concept was determined to be dissimilar to a BMT patient. If the distance was small, the participant's self-concept was determined to be similar to a BMT patient. Results show that illness intrusiveness had a small but significant correlation $(\mathrm{r}=.27)$ with this measure of self-concept (similarity to a BMT patient). Engulfment, defined as the extent to which illness comes to dominate the self-concept (McCay \& Seeman, 1998), was also measured (Beanlands et al., 2003). Surprisingly, no significant relationship between engulfment and self-concept was found $(r=.15)$, indicating that similarity to a BMT patient may not adequately capture illness self-concept.

A similar study with end-stage renal disease (ESRD) patients attempted to link self-concept, using the same semantic differential technique, to adjustment to chronic illness (Devins, Beanlands, Mandin \& Leenert, 1997). However, no simple relationship between self-concept and adjustment was observed. Only complicated interactions between illness intrusiveness, age, and self-concept were related to psychosocial well-being and emotional distress. One possible explanation is that similarity or dissimilarity to an ESRD patient does not sufficiently characterize illness self-concept. Devins et al. found that perceived similarity to an ESRD patient was 
associated with a self-view that was active and weak (compared to perceived dissimilarity) but was not associated with a self-view of good or bad. This suggests that reported similarity/dissimilarity to an ESRD patient may not represent a negative or positive self-concept. This might explain why self-concept, using the semantic differential technique, does not relate to adjustment, illness intrusiveness, or engulfment.

A major limitation of these studies is a focus on how the self-concept is dominated by illness and not how people are often able to withstand chronic illness and preserve their sense of non-illness self (Symister \& Friend, 1996). For example, the semantic differential technique assesses similarity to a BMT or ESRD patient but does not assess similarity to a healthy person. No research has examined how the self can be protected from illness and its effects. Particularly, research has not examined how the self-concept can be sustained in the face of chronic illness. The major purpose of this study is to articulate a more precise and inclusive framework for understanding how the self responds to illness, either by preserving the self or by allowing illness to define the self.

Although there is a body of research on the self-concept in general (Ashmore \& Jussim, 1997; Byrne, 1996; Markus \& Nurius, 1986; Oyserman, 2004), and others have suggested a relationship between illness and self-concept (Ashmore \& Contrada, 1999; Charmaz, 1999; Leventhal, Idler, \& Leventhal, 1999; Ouellette, 1999), no adequate framework appears to describe the relationship between illness and the self. The current research is an attempt to generate constructs that help to clarify and assess 
the extent to which the sense of self is preserved or becomes defined by illness. It will also examine personal, interpersonal, and illness-related factors (e.g., illness effects) that may help sustain self-concept or make it more vulnerable to domination by illness. We propose that those who are able to sustain their self-concept will be better adjusted than those whose self-concept becomes dominated by illness, in terms of both quality of life and depressive mood.

The notion of a self-concept has been defined in a variety of ways in the psychological literature. Many have theorized that the self-concept is the most central concept in psychology and is necessary in order to understand individual people and their behavior (Epstein, 1973). Self-concept has been described as an active agent that is influenced by its environment and experiences as well as influential in its environment. It has also been described as a mediator in many intrapersonal and interpersonal processes, such as with information processing, affect, and social perception (Markus \& Wurf, 1987). The idea of self-concept as mediator implies that the self is the agent of change as information and experience enter the self and leave in an altered form as behavior, attitude, or other outcome. The relationship between selfconcept and illness has been suggested to take several different forms. These include illness as challenging previous ideas about the self, the need to reconstruct the self when illness is encountered, and the emergence of a "sick role" that takes over one's identity (Charmaz, 1999; Leventhal, Idler \& Leventhal, 1999). (Note that the latter two citations refer to theories and ideas put forth in the authors' work and do not refer to systematic research in these areas.) 
In order to understand how illness is related to the self, I draw on Lewin (1951) and Asch (1952) and their concepts of central and peripheral regions of the life space. Following these authors, I characterize the self-concept in terms of central and peripheral regions. Central regions lie close to the core of the self (Asch, 1952, p.280) and affect many other regions of the life space. The state of the whole self is dependent on the state of the central regions (Lewin, 1951, p.123). Peripheral regions of the self, on the other hand, are dependent on the central regions for direction. For the purposes of explaining the current research, two concepts are introduced: illness peripheral to self(IPS) and illness central to self (ICS) (Chiaramonte \& Friend, 2005). Illness central to self (ICS) refers to the condition under which illness becomes one of the central regions of the life space. When illness is a central region of the self, it acts as a fundamental force driving goals, needs, actions, and relationships, and affecting many other regions of the life space. Illness peripheral to self (IPS) refers to the condition under which the core part of the self is preserved in spite of illness, and the illness is contained to a peripheral region of the life space. When illness is a peripheral part of the self, it is not a driving force and may even be seen as a constructive challenge rather than a burden.

IPS and ICS represent two extreme ends of a continuum, with most people falling somewhere in between. Those on the IPS end of the continuum have sustained more of an overall, non-illness identity than those at the ICS end. People are assumed to differ in the extent to which the illness is incorporated as a central or peripheral part of the self. In addition to individual differences, illness-related and environmental 
factors (e.g., disease severity; supportive or problematic environment) also influence the process of integration of illness into the self. Furthermore, changes in illnessrelated factors (e.g., course of the illness) or the environment may also signal a change from IPS to ICS or the reverse.

This research proposes that the relationship between illness and the self is characterized by three interdependent constructs: directionality, pervasiveness, and self-consciousness. These constructs help describe the state of illness within the life space. The first construct, directionality, specifies the causal relationship between the illness and the self, and whether the illness drives the self or the self drives the illness. If the self is the driving force, then needs, actions, goals and relationships are interpreted in light of the self, and illness is peripheral. If the illness drives the self then needs, actions, goals, and relationships are all interpreted in light of the illness.

The second construct is pervasiveness. When an illness is pervasive many parts of the life space are affected. When an illness is not pervasive (i.e., it is contained), few regions of the life space are affected. If the illness is driving the self it is a central region, and will thus affect many parts of the self. If the self is the driving force, illness is peripheral and many parts of the life space are protected from the illness. The idea of pervasiveness is similar to Wright's (1983) concept of spread. She defines spread as the bringing together of different personal traits based on their similarity of valence as positive or negative (p.61). The concept of spread claims that people tend to perceive themselves and others as either all positive or all negative. It is this principle of consistency and balance that explains how illness can spread to many 
parts of the self. If illness is viewed negatively in a person, other parts of the same person come to be viewed negatively as well (cf. Wright, 1983).

The third concept, illness self-consciousness, refers to the extent to which individuals are preoccupied with their illness. People who rarely think about their illness are said to be low in illness self-consciousness. People who are preoccupied with their illness are said to be high in illness self-consciousness. When the self drives illness, and illness influences few regions of the life space, illness self-consciousness is likely to be low. People whose illness is a peripheral region of the self may think about their illness but not incessantly. Conversely, when illness drives the self, and is pervasive across many parts of the self, individuals will likely be high in illness selfconsciousness.

Asch (1952) discusses the consequence of having a self and explains that people who see themselves as both an object and a source of experience. He labels this awareness of our experience as self-consciousness and claims that it makes self-regard possible. Consciousness of oneself as ill can elicit greater effort and pride in how one handles being ill, or it can result in judgment and disappointment in oneself for having an illness. Asch argues that having consciousness frees individuals from being influenced exclusively by immediate situational factors. Individuals' consciousness of all of their collective experiences provides a context in which to formulate self regard in a specific situation, such as illness.

In this research, we consider that individuals' degree of optimism, as well as supportive and problematic relationships, influence their self-consciousness about 
illness, how they reflect upon the experience of being ill and how they regard themselves in their illness. These factors influence self-consciousness because they contribute to the context in which people regard themselves. With greater optimism, individuals will reflect more positively on themselves and their illness. It may be that people who are optimistic have a history of enduring difficult situations while maintaining a positive attitude, which provides them with the confidence that they can withstand current negative circumstances. Similarly, a supportive environment, where illness is not reinforced as central and where positive exchanges with respect to illness are cultivated, establishes a context in which people can regard themselves well and ward off negative influences. However, if a social network (or individuals within the network) makes people conscious of the negative consequences of illness, it will likely influence their regard for themselves with respect to illness.

The concepts of illness as central and illness as peripheral, and the associated constructs, characterize the state of illness within the self, termed "illness selfconcept". Illness self-concept differentiates people in the same way that there is inherent variation in any state or trait. However, illness self-concept may also change within a person across time and situations (e.g., degree of pain or access to resources). Some external factors will produce common effects for all people, for example, the greater the social stigma of a disease, the more likely illness will be central to the self. Conversely, the more successful a treatment is, the more likely illness will be peripheral to the self. It is important to consider situational factors, in addition to personal factors, when examining the relationship between illness and self. 
Using this framework, illness self-concept (i.e., the extent to which illness is central or peripheral to the self) will be assessed. It is assumed that there are many personal, interpersonal, and illness-related factors that influence whether an illness is incorporated as a central or peripheral part of the self, including the parameters of the illness and treatment, such as the disease prognosis. The current study focuses on four factors that may be critical in influencing the relationship between illness and self: optimism and pessimism as personal factors, social support and problematic support as interpersonal factors, illness intrusiveness as a factor associated with the disease and treatment, and functional status, which is used as a marker for disease severity in fibromyalgia.

Figure 1 provides a conceptual schematic of the expected relationships between study variables. The figure shows that there are four variables (social support, optimism, illness intrusiveness, and functional status) that are expected to influence illness self-concept. It also shows that illness self-concept is expected to predict quality of life and depression, even controlling for the influence of personal, interpersonal, and illness-related factors. The purpose of this illustration is to help the audience visualize the hypotheses proposed in this study, and the anticipated directions between variables, and is not intended to convey any analytical meaning. Optimism is characterized as positive outcome expectancies and positive affect (Scheier \& Carver, 1985, 1992), and has been linked to psychological well-being (Carver, Pozo et al., 1993), psychological adjustment (Aspinwall \& Taylor, 1992), physical well-being (Fontaine \& Seal, 1997), and decreased mortality (Giltay, 
Geleijnse, Zitman, Hoekstra, Schouten, 2004). Positive outcome expectancies are the anticipation that by engaging in certain activities, desired goals will be attained. Optimism influences the ability to reevaluate a situation when goals are obstructed, due to uncontrollable factors, which involves both acceptance of the current situation and delineation of new or modified goals (Carver, Pozo et al., 1993).

The current research proposes optimism as a positive factor that influences how illness is incorporated into the self. When illness is introduced into the life space, optimism facilitates an acceptance of the current situation and redirects the self towards attainable goals, activities, and relationships. Illness is more likely to be a peripheral part of the self and life space. Markus and Nurius (1986) identified the concept of expected selves, which represent expectations for the self in the future. Carver, Reynolds \& Scheier (1994) found discrepancies between optimists and pessimists with respect to the number of expected selves, indicating that optimists have more positive outcome expectancies for the future.

Optimism, then, is likely to positively influence the relationship between illness and the self, such that optimists are more likely to incorporate it as peripheral. Acceptance of an illness and positive reframing can facilitate the identification of realistic goals, which form the basis of optimism, and result in better adjustment. For example, patients with breast cancer who engaged in acceptance and positive reframing showed fewer symptoms of distress post-surgery, and at three and six months follow-up (Carver, Pozo et al., 1993). In the present research, optimism is hypothesized to increase incorporation of illness as a peripheral part of the life space 
and self, which will result in fewer symptoms of distress (in the form of depressive mood), and better quality of life.

Pessimism, on the other hand, is defined in terms of anticipation of poor outcomes (Scheier \& Carver, 1985) and is hypothesized to facilitate incorporation of illness as a central part of the self (ICS). Pessimism is observed to be relatively stable across time and context, and persons with this characteristic are described as universally glum. Pessimism leads to giving up on objectives that are no longer attainable and does not facilitate replacing them with new ones.

Consequently, this study hypothesizes that pessimism encourages the illness to drive the self, its goals, activities and relationships. Without new goals and activities many parts of the life space are pervaded by illness. Additionally, disengagement from a goal increases self-focus (Scheier \& Carver, 1985), which amplifies limitations of an illness and illness self-consciousness. Pessimism is proposed to negatively influence the relationship between illness and the self, such that it will be incorporated as central to the life space.

Studies have shown that interpersonal relationships have an important impact on adjustment in chronically ill populations (Griffin, Friend, Kaell, \& Bennett, 2001; Hatchett, Friend, Symister, \& Wadhwa, 1997; Symister \& Friend, 2003). The current study proposes that social support, as one aspect of interpersonal relationships, is important to the extent that it either encourages a person to incorporate illness as a central or peripheral part of the self. However, positive and negative social support are relatively independent constructs (Symister \& Friend, 2003). This suggests that 
positive social support and negative support, or problematic relationships, will have differential effects on adjustment to chronic illness.

Research with Rheumatoid Arthritis (RA) patients has shown that positive social support and problematic support are both related to depression (Revenson, Schiaffino, Majerovitz \& Gibofsky, 1991; Riemsma et al., 2000) but not to each other. Positive social support is related to fewer depressive symptoms while problematic support is related to more depressive symptoms in patients with RA. Several other studies have demonstrated a direct relationship between social support and mood in RA patients (Doeglas et al., 1994; Goodenow, Reisine, \& Grady, 1990; Kraaimaat, van Dam-Baggen, \& Bijlsma, 1995). Symister and Friend found that self-esteem partially mediated the relationship between social support and adjustment with chronically ill patients. This indicates that social support increases self-esteem and in turn influences adjustment. The current study proposes a similar relationship between social support and self-concept, such that positive social support will increase positive self-concept, and illness will likely be incorporated as peripheral to the self(IPS).

On the other hand, problematic support is proposed to negatively influence self-concept and illness is more likely to be incorporated as central to the self (ICS). Problematic relationships exist when important people (family and/or friends) do not understand the nature of an illness, its treatment, symptoms and subsequent limitations (Bediako \& Friend, 2004; Hatchett, et al., 1997; Revenson et al., 1991; Riemsma et al., 2000; Symister \& Friend, 2003). When individuals with chronic illness do not feel that important others understand what they are going through, the illness self is 
reinforced. Those who receive problematic support are more likely to integrate illness as central to their self-concept.

Hatchett et al. (1997) found direct support for the relationship between family's lack of knowledge about disease characteristics and adjustment to illness in a prospective study with renal patients. More specifically, they found that problematic support (including excessive family expectations and feeling misunderstood) predicted depression, hopelessness, illness intrusiveness and quality of life. Controlling for negative affect, Symister and Friend (2003) found that self-esteem significantly reduced the relationship between problematic support and depression. This suggests that problematic relations decrease self-esteem, which in turn influences depression. Similarly, the current research proposes that problematic support will negatively influence self-concept, such that illness will more likely be central to the self.

The parameters of a chronic illness, for example the progression of the disease, are likely to influence the course of the illness and how the self responds (Griffin, Friend, Kaell, Bennett, \& Wadhwa, 1999). This research identifies illness intrusiveness as a factor that represents the extent to which an illness disrupts valued activities and life domains, and examines its relationship to self-concept. Following Devins and colleagues (Beanlands et al., 2003; Devins, Beanlands, Mandin, \& Paul, 1997), the study proposes that when illness intrusiveness is minimal, illness is more likely to be peripheral to the self. However, as illness intrusiveness increases, illness is more likely to be central to the self. 
Fibromyalgia affects individuals’ physical functioning and abilities, work status, sleep, pain, stiffness, fatigue, anxiety, and well-being. Unlike other chronic illnesses, there are no biological markers that can be used to identify the severity of an individual's condition. Physicians and researchers use a measure of functional status, which stands as a measure of disease severity. As functional status decreases (and physical impairment and symptoms increase), illness is likely to pervade many regions of the life space and illness self-consciousness will increase. Consequently, the poorer the functional status, the more likely illness will be central to the self. However, when functional status is good, and physical impairment and symptoms are minimal, illness is likely to pervade few regions of the life space, and illness self-consciousness will be low. Consequently, the better the functional status, the more likely illness will be peripheral to the self.

The current research tested this framework (see Figure 1) on patients with fibromyalgia syndrome (FMS). Fibromyalgia is a chronic disorder characterized by widespread musculoskeletal pain and tenderness in specific areas of the body (tender points). Symptoms of fibromyalgia include headaches, sleep disturbance, fatigue, morning stiffness, and irritable bowel syndrome (Bennett, 2002; Wolfe, Smythe, Yunus, Bennett, Bombardier, Goldenberg, et al., 1990). Although there is now substantial evidence that fibromyalgia is a disorder of the central nervous system and has an established pathogenesis (Bennett, 2004; Inanici \& Yunus, 2004), fibromyalgia is sometimes not recognized as a legitimate diagnosis (Bennett, 2002). As a result, 
these patients may be more vulnerable to stigma and psychological distress, compared to a population with a less contested diagnosis.

FMS is difficult to successfully treat (Wolfe, Anderson, Harkness, Bennett, Caro, Goldenberg, et al., 1997), and studies have suggested that treatment should focus on both physical and emotional functioning (Bennett, 2002; Thieme, Turk, \& Flor, 2004). Wolfe et al. examined outcomes for 538 patients across six U.S. rheumatology centers and found no substantial change over time with respect to pain, functional disability, fatigue, sleep disturbance, or psychological status. As a result, it is essential to examine treatment alternatives for fibromyalgia patients, specifically seeking ways to improve quality of life and functional status. The current research attempts to define the relationship between illness self-concept and adjustment in an effort to improve the quality of life for patients with fibromyalgia and other chronic conditions.

The present study goes beyond previous research in attempting to describe the specific relationship between illness and the self. The main purpose of the study was to generate and assess constructs that characterize the state of illness within the self, using a newly developed tool which measures illness self-concept, and to examine its relationship to adjustment in fibromyalgia. A second purpose was to identify personal, interpersonal, and illness-related factors that help to determine illness self-concept. The following hypotheses were proposed:

1. Illness self-concept is related to adjustment, such that the more illness is perceived as a peripheral part of the self (IPS), the greater 
the quality of life and the lower the depressive mood. Conversely, the more illness is perceived as central to the self (ICS), the poorer the quality of life and the greater the depressive mood.

2. Personal, interpersonal, and illness-related factors influence illness self-concept, such that the more optimism and social support, the lower the illness intrusiveness and the better the functional status, the more likely that illness will be incorporated as peripheral to the self. In contrast, the more pessimism and problematic support, the higher the illness intrusiveness and the worse the functional status, the more likely that illness will be incorporated as central to the self.

3. Illness self-concept will predict quality of life and depressive mood over and above the impact of any of the following taken alone: optimism, social support, illness intrusiveness, and functional status. 


\section{Method}

\section{Sample}

Data were collected from 109 subjects with fibromyalgia, recruited from the Oregon Fibromyalgia Foundation's online volunteer database. To be eligible for the study, participants had to have a primary diagnosis of fibromyalgia. Demographic characteristics of the participants are shown in Table 1. The mean length of diagnosis was 9.7 years $(\mathrm{SD}=7.45)$. Participants ranged in age from 16 to 77 years, with a mean age of $53(\mathrm{SD}=10)$. The sample was predominantly white $(97 \%)$ and most had at least some college education (83\%). Ninety-five percent of the sample were women and $5 \%$ were men. Sixty-three percent of the sample were married, versus $37 \%$ who were not, and $37 \%$ were currently working, versus $63 \%$ who were not. Forty-two percent of the sample reported that they stopped working because they were ill. Procedure

Two hundred people with fibromyalgia were randomly selected from a database of over 300 people, maintained by the Oregon Fibromyalgia Foundation. The foundation is a volunteer, non-profit organization that provides information about fibromyalgia online and encourages fibromyalgia-related research. The foundation maintains a database of people with fibromyalgia who have volunteered to participate in research. Subjects were identified through the database and asked to participate via mail. A questionnaire, accompanied by a letter explaining the purpose of the research and what participation entails, was mailed to each potential participant. Participants 
were asked to complete the written questionnaire and return it in the provided stamped, return envelope.

Three weeks after the questionnaires were sent to participants, a reminder postcard was sent to participants who had not yet responded. If, after the second letter, there was still no response, participants were telephoned to ask for their participation. If they were uninterested, they were asked to return the questionnaire in the pre-paid envelope. Of the two hundred questionnaires that were sent out, 171 subjects received the questionnaire or were eligible to participate (i.e., had a primary diagnosis of fibromyalgia). One hundred and nine subjects returned the completed questionnaire, with a total response rate of $64 \%$. Sixteen subjects ( $9 \%$ ) refused to participate and another $27 \%$ did not respond at all to the questionnaire.

\section{Measures}

\section{Independent Variables}

Illness Self-Concept. The Illness Self-Concept Scale was developed for the purpose of this study. Twenty-three items were used to assess the extent to which a participant's illness permeates the self-concept (i.e., is as a central or peripheral part of their self-concept). Items assessed the centrality of illness using three constructs: directionality, pervasiveness, and self-consciousness. Directionality indicates whether illness occupies a central region of the life space and, thus, is a driving force, or whether the pre-illness self has been preserved. An example of an item from this construct is, "My illness is at the center of who I am". Pervasiveness indicates the extent to which illness has pervaded important and valued regions of the life space. An 
example of an item measuring pervasiveness is, "I do not allow my illness to affect too many parts of my life". Illness self-consciousness refers to the extent that a person is focused on their illness and how much time they spend thinking about their illness. An example of an illness self-consciousness item is, "I am preoccupied with my illness".

Some items assess more than one construct. For example, "Sometimes I feel consumed by my illness" illustrates that illness is a driving force, that many or all regions of the life space are "consumed" or pervaded, and implies a preoccupation with illness (self-consciousness). Thirteen items measure directionality, seven measure pervasiveness, and three measure illness self-consciousness. Participants rated their level of agreement with each item on a six point scale from "Strongly disagree" (1) to "Strongly agree" (6). Negative items were reverse scored and higher scores indicate that illness is more central to the self-concept. A reliability analysis was conducted and the illness self-concept scale demonstrated high internal consistency $(\alpha=.94)$. Item analysis and further psychometric characteristics are described in the results section since the scale was developed for the purposes of this study.

Items for the Illness Self-Concept Scale were derived from the theory developed in this research, which claims that the relationship between illness and the self can be described in terms of occupying central and peripheral regions of the self and life space, and through three subsidiary constructs. Items that reflect illness as a central or peripheral region of the self-concept and life space were generated. In addition, items addressing the pervasive aspects of illness and the extent to which a person is preoccupied with their illness were generated. A meeting was conducted 
with a woman who suffers from Rheumatoid Arthritis. She gave feedback as to which items were worded awkwardly, which reflected experiences that she has had, and provided insight as to other experiences which reflect illness self-concept. Items were eliminated or modified in order to measure illness self-concept, as developed in this study, and to address actual experiences of people with chronic illness.

After the items were revised, they were pilot-tested with approximately ten people that had chronic conditions, varying from chronic back pain to pulmonary disease. The interviews took place as a student project, required for participation in the Advanced Applied Developmental Psychology graduate seminar in Winter 2005.This process was especially useful as the items were pilot-tested in an interview format, which allowed participants to provide verbal feedback regarding item interpretation and how items could be changed to be more effective. In addition, some items were identified as more relevant than others. This process validated which items were measuring the intended underlying constructs and additional items addressing these constructs were generated to create the final scale.

Illness Self-Concept Support (ISC Support). The ISC Support Scale was developed for the purpose of this study and assesses the extent to which a participant's social support network reinforces illness as central or peripheral to their self-concept. The scale contains items that measure positive support, where illness is reinforced as a peripheral part of the self-concept, and items that measure negative support, where illness is reinforced as central. The intimate social network referenced in the scale is defined as partner or spouse, family, and close friends. Fourteen items focus on the 
three constructs proposed to facilitate the relationship between illness and the self: directionality, pervasiveness, and illness self-consciousness. Six items measure directionality, three measure pervasiveness, and five measure illness selfconsciousness, with some items addressing more than one construct. For example, "Reminds me that my illness does not define me", assesses both directionality and illness self-consciousness.

Participants rated their level of agreement with each item on a six point scale from "Strongly disagree" (1) to "Strongly agree" (6). Negative items were reverse scored with higher scores indicating that a participant's social support network reinforces illness as a central part of the self-concept. A reliability analysis was conducted and the ISC Support Scale demonstrated high internal consistency ( $\alpha=$ .89). Item analysis and further psychometric characteristics of the scale are discussed in the results section.

The three sub-constructs measured by the ISC Support Scale are the same constructs assessed in the self using the Illness Self-Concept Scale. In developing the Illness Self-Concept Scale, more items fell under the directionality construct, since the primary component of illness self-concept is whether illness occupies a central part of the self-concept and life space and, thus, directs the self. Pervasiveness and illness self-consciousness are also measured, but are subsidiary constructs that help to further describe how illness is either central or peripheral. The ISC Support Scale intends to measure how a social network reinforces illness as central or peripheral. The nature of social interactions is such that people may influence the self through verbal and 
behavioral exchanges. The constructs of pervasiveness and illness self-consciousness lend themselves to these exchanges. For example, an individual in a social network may remind someone of their illness (illness self-consciousness), or suggest an activity that expands the life space (pervasiveness). Because these two constructs are more prevalent in social exchanges, there are more items (proportionally) that fall under these two constructs in the ISC Support Scale than in the Illness Self-Concept Scale.

Illness Intrusiveness. In order to measure illness intrusiveness, the Illness Intrusiveness Rating Scale was employed (Devins, Yitzchak, et al., 1983). The Illness Intrusiveness Rating Scale (IIRS) is a 13-item self-report measure that assesses the extent to which a disease and/or its treatment interfere with 13 life domains, including health, diet, work, financial situation, active recreation, passive recreation, relationship with partner, sex life, family relations, other social relations, self-expression/selfimprovement, religious expression, and community and civic activities. Respondents rate intrusiveness along a 7-point scale from "Not Very Much" to "Very Much". Prior studies demonstrate construct validity of the scale, and internal consistency across illness groups $($ alpha $=.85)$ and within Rheumatoid Arthritis patients $($ alpha $=.90)$ (Devins, Edworthy, Seland et al., 1993). Internal consistency for this scale in the current study is alpha $=.87$, showing reliability consistent with other chronically ill populations.

Fibromyalgia Impact Questionnaire (FIQ). In order to measure functional status in fibromyalgia, the Fibromyalgia Impact Questionnaire was employed (Burckhardt, Clark, \& Bennett, 1991). The Fibromyalgia Impact Questionnaire (FIQ) 
measures patient functional status by evaluating physical dysfunction and impairment. The FIQ contains items that assess physical, psychological, social, and global well being. Ten items form the physical functioning scale, which addresses a patient's ability to do large muscle tasks (e.g., shopping, laundry, preparing meals). Two items ask how many days a patient felt good during the previous week, and how many days they missed work due to their illness. Seven additional items assess the severity of specific symptoms over the last week, including difficulty with work, pain, fatigue, waking rested, stiffness, anxiety, and feelings of depression. Prior to analysis, items assessing anxiety and depression were eliminated to avoid confounding functional status with depression. The FIQ has shown internal consistency $($ alpha $=.79)($ Oliver \& Cronan, 2005), and has demonstrated test-retest reliability ( 0.56 to 0.95$)$, over six one-week intervals, and construct validity (Burckhardt, et al., 1991). The internal reliability for the FIQ in the current study is alpha $=.90$.

Optimism/Pessimism. In order to measure optimism, the Life Orientation TestRevised was employed (Scheier, Carver, \& Bridges, 1994). The Life Orientation TestRevised is a 10-item scale used to measure optimism and pessimism. The scale contains three questions measuring optimism (positive outcomes), three measuring pessimism (negative outcomes), and four filler questions. Negative items were reverse-scored and added to the overall optimism scale, with high scores on the scale indicating greater optimism and low scores indicating greater pessimism. The LOT-R shows internal consistency $(\alpha=.71)$ and test-retest reliability of .45 (separated by three months) with chronic kidney patients (Symister \& Friend, 2003). In the current 
study using fibromyalgia patients, the internal consistency for the LOT-R is alpha= .89 .

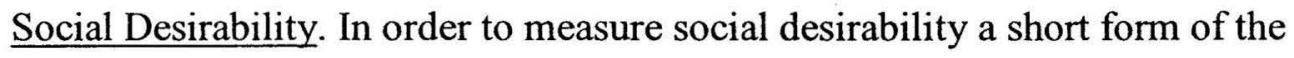
Marlowe-Crown Social Desirability Scale was employed (Reynolds, 1982). The Marlowe-Crowne Social Desirability Scale (Crowne \& Marlowe, 1960) was included in order to identify participants' tendency to respond in culturally appropriate ways. It is a 13-item scale that is controlled for in the study analyses. The short form has been shown to be a viable alternative to the full scale (Zook \& Sipps, 1985).

\section{Dependent Variables}

Quality of Life. In order to measure global quality of life, four items reviewed and suggested by Campbell, Converse, and Rodgers (1976) were used. The first two items, "I generally feel in good spirits", and "I find a good deal of happiness in life", measure a degree of optimism and an individual's overall happiness (Bachman, Kahn, Davidson, and Johnston, 1967). A third item measures how satisfied an individual is with their current life, and the fourth asks for an overall rating or evaluation of their current life (Cantril, 1965). All four items have shown a Cronbach's alpha of .74 and a test-retest correlation (approximately three months apart) of .76 in patients with chronic renal disease (Hatchett et al., 1997). In the current study, the internal consistency for these items is alpha $=.88$.

Depressive Symptoms. The Beck Depression Inventory (Beck, Ward, Mendelson, Mock, \& Erbaugh, 1961) was used to assess depression as a measure of adjustment. Items that assess common symptoms of fibromyalgia (effort, fatigue, and 
poor sleep) were eliminated as they are highly endorsed by people with fibromyalgia. The remaining items were scored to obtain a measure of cognitive depression. Respondents answer items on a 4-point scale where 0 represents the absence of a problem and 3 represents an extreme problem. This scale has shown internal consistency $(\alpha=.85)$, and a test-retest correlation of .73 in chronically ill populations, when assessed approximately three months apart (Hatchett, L., Friend, R., Symister, P., \& Wadhwa, N., 1997). The internal consistency for this scale in the current study is similar to that in other chronically ill populations $(\alpha=.87)$.

\section{Control Variables}

After the three study hypotheses were tested, additional analyses were conducted to further specify illness self-concept as a new construct. The hierarchical regression analyses utilized control for several variables, which are described below.

Control Over Pain \& Fatigue. In order to measure participants' perceptions of control over pain and fatigue (two primary symptoms of fibromyagia), two items were added to the Fibromyalgia Impact Questionnaire (FIQ). The items asked, "How much control do you have over your pain/fatigue", and respondents answered on a visual analog scale from 1 (no control) to 10 (a lot of control). These items are not part of the FIQ and were added specifically to measure (and control for) participants perceptions of control.

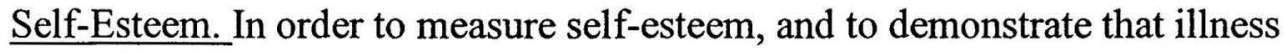
self-concept is a construct apart from self-esteem, the Rosenberg Self-Esteem Scale (Rosenberg, 1979) was employed. This scale has ten items, five addressing negative 
perceptions of self, and five addressing positive perceptions of self. Higher scores indicate higher self-esteem. Previous research had demonstrated high internal consistency for this scale $(\alpha=.87)$ (Rosenberg, 1979).

Victimization. In order to measure victimization, one item was added to the Fibromyalgia Impact Questionnaire (FIQ). The items asked, "How victimized do you feel by your illness", and respondents answered on a 10-point visual analog scale from 1 (not victimized) to 10 (very victimized). This item is not part of the FIQ and was added to measure the extent to which participants feel victimized by their illness. It was thought that this was an important variable to assess in fibromyalgia patients who may feel victimized as a result of the stigma attached to the diagnosis, and because some physicians do not validate fibromyalgia as a legitimate condition. This item was included to demonstrate that it is sufficiently related to illness self-concept, but is not synonymous with illness self-concept. 


\section{Results}

Results for the current study are presented in two sections. The first section consists of scale construction and psychometrics for the Illness Self-Concept and ISC Support scales. The second section begins with a description of the relationships between study and demographic variables, followed by a presentation of results for the three study hypotheses, and concludes with additional analyses which were conducted to further evaluate the hypotheses and illness self-concept. Psychometric Properties of the Illness Self-Concept and ISC Support Scales

\section{Illness Self-Concept Scale}

Item-total correlations for the overall scale were examined (Table 1), with an average item-total correlation of .63 , and a range of .52 to .80 . Several items correlated very highly with the total score, indicating that these items are most representative of the concept underlying the scale. These items include item eight, "I feel consumed by my illness" $(r=.78)$, item seven, "I do not allow my illness to affect too many parts of my life" $(r=.74)$, item 23, "My illness dictates nearly everything I do" $(r=.80)$, and item two, "I am preoccupied with my illness" $(r=.73)$. Each item was also significantly and positively correlated with each other.

A box and whisker plot displaying the distribution of each of the 23 items in the Illness Self-Concept scale was examined to determine which items contributed variance to the total score (Figure 2). Examination of the box-whisker plot revealed that the mean and standard deviations varied among items. The variation in mean scores for each item demonstrates that participants endorsed each item differently. The 
variation in standard deviations demonstrates that there is more variation is some items than others. This suggests that each item contributed to the overall variance of the scale. The mean for the first item in the scale is higher than all other item means, reflecting that it was endorsed strongly by participants. This item, "My illness is with me most of the time", is a fairly neutral item that was intentionally situated as the first item in order to ease participants into the scale, since some items are fairly poignant (e.g., "I am dominated by my illness").

Thirteen items of the Illness Self-Concept scale were worded in such a way that, if endorsed, subjects were reporting illness as central to their self-concept (see Table 2). For example, if a subject positively endorsed the item, "My illness is at the center of who I am", they are agreeing that illness is at least somewhat central to their self-concept. Ten items were worded in such a way that, if endorsed, subjects were reporting that they are able to preserve their sense of self and life space in spite of illness (See Table 3). For example, if a subject positively endorsed the item, "I do many of the same things as healthy others, despite my illness", they are agreeing that they are able to preserve a sense of non-illness self.

Items that were worded in the same way were summed to create two subscales. One subscale represents items that reflect illness as central to the self (Table 2) and one represents items that reflect illness as peripheral to the self (Table 3). The two subscales were formed specifically for analyzing whether or not items worded in one direction had a greater influence on participants' responses. These subscales are not 
conceptual or substantive in nature, and were only used to examine the impact, if any, of item wording.

Means and standard deviations for the two subscales are shown in Tables 2 and 3. The mean for the scale with items worded to reflect illness as central to the self is significantly higher than for the subscale that reflects an ability to preserve the self (M $=3.69, \mathrm{SD}=1.07$ and $\mathrm{M}=3.11, \mathrm{SD}=1.03$, respectively). A paired sample t-test confirms this, $\mathrm{t}=7.86, \mathrm{p}<.001$. This suggest that participants endorsed items that reflect illness as central slightly more strongly than items that reflect an ability to preserve the self.

The Marlowe-Crowne Social Desirability scale provided a measure of the likelihood that participants will respond in culturally appropriate or socially expected ways, rather than responding accurately to study questions. Correlations between each item in the Illness Self-Concept Scale and individual scores on the social desirability scale were examined to determine if items should be eliminated due to biases in how participants responded. Theses correlations are shown in Table 1. Although some items correlated with social desirability scores, no item correlated more highly with social desirability than with the overall Illness Self-Concept Scale. This analysis provided further confirmation that all items in the Illness Self-Concept Scale should be retained in the study analyses.

The above item analyses provided statistical evidence that all items in the Illness Self-Concept Scale should be retained. Although fewer items are less cumbersome for participants, reducing the number of items may diminish reliability. 
At this stage of development, all items will be retained. It should be noted, however, that there are theoretical reasons to retain all items. We strongly suspect that illness self-concept will vary across chronically ill populations and, specifically, that mean scores on individual items in the scale may vary according to symptoms, treatment and other parameters of an illness. There is added value in examining illness self-concept mean scores across chronically ill populations in order to determine if some illnesses are more prone to consuming its sufferers. As such, all items should be retained until the scale is tested in other populations so that distributions, means, variances and other psychometric properties can be accurately compared across illnesses.

The three theoretical Illness Self-Concept subscales were correlated with each other, and with the overall scale (subscale items, item means, and standard deviations are shown in Table 4). The directionality and pervasiveness subscales were correlated at .79, the directionality and illness self-consciousness were correlated at .73, and the pervasiveness and illness self-consciousness subscales were correlated at .63. All three subscales correlated with the overall Illness Self-Concept Scale (directionality, $r=.97$, pervasiveness, $r=.90$, and illness self-consciousness, $r=.80$ ) and with the main study variables (see Table 5). It should be noted that the correlations between the subconstructs and the overall scale are inflated because the total scale included each subconstruct. The correlations between the subscales and the total scale confirm that the directionality subscale was the most conceptually similar to the overall scale. This makes sense as the directionality subscale intended to measure how central or peripheral illness is to the self-concept. 
The correlations between the subscales were squared to calculate the percent of common variance shared by each pair of subscales, and demonstrates that pervasiveness and illness self-consciousness measure something somewhat different than the central or peripheral position of illness within the self. The directionality and pervasiveness subscales share $63 \%$ common variance, indicating that the scales are not synonymous. The directionality and illness self-consciousness share $53 \%$ common variance, indicating that although some variance is shared, they measure something different. The pervasiveness and illness self-consciousness subscales share $40 \%$ variance, indicating that theses two subscales are not measuring the exact same thing. The squared correlations provide evidence that each subscale measures something different and that each should be retained in order to achieve a comprehensive conceptualization of illness self-concept. Pervasiveness intends to measure how pervasive illness is in terms of time and space. This subscale measures how much of the life space is taken over by illness, and how often illness permeates the life space. Illness self-consciousness intends to measure the extent to which a person is preoccupied with their illness (i.e., thinks about their illness). Each of these subscales and subsidiary constructs are important in understanding what factors contribute to the overall position of illness within the self, and can be important tools in understanding how to minimize illness or preserve the self.

The psychometric properties of the total Illness Self-Concept Scale were examined to determine the overall distribution of the scale and the extent of variation within the scale. Figure 3 presents a histogram revealing that the scale is normally 
distributed with a total mean of $79.04(\mathrm{SD}=22.53)$ and a mean item score of 3.44 (on a scale from one to six, $\mathrm{SD}=.98)$. By comparing the possible range $(23-138)$ with the observed range (23-130), it is clear that individuals within the study sample range over the whole scale and extend to both ends of the scale. The low end of the scale represents individuals who were able to preserve their sense of self in spite of illness. The high end of the scale represents individuals who are consumed by illness, and whose illness is central to the self-concept.

The mean for the total scale $(M=79.04, \mathrm{SD}=22.53)$ is approximately in the center of the distribution. This demonstrates that the average individual is consumed to some extent by their illness. The observed range and the standard deviation demonstrate sufficient variability within the study population with respect to illness self-concept. Responses to the Illness Self-Concept Scale were on a six-point scale, from 1 ("strongly disagree") to 6 ("strongly agree"). The mean item score using the six-point scale was $3.44(\mathrm{SD}=.98)$, reinforcing that scores for illness self-concept items are approximately at the mean. Cronbach's alpha for the scale was .94, demonstrating high internal consistency.

\section{Summary}

All items correlate with the total scale and the means vary such that each item contributes to the overall score of illness self-concept. The three conceptual subscales, while correlated, measure unique aspects of illness self-concept and provide further information regarding the position of illness within the self. The Illness Self-Concept Scale is normally distributed with some subjects reporting that they are consumed by 
illness and others reporting that they are able to preserve their sense of self in spite of illness. The scale demonstrated high internal consistency $(\alpha=.94)$.

\section{Illness Self Concept Support Scale (ISC Support Scale)}

The purpose of the ISC Support Scale was to measure the extent to which a participant's social support network (i.e., partner, family, close friends) reinforce illness as central or peripheral to the self and life space. The scale used 14 items to examine illness self-concept support with items addressing the three theoretical subconstructs: directionality, pervasiveness, and illness self-consciousness. Items were worded positively to represent a social network that reinforces illness as central, and negatively to represent a social network that reinforces illness as peripheral. Subjects were asked to respond to the scale items from 1 ("strongly disagree") to 6 ("strongly agree"). The study examined the psychometric properties of this scale using the same analyses as those used in analyzing the Illness Self-Concept Scale.

Item-total correlations for the overall scale are shown in Table 6. Each item was substantially correlated with the total scale (ranging from $r=.38$ to $r=.71$ ). The average item-total correlation for the ISC Support Scale is .57. The three items that correlated most highly with the total scale were, item number four, "Makes me feel that I am a capable person", item number six, "Makes it seem as though my illness runs my life", and item number eleven, "Undermines my confidence in myself and what I can do".

A box and whisker plot examining the distribution of all items in the ISC Support Scale (Figure 4) demonstrates that individual items each contributed variance 
to the overall scale. The mean response across items showed less variation than in the Illness Self-Concept Scale, but still demonstrated sufficient variability. Mean responses to the majority of items fell between 2 and 3, on a six-point scale. However, because items were worded in two different ways (i.e., to represent illness reinforced as central or peripheral), there is evidence that respondents were not simply answering questions systematically, but were taking the time to read and evaluate each item. The standard deviations varied sufficiently across items (although not as substantially as with the Illness Self-Concept Scale), demonstrating that each item contributed variance to the overall scale. The standard deviations provide information as to which items contributed more variance to the overall scale, and which items elicited similar responses from the majority of subjects. For example, item three (Table 6), "Sometimes makes me conscious of my physical limitations", varied considerably, indicating that respondents both agreed and disagreed that this was true of their social support network. Other items, for example number 11, "Undermines my confidence in myself and what I can do", and number four, "Makes me feel I am a capable person", had relatively less variation, demonstrating that the majority of subjects answered these items more similarly.

Seven items of the ISC Support Scale were worded in such a way that, if endorsed, subjects were reporting a social support network that reinforces illness as central to their self-concept. For example, if a subject positively endorsed, "Makes it seem as though my illness runs my life", they are agreeing that their network reinforces illness as at least somewhat central to their self-concept and life space. 
Seven items were worded in such a way that, if endorsed, subjects were reporting that their network reinforced illness as a peripheral part of the self and life space. For example, if a subject positively endorsed, "Reminds me that my illness does not define me", they are agreeing that their social network tries to preserve a sense of non-illness self.

Items that were worded in the same way were summed to create two subscales. Theses subscales were created solely to evaluate the impact of item wording on participant responses and are not substantive in nature. The mean for the subscale that endorsed a social network that reinforces illness as central was $2.42(\mathrm{SD}=.96)$. The mean for the subscale that endorsed a social network that supports illness as peripheral to the self was $2.56(\mathrm{SD}=.89)$. The means for the two subscales were not significantly different $(t=-1.35, p=.18)$, indicating that participants endorsed items worded both ways.

Table 6 shows how each item correlates with social desirability. Two items correlated significantly with social desirability: number three, "Sometimes makes me conscious of my physical limitations" $(r=-.34, p<.01)$, and number 13, "Sometimes views me as a 'sick' person in a way that makes me feel helpless" $(r=-.20, p<.05)$. The correlation between these items and social desirability indicates that subjects were somewhat biased in their responses such that the more conscious a participant was of social expectations, the less likely they were to endorse that item.

However, since other items such as number 12, "Makes me feel I cannot do much now that I am ill", and number six, "Makes it seem as though my illness runs 
my life", were both highly correlated with the total and did not correlate with social desirability, the issue may be in the specific wording of the item. For example, it may be that "views me as a sick person in a way that makes me feel helpless" is worded too strongly. Or, the relationship of this item to social desirability could mean that participants have difficulty with the idea of being perceived as helpless, and thus do not want to endorse the item. Importantly, no items correlated more highly with social desirability than with the overall ISC Support Scale. As a result, all items were retained in the study analyses.

The three ISC Support subscales were correlated with each other, and with the overall scale (subscale items, item means, and standard deviations are shown in Table 7). The directionality and pervasiveness subscales were correlated at .66, the directionality and illness self-consciousness were correlated at .58, and the pervasiveness and illness self-consciousness subscales were correlated at .72. The correlations between the subscales were squared to determine the amount of variance shared by each pair of subscales. The directionality and pervasiveness subscale share $44 \%$ of common variance, the directionality and illness self-consciousness subscales share $32 \%$ common variance, and the pervasiveness and illness self-consciousness subscales share $52 \%$ common variance. The squared correlations demonstrate that although the subscales measure shared aspects of ISC support, the subscales are not synonymous and each subscale measures something different.

All three subscales correlated with the overall ISC Support Scale (directionality, $\mathrm{r}=.90$, pervasiveness, $\mathrm{r}=.86$, and illness self-consciousness, $\mathrm{r}=.86$ ) 
and with the main study variables (see Table 8). It should be remembered that these correlations are inflated because the overall scale includes each of the subscales. The magnitude of the correlations between the subscales and the overall scale demonstrate that each contributes similarly to the overall scale. That is, the three subscales of the ISC Support Scale are equally important in defining how the social support network reinforces illness as either central or peripheral.

A social support network can reinforce illness as central by insinuating that "illness runs their life" (directionality), by "undermining their confidence in what they can do" (pervasiveness), and by "making them conscious of their physical limitations" (illness self-consciousness). The pervasiveness subscale identifies how social networks help find ways to minimize illness, or they can make it seem as though all aspects of a person's life are influenced by illness. The illness self-consciousness subscale characterizes ways that a social network can minimize preoccupation with illness or make illness more cognitively salient. Each subscale provides information as to how a network either minimizes or reinforces illness.

A histogram was drawn to examine the overall distribution of the total ISC Support Scale. Examination of the histogram (Figure 5) yields a scale that is normally distributed in the study sample. The mean for the total scale is $34.78(\mathrm{SD}=10.97)$, which is slightly positively skewed. Possible scores on the scale ranged from 14-84 with observed scores ranging from 14-68. The range of observed scores indicates that while some participants report that their network reinforces illness as peripheral, others report that their social network reinforces illness as central to the self-concept. 
The item mean for the scale is $2.48(\mathrm{SD}=0.78)$ with a possible range from one to six, reinforcing that responses to most items were positively skewed. This demonstrates that subjects reported that their social support network reinforced illness as more peripheral than central to the self.

\section{Summary}

All items correlated with the total scale and with each other, and each contributed to the overall variance of the scale. The three subscales measured both similar and distinct aspects of ISC support and provide further information as to how social networks reinforced illness as either central or peripheral to participants. Overall, the ISC Support Scale achieved high internal consistency $(\alpha=.88)$, and displayed a normal distribution in the study population, with participants ranging from low ISC support to high ISC support.

Whereas the Illness Self-Concept Scale's main purpose was to establish the position of illness within the self, the ISC Support Scale aimed to measure the extent to which family and friends influence the position of illness within the self. Examining item box-whisker plots for each scale reveals that the means for ISC Support items do not vary as much as items making up the Illness Self-Concept Scale. The observed range for the ISC Support Scale was not as large as for the Illness Self-Concept Scale. As mentioned previously, it may be that participants were more comfortable answering questions regarding their own self-concept, and less comfortable answering questions that suggest that their social support networks may not always be supportive. 
The correlation between the Illness Self-Concept and ISC Support scales is $r=$ $.55(\mathrm{p}<.01)$, indicating a positive relationship between the two variables, such that the more illness is reinforced as central by a social network, the more likely illness is a central part of the self-concept. The relationship between these two variables will be discussed further when the results of hypothesis two are presented. The importance of the positive and significant relationship between the two scales is that it provides construct validity for each scale. If both scales measure what they intend to measure, a moderate to strong, positive correlation is expected and is, in fact, demonstrated. Tests of Study Hypotheses

This section begins by examining which demographic variables are related to study variables in order to determine which need to be controlled for when testing the study hypotheses. Next, the relationships between the study variables will be presented briefly, followed by tests of each of the study hypotheses. Lastly, additional analyses, which were included to further evaluate illness self-concept and describe its relationship to other variables known to be important in chronic illness, are presented.

\section{Relationships Between Study and Demographic Variables}

Table 9 presents the correlations between study variables and demographic variables. Education, marital status, employment status, and whether participants stopped working because they were ill correlated significantly with one or more of the study variables. Education correlated significantly with several study variables, such that the greater the participant's education, the greater quality of life $(r=.25)$, the less depression $(r=-.31)$, the less central their illness self-concept $(r=-.28)$, the less their 
social support network reinforced illness as central $(r=-.26)$, the greater their optimism $(\mathrm{r}=.26)$, and the better their functional status $(\mathrm{r}=-.28)$. Marital status was significantly associated with study variables, such that participants who were married reported better quality of life $(r=-.32)$, less depression $(r=.25)$, and better functional status $(\mathrm{r}=.21)$. Employment status was significantly associated with one independent variable, such that those who were not employed had poorer functional status $(r=.33)$.

Lastly, whether participants stopped working because they were ill correlated significantly with several study variables, such that those who had to stop working reported lower quality of life $(r=.23)$, more depression $(r=-.23)$, higher illness selfconcept scores $(r=-.31)$, a social network that reinforced illness as central $(r=-.24)$, greater illness intrusiveness $(r=-.34)$, and poorer functional health status $(r=-.31)$. Subsequently, these variables were controlled for in analyses in which they correlate significantly with an independent or dependent study variable.

Several variables did not correlate significantly with any of the study variables. Age of study participants and length of diagnosis did not correlate significantly, and ethnicity related only to depression $(\mathrm{r}=.25, \mathrm{p}<.01)$. It is notable that age and length of diagnosis were not related to illness self-concept. Presumably, the older participants are and the more time they have had to adjust to their diagnosis, the less likely illness would be central to the self-concept. The fact that this relationship was not found suggests that illness self-concept is not simply a phenomenon that occurs at the onset of a diagnosis, but remains an important factor throughout the course of chronic 
illness. The correlation between ethnicity and depression should be considered cautiously as there were only three study participants who were not Caucasian.

Interestingly, gender was associated with each of the study variables except for optimism. Being male gender was associated with poorer functional status $(\mathrm{r}=.19$, $\mathrm{p}<.05)$, poorer ISC support $(\mathrm{r}=.22, \mathrm{p}<.05)$, worse illness self-concept $(\mathrm{r}=.23, \mathrm{p}<.05)$, more illness intrusiveness $(\mathrm{r}=.29, \mathrm{p}<.01)$, greater depression $(\mathrm{r}=.22, \mathrm{p}<.05)$, and poorer quality of life $(r=-.27, p<.01)$. There were only five males in the sample, so results should be considered with caution. However, fibromyalgia is often stereo-typed as a predominantly "female" disorder. As such, it may be more difficult for men who have fibromyalgia to come to terms with their diagnosis, resulting in poorer psychological outcomes.

In addition, social desirability was correlated with study variables. Social desirability measures the extent to which a participant is likely to provide answers that are socially desirable or acceptable and which are not necessarily a true representation of where they stand on a particular study variable. Accordingly, where social desirability was associated with either an independent or dependent variable, it was controlled for in Step 1 of subsequent analyses. Social desirability significantly correlated with illness self-concept $(r=-.28, p<.01)$, such that the greater the social desirability, the more illness was reported as peripheral to the self. This relationship is in accordance with what is expected. A subject who is conscious of socially appropriate responses is more likely to downplay the extent to which illness has come to consume their self-concept and life space. 
Similarly, those who report more bias towards socially appropriate responses are more likely to report an optimistic outlook on life. The relationship between social desirability and optimism is $r=.33(p<.01)$. The correlation between illness intrusiveness and social desirability is $r=-.24(p<.05)$, indicating that subjects who scored higher on social desirability reported illness as less intrusive than other subjects. Likewise, the correlation between depression and social desirability is $r=-$ $.39(p<.01)$, such that the greater the social desirability, the lower the reported depression scores. Lastly, the relationship between quality of life and social desirability was $r=.29(p<.01)$, such that the greater the social desirability scores, the better the reported quality of life.

\section{Summary}

In summary, the demographic variables which correlated with several study variables include education, marital status, stopped work due to illness, and social desirability. Education is a difficult variable to disentangle because it encompasses aspects of family educational background and current socioeconomic status, as well as the objective level of education achieved. Marital status correlated with functional status, which may be due to the fact that those who were married had more help with household chores and tasks. Much of the FIQ (measure of functional status) is based on the ability to carryout routine household tasks. Marital status was also related to depression and quality of life and, as is shown in subsequent analyses, remains a strong predictor of quality of life. This suggests, in general, that those who are married 
report a better quality of life. Lastly, whether subjects stopped work because of illness correlated with each study variable with the exception of optimism.

There are several explanations for these correlations. With respect to functional status, it may be that having to stop work is a marker for the severity of disease. The correlation between stopped work and illness intrusiveness may be explained by the overlap in constructs, such that illness intrusiveness specifically asks about intrusion in the work domain. It is not surprising that having to stop work because of illness would be associated with increases in depression, decreases in quality of life, and that illness would occupy a more central region of the self-concept. Much of our identity and sense of self-efficacy are related to our work life and it is logical that the inability to work would be associated with negative psychological outcomes.

The intercorrelations among study variables are shown in Table 10. The two dependent adjustment variables, depression and quality of life, were significantly negatively associated $(r=-.78)$. Illness self-concept was strongly correlated with both of the dependent variables: quality of life $(r=-.76)$ and depression $(r=.67)$. The independent variables (ISC support, optimism, illness intrusiveness, and functional status) were significantly correlated with illness self-concept, quality of life, and depression, and were moderately correlated with each other (see Table 10).

The Fibromyalgia Impact Questionnaire (FIQ) contains two items which assess depression and quality of life. These items are included in the measure of functional status in fibromyalgia because anxiety and depression are common symptoms in this population. However, in order to eliminate common variance shared by the FIQ and 
depression, these two items were eliminated. The modified version of the FIQ was used in all study analyses.

Similarly, the Beck Depression Inventory (BDI) is often adjusted in fibromyalgia research to eliminate items that assess common fibromyalgia symptoms. To adjust the BDI, three items addressing fatigue, sleep, and effort were eliminated to create the BDI-Adjusted (BDI-A). The adjusted measure was used in all study analyses. In addition, one item addressing suicide and suicidal ideation was eliminated since, if endorsed, the study investigator was responsible for mandatory reporting of harmful behavior. Since I wanted participants to feel that their confidentiality would be maintained, as promised, this item was eliminated. It should be noted that since four total items were taken out of the BDI, the overall score was affected. That is, BDI-A depression scores in this study are somewhat deflated as compared to BDI scores for chronically ill populations in other studies using the full range of questions.

\section{Hypothesis One}

All hypotheses were tested using hierarchical regression analyses with demographic variables, including social desirability, entered in step 1 of the analysis. Hypothesis 1 states that illness self-concept scores will predict quality of life and depression, such that the more illness is central to the self, the poorer the quality of life and the greater the depression. To examine Hypothesis 1, two hierarchical regression analyses were conducted, with demographic variables (education, marital status, stopped work, and social desirability) entered in step 1, and illness self-concept entered in step 2, with quality of life and depression (BDI-A) scores as dependent 
variables (Tables $11 \mathrm{a} \& \mathrm{~b}$ ). After controlling for demographic variables, illness selfconcept accounted for an additional $39 \%$ of the variance in quality of life scores $\left(\mathrm{R}^{2}=\right.$ $.39, \mathrm{~F}(1,97)=113.85, \mathrm{p}<.001)$. In the second regression analysis, after controlling for education, marital status, whether participants stopped work due to illness, and social desirability, illness self-concept accounted for an additional $24 \%$ of the variance in depression scores $\left(\mathrm{R}^{2}=.24, \mathrm{~F}(1,97)=56.60, \mathrm{p}<.001\right)$. Thus, the data support Hypothesis 1.

Results for hypothesis 1 are presented in Tables 11a and 11b. Table 11a shows that in step 2 , only marital status remained a significant predictor of quality of life $(\beta=$ $-.21, \mathrm{p}<.01)$, demonstrating that marital status is a strong predictor of quality of life. Table $11 \mathrm{~b}$ shows that in step 2 , education and social desirability remained significant predictors of depression $(\beta=-.16, p<.05$ and $\beta=-.26, p<.001$, respectively). This demonstrates that education and social desirability both strongly influence subjects' reporting of depressive symptoms.

\section{Hypothesis Two}

Hypothesis 2 states that ISC support, optimism, illness intrusiveness and functional disease status will predict illness self-concept. Specifically, this hypothesis states that the poorer the ISC support (the more illness is reinforced as central to the self-concept), the more pessimistic, the greater the illness intrusiveness, and the poorer the functional status, the more likely illness will be incorporated as central to the self. To examine Hypothesis 2, four regression analyses were conducted (Tables 12a-12d). 
The first analysis (Table 12a) examined ISC support as a predictor of illness self-concept, controlling for education, whether participants stopped work due to illness, and social desirability. After entering demographic variables in step 1, ISC support predicted an additional $16 \%$ of the variance in illness self-concept scores $\left(\mathrm{R}^{2}=\right.$ $.16, \mathrm{~F}(1,98)=25.47, \mathrm{p}<.001)$. Table $12 \mathrm{a}$ shows that whether participants stopped work due to illness and social desirability remained significant predictors of illness self-concept in step $2(\beta=-.19, p<.05$ and $\beta=-.17, p<.05$, respectively), demonstrating that both of these variables are important variables in relation to illness self-concept.

In the second regression analysis (Table 12b), after entering the demographic variables in the first step (education, stopped work, and social desirability), optimism predicted an additional $23 \%$ of the variance in illness self-concept scores $\left(\mathrm{R}^{2}=.23, \mathrm{~F}\right.$ $(1,98)=41.45, \mathrm{p}<.001)$. Table $12 \mathrm{~b}$ shows that in step 2 , whether participants stopped work due to illness remained a significant predictor of illness self-concept. However, social desirability did not remain a significant predictor (although it was in the previous analysis). This suggests that perhaps there is some shared variance between social desirability and optimism in relation to illness self-concept that is accounted for when optimism is entered into the model.

The third regression analysis (Table 12c) examined illness intrusiveness as a predictor of illness self-concept, controlling for education, whether participants stopped work due to illness, and social desirability. After entering the demographic variables in step 1, illness intrusiveness predicted $32 \%$ of the variance in illness self- 
concept scores $\left(\mathrm{R}^{2}=.32, \mathrm{~F}(1,98)=69.28, \mathrm{p}<.001\right)$. Table $12 \mathrm{c}$ indicates that education remained a significant predictor of illness self-concept in step 2 of the analysis $(\beta=$ $.19, \mathrm{p}<.05)$. The fact that education remained a significant predictor when illness intrusiveness was entered into the model is not surprising given that education and illness intrusiveness were not significantly correlated (see Table 9), whereas education correlated with all other study variables. This indicates that upon examining predictors of illness self-concept so far, the contribution of education was accounted for by ISC support and optimism, but not by illness intrusiveness.

The fourth regression analysis (Table 12d) examined functional status as a predictor of illness self-concept, controlling for education, martial status, employment status, whether a participant stopped working due to illness, and social desirability. After entering demographic variables in step 1, functional status predicted an additional $8 \%$ of variance in illness self-concept scores $\left(\mathrm{R}^{2}=.08, \mathrm{~F}(1,95)=10.85\right.$, $\mathrm{p}=.001)$. Table $12 \mathrm{~d}$ reveals that in step 2 of the analysis, social desirability was the only demographic variable to remain a significant predictor of illness self-concept $(\beta=$ $-.24, \mathrm{p}<.05)$.

The results of the analyses indicate support of Hypothesis 2 . That is, ISC support, optimism, illness intrusiveness and functional status each predicted variance in illness self-concept scores. The results confirm that personal, interpersonal, and illness-related factors influence whether illness is incorporated as a central or peripheral part of the self-concept and life space. In addition, some demographic 
variables contributed uniquely to illness self-concept, while others were accounted for by the personal, interpersonal, and illness-related variables tested in hypothesis 2 .

An additional analysis was conducted to examine the amount of variance in illness self-concept scores accounted for by all four independent variables entered together in step 2. ISC Support, optimism, illness intrusiveness, and functional status were entered together as independent variables predicting illness self-concept. Results indicate that after entering the demographic variables (education, marital status, employment status, stopped work due to illness, and social desirability), the independent variables accounted for an additional $44 \%$ of the variance in illness selfconcept scores $\left(\mathrm{R}^{2}=.44, \mathrm{~F}(4,92)=30.88, \mathrm{p}<.001\right)$. With all four independent variables in the model, illness intrusiveness and optimism remained significant predictors of illness self-concept $(\beta=.43, \mathrm{p}<.001$, and $\beta=-.35, \mathrm{p}<.001$, respectively). None of the demographic variables entered in step 1 remained significant in step 2 . Results for this analysis are reported in Table 13.

Entering ISC support, optimism, illness intrusiveness, and functional status together to predict illness self-concept revealed a Multiple $\mathrm{R}$ of .82 . This indicates that the correlation between the predicted illness self-concept scores and the actual selfconcept scores was .82. This analysis demonstrates that these four variables, hypothesized to account for whether illness was a central or peripheral part of participants' self-concept, were successful in accurately predicting the criterion variable. Furthermore, illness intrusiveness and optimism were especially important in determining illness self-concept, such that the more intrusive the illness, and the less 
optimism reported by participants, the more likely illness was reported as central to the self.

\section{Hypothesis Three}

Hypothesis 3 states that illness self-concept will contribute unique variance to quality of life and depression scores, controlling for ISC support, optimism, illness intrusiveness, and functional status separately (see summary Table 14). To examine Hypothesis 3, eight hierarchical regression analyses were conducted (Tables 15a15h). Four analyses examined illness self-concept predicting quality of life, controlling for ISC support, optimism, illness intrusiveness, and functional status. Four others examined illness self-concept predicting depression, controlling for ISC support, optimism, illness intrusiveness, and functional status. Results for hypothesis 3 , with quality of life as the dependent variable are reported in Tables $15 \mathrm{a}, 15 \mathrm{c}, 15 \mathrm{e}$, and 15g. Results with depression as the dependent variable are reported in Tables $15 \mathrm{~b}$, $15 \mathrm{~d}, 15 \mathrm{f}$, and $15 \mathrm{~h}$.

In the first regression analysis (Table 15a), demographic variables (education, stopped work, and social desirability) were entered in step 1, ISC support entered in step 2, and illness self-concept entered in step 3, with quality of life as the dependent variable. Results indicate that illness self-concept accounts for an additional $32 \%$ of the variance in quality of life scores, over and above ISC support $\left(\mathrm{R}^{2}=.32, \mathrm{~F}(1,97)\right.$ $=82.20, \mathrm{p}<.001)$. In the second regression analysis (Table $15 \mathrm{~b}$ ), the same control variables (education, stopped work, and social desirability) were entered into step 1, ISC support entered into step 2, and illness self-concept entered in step 3, with 
depression scores as the dependent variable. Results indicate that illness self-concept accounts for an additional $16 \%$ of the variance in depression scores over and above ISC support $\left(\mathrm{R}^{2}=.16, \mathrm{~F}(1,97)=37.86, \mathrm{p}<.001\right)$.

It should be noted that education and social desirability remained significant predictors of depression scores in step 3 of the second regression analysis $(\beta=-.15$, $\mathrm{p}<.05$ and $\beta=-.26, \mathrm{p}<.001$, respectively). This suggests that education and social desirability are strong predictors of depression, such that the poorer the education and the less social desirability, the greater the reported depression. Standardized Beta coefficients are conceptually similar to correlations in the sense that the magnitude of each coefficient, with a range between -1.0 and 1.0 , can be compared to determine their relative importance in predicting the criterion variable. In step 3 of this analysis, the Beta coefficient for illness self-concept $\beta=.51(\mathrm{p}<.001)$, indicating that it is a stronger predictor of depression than education or social desirability.

In the third regression analysis (Table 15c), demographic variables (education, stopped work, and social desirability) were entered in step 1, optimism in step 2, and illness self-concept in step 3, with quality of life as the dependent variable. Results indicate that illness self-concept accounts for $17 \%$ of additional variance in quality of life scores, over and above optimism $\left(\mathrm{R}^{2}=.17, \mathrm{~F}(1,97)=52.38, \mathrm{p}<.001\right)$.

The fourth analysis (Table 15d) entered demographic variables in step 1 (education, stopped work, and social desirability), optimism in step 2, illness selfconcept in step 3, with depression scores as the dependent variable. Results indicate that illness self-concept accounts for an additional $9 \%$ of the variance in depression 
scores, over and above optimism $\left(\mathrm{R}^{2}=.09, \mathrm{~F}(1,97)=24.12, \mathrm{p}<.001\right)$. Optimism, however, remained a significant predictor of quality of life $(\beta=.32, \mathrm{p}<.001)$, indicating that it is an important predictor of quality of life. It should be noted that the standardized Beta coefficient for illness self-concept in step 3 is $\beta=-.56(p<.001)$, demonstrating that although optimism remains a strong predictor, by comparison, illness self-concept is a more significant determinant of quality of life.

The fifth analysis (Table 15e) entered demographic variables in step 1 (education, stopped work, and social desirability), illness intrusiveness in step 2, and illness self-concept in step 3, with quality of life as the dependent variable. Results indicate that illness self-concept accounts for $24 \%$ of additional variance in quality of life scores, over and above illness intrusiveness $\left(\mathrm{R}^{2}=.24, \mathrm{~F}(1,97)=61.33, \mathrm{p}<.001\right)$. The sixth regression analysis (Table $15 f$ ) entered control variables (education, stopped work, and social desirability) in step 1, illness intrusiveness in step 2, and illness selfconcept in step 3, with depression scores as the dependent variable. Results indicate that illness self-concept accounts for an additional $14 \%$ of the variance in depression scores, over and above illness intrusiveness $\left(\mathrm{R}^{2}=.14, \mathrm{~F}(1,97)=32.06, \mathrm{p}<.001\right)$. Education and social desirability scores remained significant predictors of depression in step $3(\beta=-.17, p<.05$ and $\beta=-.27, p<.001$, respectively), suggesting that these two variables are important predictors of depression. The standardized Beta coefficient for illness self-concept in step 3 is $\beta=.55(\mathrm{p}<.001)$, indicating that although education and social desirability remain significant, illness self-concept is a much stronger predictor of depression. 
The seventh analysis (Table 15g) entered demographic variables (education, marital status, employment status, stopped work, and social desirability) in step 1, functional status in step 2, and illness self-concept in step 3, with quality of life as the dependent variable. Results indicate that illness self-concept accounts for $33 \%$ of additional variance in quality of life, over and above functional status $\left(\mathrm{R}^{2}=.33, \mathrm{~F}(1\right.$, $94)=93.54, p<.001)$. It should be noted that marital status remained a significant predictor of quality of life in step $3(\beta=-.20, p<.01)$, indicating that marital status is an important predictor of quality of life. The standardized Beta coefficient for illness self-concept in step 3 is $\beta=-.69(\mathrm{p}<.001)$, revealing that although marital status remains a significant predictor, illness self-concept is a relatively stronger predictor of quality of life.

In the last regression analysis (Table 15h), demographic variables (education, marital status, employment status, stopped work, and social desirability) were entered in step 1, functional status in step 2, and illness self-concept in step 3, with depression scores as the dependent variable. Results indicate that illness self-concept accounts for an additional $22 \%$ of the variance in depression scores, over and above functional status $\left(\mathrm{R}^{2}=.22, \mathrm{~F}(1,94)=52.14, \mathrm{p}<.001\right)$. Education, marital status, and social desirability remained significant predictors of depression in step $3(\beta=-.18, p<.05, \beta$ $=.14, \mathrm{p}<.05$, and $\beta=-.24, \mathrm{p}<.01$, respectively). However, the standardized Beta coefficient for illness self-concept in step 3 is $\beta=.57(\mathrm{p}<.001)$, revealing that illness self-concept is a more important predictor of depression that any of the demographic variables that remained significant. 


\section{Summary}

The eight regression analyses used to test hypothesis 3 reveal that illness selfconcept is an important predictor of quality of life and depression, even after controlling for the effects of ISC support, optimism, illness intrusiveness, and functional status. Optimism and illness intrusiveness have received a lot of attention in the literature examining adjustment in chronic illness. That illness self-concept predicts adjustment equally or above these two variables is important. Hypothesis 3 also demonstrated which demographic variables are strong predictors of quality of life and depression in this population.

Additionally, the results of hypothesis 3 indicate that the Illness Self-Concept Scale has discriminant validity. The fact that illness self-concept predicted variance over and above social support, optimism, illness intrusiveness, and functional status, demonstrates that the Illness Self-Concept Scale measured something other than what was measured by the aforementioned variables.

To further establish the discriminant validity of this scale, two additional hierarchical multiple regression analyses were conducted to examine illness selfconcept as a predictor of quality of life and depression when all four variables, ISC support, optimism, illness intrusiveness, and functional status were entered together (see Table $16 \mathrm{a}$ and $\mathrm{b}$ ). In the first analysis, with quality of life as the dependent variable, demographic variables (education, marital status, employment status, stopped work, and social desirability) were entered in step 1, ISC support, optimism, illness intrusiveness, and functional status were entered in step 2, and illness self-concept was 
entered in step 3. Results indicate that illness self-concept accounts for an additional $8 \%$ of the variance in quality of life, even after controlling for all four variables (ISC support, optimism, illness intrusiveness, and functional status) taken together $\left(\mathrm{R}^{2}=\right.$ $.08, \mathrm{~F}(1,91)=25.64, \mathrm{p}<.001)$

In the second multiple regression analysis, with depression as the dependent variable, demographic variables (education, marital status, employment status, stopped work, and social desirability) were entered in step 1, ISC support, optimism, illness intrusiveness, and functional status were entered in step 2, and illness self-concept was entered in step 3. Results indicate that illness self-concept accounts for an additional $4 \%$ of the variance in quality of life, even controlling for all four variables (ISC support, optimism, illness intrusiveness, and functional status) taken together $\left(\mathrm{R}^{2}=\right.$ $.04, F(1,91)=11.16, p=.001)$

These two analyses are important because they demonstrate that after partialling out the effects of four variables, that have been previously shown to predict quality of life and depression, illness self-concept still accounts for significant variance in the dependent variables. When conducting hierarchical regression analyses, variables entered first in the regression model will retain any variance in predicting the criterion variables that are shared with subsequent independent variables. For example, if optimism and illness self-concept share variance in quality of life scores, but optimism is entered in step 2 and illness self-concept is entered in step 3, the shared variance will be represented in the coefficient for optimism. As a result, the regression coefficients for variables entered earlier in the model may be 
somewhat inflated and the coefficients for the variables entered last may be somewhat deflated. Consequently, the fact that illness self-concept accounted for an additional $8 \%$ of variance in quality of life scores and an additional $4 \%$ of variance in depression scores, is noteworthy.

Additional Analyses

To further evaluate and delineate the construct of illness self-concept, several additional analyses were conducted. Illness self-concept encompasses some aspects of control, which are included in the sub-construct directionality. Directionality implies that illness directs the self and other facets of the life space, or that the non-illness self directs illness and other facets of the life space. While the concept of directionality implies that either illness or the self are "in control", this is only a small aspect of the overall illness self-concept construct. Analyses that examine control over illness and specific symptoms are examined in order to demonstrate that illness self-concept is more than simply control.

A second regression analysis was conducted in order to establish that illness self-concept is more than depressive symptoms. To accomplish this, depression was entered in a hierarchical regression predicting quality of life, with illness self-concept entered in a subsequent step. Lastly, the concept of victimization was examined in a hierarchical regression to demonstrate that while victimization may be part of illness self-concept, it is not a synonymous concept.

In order to distinguish illness self-concept from control over illness and symptoms, two analyses were conducted (see Tables 17a and 17b). Pain and fatigue 
are the two primary symptoms of fibromyalgia and participants in the current study were asked to rate the extent to which they have control over their pain and fatigue on a ten point scale, with high scores indicating greater control. These two items were used in the following analyses. Illness self-concept was entered as the independent variable predicting quality of life and depression, controlling for participant-reported control over pain and fatigue.

Results from the first regression analysis (Table 17a) indicate that after entering demographic variables (education, stopped work, and social desirability) in step 1, control over pain and fatigue in step 2, and illness self-concept in step 3, illness self-concept accounted for an additional $35 \%$ of variance in quality of life scores $\left(\mathrm{R}^{2}=\right.$ $.35, \mathrm{~F}(1,96)=88.60, \mathrm{p}<.001)$. Control over pain and fatigue did account for $8 \%$ of variance in quality of life scores $(\mathrm{p}<.01)$, but the standardized Beta coefficients for these two variables were not significant in step 2 or step 3, when illness self-concept was entered into the model. This suggests that while control over illness and symptoms may be one aspect of illness self-concept, and may contribute some variance to quality of life scores, illness self-concept is a much broader concept.

In the second analysis (Table 17b), demographic variables (education, stopped work, and social desirability) were entered in step 1, control over pain and fatigue in step 2, and illness self-concept in step 3, with depression scores as the dependent variable. Results indicate that illness self-concept accounts for $21 \%$ of additional variance in depression scores, over and above participant control over pain and fatigue $\left(\mathrm{R}^{2}=.21, \mathrm{~F}(1,96)=47.25, \mathrm{p}<.001\right)$. Control over pain and fatigue accounted for $5 \%$ 
$(\mathrm{p}<.05)$ of the variance in depression scores when added in step 2, but the standardized Beta coefficients were not significant in step 2 or step 3, when illness self-concept was added to the model. These results indicate that illness self-concept is a more global construct than specific perceptions of symptoms and control over symptoms.

A regression analysis with illness self-concept predicting quality of life (adjustment), controlling for depression, was conducted in order to demonstrate that illness self-concept is measuring more than simply depression (Table 18). This analysis clarified that illness self-concept and depression are not overlapping constructs and that depressive mood alone cannot explain adjustment to chronic illness. Demographic variables (education, stopped work, and social desirability) were entered into step 1 of the analysis, depression was entered in step 2, and illness selfconcept was entered in step 3 , with quality of life as the dependent adjustment variable. Results indicate that illness self-concept accounts for $12 \%$ of additional variance in quality of life after controlling for depression $\left(\mathrm{R}^{2}=.12, \mathrm{~F}(1,97)=38.27\right.$, $\mathrm{p}<.001)$.

Depression accounted for $38 \%$ of additional variance in quality of life beyond the demographic variables. However, since depression was entered into the analysis prior to illness self-concept, any variance in adjustment shared by the two variables is retained in the variable depression. In order to compare the contribution of depression and illness self-concept to adjustment, the standardized Beta coefficients were examined. In step 3, the standardized coefficient for depression is $\beta=-.43(p<.001)$, and the standardized coefficient for illness self-concept is $\beta=-.49(\mathrm{p}<.001)$. 
Comparing the two coefficients suggests that illness self-concept is a slightly stronger predictor of quality of life, which is impressive considering the importance of depression in influencing quality of life. Additionally, this analysis indicates that illness self-concept predicted quality of life at all levels of depression. This is important because the study sample consists of many clinically depressed patients.

Self-esteem and depression are highly correlated in the general population (Roberts \& Monroe, 1999), and specifically in chronic illness (Symister \& Friend, 2003). In order to demonstrate that illness self-concept is a construct apart from selfesteem, and that self-esteem alone does not account for depression and quality of life in this sample, two regression analyses were conducted (Tables 19a and 19b). In the first analysis, demographic variables (education, stopped work, and social desirability) were entered in step 1, self-esteem was entered in step 2, and illness self-concept in step 3, with quality of life as the dependent variable. Results indicate that illness selfconcept contributed an additional $19 \%$ of variance in quality of life scores, over and above self-esteem $\left(\mathrm{R}^{2}=.19, \mathrm{~F}(1,97)=54.00, \mathrm{p}<.001\right)$. Self-esteem remained a significant predictor of quality of life $(\beta=.29, \mathrm{p}=.001)$ in step 3 . However, illness self-concept was a stronger predictor, $\beta=-.59(p<.001)$, indicating that illness selfconcept is more than simply self-esteem and that illness self-concept is a stronger predictor of quality of life in this sample.

In the second analysis, demographic variables (education, stopped work, and social desirability) were entered in step 1 , self-esteem was entered in step 2, and illness self-concept entered in step 3, with depression scores as the dependent variable. 
Results indicate that illness self-concept contributed an additional $7 \%$ of the variance in depression scores, over and above self-esteem $\left(\mathrm{R}^{2}=.07, \mathrm{~F}(1,97)=19.00, \mathrm{p}<.001\right)$. When examining the standardized coefficients, it is apparent that self-esteem is a strong predictor of depression $(\beta=-.42, \mathrm{p}<.000)$, as indicated in the literature (Roberts \& Monroe, 1999). Comparatively, illness self-concept maintained a significant but slightly less powerful standardized Beta coefficient $(\beta=.35, \mathrm{p}<.001)$. These results demonstrate that illness self-concept is a distinct construct apart from self-esteem and that both variables are important predictors of depression in the current sample.

One concept that is relevant to people with chronic illness, and fibromyalgia specifically, is a feeling of victimization. Physical symptoms, disruption to daily life, functional status, and the psychological and social ramifications of chronic illness can elicit feelings of victimization. While victimization may be one aspect of illness selfconcept, it is not all of it. In order to examine this proposition, two regression analyses were conducted, with illness self-concept predicting quality of life and depression, controlling for victimization (Tables $20 \mathrm{a}$ and $20 \mathrm{~b}$ ). Victimization was assessed by one item that asked participants to rate the extent to which they felt victimized by their illness, from (1) "not victimized" to (10) "very victimized".

In both analyses, demographic variables (education, stopped work, marital status, and social desirability) were entered in step 1 , victimization in step 2 , and illness self-concept in step 3. Results indicate that illness self-concept predicts an additional $19 \%$ of variance in quality of life, over and above feelings of victimization $\left(\mathrm{R}^{2}=.19, \mathrm{~F}(1,96)=54.95, \mathrm{p}<.001\right)$. In step 2 , victimization accounted for $21 \%$ of 
variance in quality of life scores $(\mathrm{p}<.001)$. Comparing standardized Beta coefficients in step 3, illness self-concept was a stronger predictor of quality of life than was victimization $(\beta=-.63, p<.001$ and $\beta=-.12, p=.14)$. The fact that the coefficient for victimization dropped to non-significant when illness self-concept was entered into the model suggests that victimization may be encompassed in the illness self-concept construct.

The second regression analysis indicates that after demographic variables were entered in step 1, and victimization was entered in step 2, illness self-concept accounted for an additional $8 \%$ of variance in depression $\left(\mathrm{R}^{2}=.08, \mathrm{~F}(1,96)=20.85\right.$, $\mathrm{p}<.001)$. Degree of victimization accounted for $17 \%$ of variance in depression scores $(\mathrm{p}<.001)$. In order to examine the comparative contribution of illness self-concept and victimization to depression, the standardized Beta coefficients were examined. In step 3 , the standardized coefficient for victimization was $\beta=.19(p=.03)$, and the coefficient for illness self-concept was $\beta=.43(\mathrm{p}<.001)$, indicating that illness selfconcept is a stronger predictor of depression. Furthermore, these results indicate that while illness self-concept likely includes elements of victimization, it is a broader construct.

\section{Summary}

Two scales were constructed for the purpose of this study, one to measure illness self-concept, and the other to measure the extent to which illness is reinforced as central to the self-concept. Both scales achieved good reliability. Cronbach's alpha was .94 for the Illness Self-Concept Scale and .89 for the ISC Support Scale. 
Hypothesis one was supported by the data, indicating that illness self-concept significantly predicted quality of life $\left(\mathrm{R}^{2} \Delta=.39\right)$ and depression $\left(\mathrm{R}^{2} \Delta=.24\right)$.

Hypothesis two was also supported by the data, which demonstrated that ISC support, optimism, illness intrusiveness, and functional status each independently predicted illness self-concept $(\beta=.43, \mathrm{p}<.001, \beta=-.54, \mathrm{p}<.001, \beta=.63, \mathrm{p}<.001$, and $\beta=.32$, $\mathrm{p}<.01$, respectively). Lastly, hypothesis three was supported by the data, indicating that illness self-concept predicted unique variance in quality of life and depression scores, over and above the impact of ISC support $\left(\mathrm{R}^{2} \Delta=.32\right.$ and .16 , respectively), optimism $\left(\mathrm{R}^{2} \Delta=.17\right.$ and .09 , respectively), illness intrusiveness $\left(\mathrm{R}^{2} \Delta=.24\right.$ and .14 , respectively), and functional status $\left(\mathrm{R}^{2} \Delta=.33\right.$ and .22 , respectively).

The primary purpose of this study was to conceptualize and measure the extent to which illness has come to permeate the self (illness self-concept) in patients with chronic illness. A secondary purpose was to demonstrate that illness self-concept is related to quality of life and depression, such that the more illness occupies a central position in the life space, the poorer the quality of life and the greater the depression. The study also sought to identify variables that influence illness self-concept. Results indicate that optimism, ISC support, illness intrusiveness, and functional status all independently predict the extent to which illness is central to an individual's selfconcept. Lastly, the study sought to demonstrate the importance of the illness selfconcept construct in predicting adjustment in patients with chronic illness, relative to other predictors. After accounting for the effects of optimism, social support, illness intrusiveness, and disease severity, all variables that have been shown in the literature 
to predict adjustment, illness self-concept accounted for significant variance in quality of life and depression. 


\section{Discussion}

The primary purpose of this study was to conceptualize the relationship between the self and illness. Although prior researchers have speculated about the nature of such a relationship (Ashmore \& Contrada, 1999; Charmaz, 1999, 2002; Oullette, 1999) few have actually attempted to characterize the self in illness (Beanlands, et al., 2003, Devins, Beanlands, et al., 1997; McCay \& Seeman, 1998). The conceptualization of the self and illness in the current research, illness selfconcept, is theory driven and characterizes the extent to which illness penetrates the self-concept and regions of the life space. This conceptualization was successful in predicting how people with fibromyalgia adjust to their illness in spite of disease severity, and personal and interpersonal factors. The results of the study confirm that "illness self-concept", as characterized in this study, is a psychological construct which exists in persons with chronic illness, and which is related to adjustment.

The results of specific hypothesis tests provide evidence that illness selfconcept is an important variable in examining adjustment to chronic illness, and demonstrate how the concept differs from other important psychological and illnessrelated factors. In analyses evaluating the first hypothesis, illness self-concept was established as a variable that contributes substantially to measures of adjustment in chronic illness. Illness self-concept explained a large portion of the variance in depression and quality of life by itself, and also remained an important variable when compared with other known predictors of adjustment. 
Analyses testing hypothesis two confirmed that optimism, social support, illness intrusiveness and functional status each influenced the extent to which illness is either central or peripheral to the self. Following from hypothesis two, analyses testing hypothesis three demonstrated that illness self-concept fared well in predicting adjustment even after the effects of other important predictors were statistically partialled out. Illness self-concept predicted substantial variance in quality of life and depression after controlling for the effects of optimism, social support, illness intrusiveness, and functional status.

Numerous studies have demonstrated that the degree of optimism and illness intrusiveness displayed in patients has a profound impact on how they adjust to illness (Devins, Yitzchak, et al., 1983; Devins, Armstrong, et al., 1990; Devins, Mandin, et al., 1990; Scheier, et al., 1989; Eitel, Hatchett, Friend, Griffin \& Wadhwa, et al., 1995; Fontaine \& Seal, 1997; Giltay et al., 2004; Symister \& Friend, 2003). The fact that illness self-concept was a more powerful predictor of adjustment controlling for these variables speaks to the depth and breadth of this concept in characterizing how illness affects the self. While illness self-concept encompasses aspects of optimism and illness intrusiveness, it extends beyond these constructs as well.

Illness self-concept is also more than merely self-esteem. It would be easy to assume that illness self-concept and self-esteem are synonymous since they both address one's perceptions of the self. However, self-esteem and illness self-concept each predict quality of life and depression uniquely, suggesting that they each impact adjustment, but that they are separate entities. While self-esteem provides a broad 
measure of how self-perceptions are influenced in general (i.e., by evaluations of selfworth), illness self-concept addresses how the self is perceived specifically in the context of illness.

The main purpose of this study was to establish that illness self-concept is a construct that is influenced by factors related to the self and the environment. The measure of ISC support provides additional evidence that illness self-concept is influenced by, and embedded in, a social context. ISC support assessed the extent to which family and close friends are perceived to influence illness self-concept by either reinforcing aspects of the non-illness self, or by reinforcing illness as central to the self. The .55 correlation between illness self-concept and ISC support, and the fact that ISC support predicts adjustment, suggests that illness self-concept is determined not only by self-perceptions, but by how participants perceive that their social network perceives them. The fact that illness self-concept is influenced by perceptions of family and friends provides evidence that illness self-concept is a psychological construct which is embedded in the social environment. However, the social environment in the current study was only measured through perceptions of social support and did not take into account received support (i.e., support as reported by family and friends).

\section{Distinguishing Illness Self-Concept From Other Research}

Devins and colleagues conducted two studies, which are the only empirical studies to date which attempt to measure the self-concept in chronic illness and link self-concept with adjustment. There are notable differences between the way that 
Devins and colleagues (Devins, Beanlands, et al., 1997; Beanlands, et al., 2003) conceptualized and measured self-concept in illness, and how the current study conceptualized and measured illness self-concept. Devins characterized the selfconcept in illness as the situation where people identify themselves exclusively in terms of their specific disease (i.e., as a "typical cancer patient" or a "typical kidney disease patient"). Devins measured identification with a "typical patient" using the Osgood Semantic-Differential technique (Osgood, Suci, \& Tannenbuam, 1957), which asked participants to rate "myself as I am now" and "a typical patient" on potency (strong-weak, hard-soft), evaluative (good-bad, kind-cruel) and activity (activepassive, rash-cautious) dimensions. The difference scores between the two ratings were then used to determine the extent to which participants viewed themselves as similar or dissimilar to the "typical patient".

Using this technique, Devins (1997) found that identification with a typical dialysis patient was associated with the potency and activity dimensions, but was not associated with a self-view of good or bad (evaluative dimension), suggesting that perceived similarity or dissimilarity to a typical patient does not represent a negative or positive self concept. This may explain why self-concept was not related to adjustment in this study. This technique places an emphasis on the self as negatively influenced by illness (i.e., identity as a "dialysis patient"), but not on how individuals withstand the effects of illness. Specifically, this conceptualization affords no opportunity for participants to evaluate themselves compared to a healthy individual. 
The findings in the Devins et al. (1997) study were also weak in terms of establishing a relationship between self-concept in illness and adjustment. Selfconcept, as measured by the Osgood semantic-differential technique was not related to depression, measured by the CES-D. By contrast, in the current study, illness selfconcept demonstrated a strong relationship with depression $(r=.67)$ as measured by the BDI-A. Similarly, Devins et al. found no significant relationship between similarity to a typical patient and psychological well-being, part of which was measured by quality of life. In the current study, however, illness self-concept demonstrated a strong relationship with quality of life $(r=.76)$. Thus, self-concept, as measured by perceived similarity to a typical patient was not a significant predictor of psychological adjustment in chronically ill patients, whereas illness self-concept, as defined in this study, was a strong predictor of both depression and quality of life. These findings demonstrate the utility of the illness self-concept construct, as presented in this study, in predicting adjustment in chronic illness.

In a second study, also using the semantic-differential technique to measure self-concept in illness, Devins and colleagues (2003) attempted to link the self-concept to the typical bone marrow transplant patient, the extent of illness intrusiveness, and a new concept called engulfment, to describe the experience of illness and treatment. Engulfment, a concept taken from the mental health field with regard to selfevaluation in schizophrenia (McCay \& Seeman, 1998), was defined as the situation where illness and the patient role evolve to dominate the self-concept. This was thought to occur largely through social interactions where the individual is perceived 
differently because of the stigma of illness. In the study, engulfment was hypothesized to impact self-concept, such that the more engulfed a person was, the more likely they would identify themselves as similar to a typical bone marrow transplant patient. However, there was an omission in describing specifically what constitutes a typical bone marrow patient. Findings indicate that engulfment did not correlate with selfconcept as a typical patient $(\mathrm{r}=.15)$, reaffirming that this characterization of selfconcept as similar to a patient was not sufficient to define the self in illness, at least using the semantic-differential technique.

The concept of engulfment is distinguished from the current conceptualization of self-concept on a number of dimensions. Theoretically, engulfment places a focus on how individuals are consumed by illness, but does not identify how individuals can preserve their sense of self in spite of illness. The absence of illness self-concept (i.e., a self-concept that is not consumed by illness and the patient role) is not explicitly defined in engulfment theory. The construct of illness self-concept in the current study emphasizes that while in some people illness may consume the self-concept, there are many individuals who are able to preserve a sense of self in spite of illness, and the results of the study indicate that this is the case.

The current theory of illness self-concept goes beyond mere description by positing explicitly three different theoretical processes that help describe how illness comes to permeate the self or how the self is preserved in the face of chronic illness. Directionality, pervasiveness, and illness self-consciousness each describe a process that reflects the extent to which illness is incorporated into the self-concept and life 
space or how the non-illness self, on the other hand, is preserved. Directionality refers to the causal relationship between different regions of the life space (Lewin, 1951). Specifically, it describes whether illness occupies a central region, where all other regions of the self are influenced by illness, or whether the non-illness self is central and illness is then interpreted in light of the self. Pervasiveness describes the extent to which illness pervades many or few parts of the life space, and how much of the self is preserved from illness. Illness self-consciousness refers to the extent of consciousness and preoccupation with illness.

Engulfment (measured by the Modified Engulfment Scale), which intends to assess whether the self-concept is defined solely in terms of illness, appears to actually be a heterogeneous concept which measures a number of different constructs, including perception of self, optimism, pessimism, self-esteem, self-efficacy, social comparison, illness intrusiveness, and fear ["I will probably need to be hospitalized again" (pessimism), "My mind is normal" (self-view), "I believe I am more anxious and nervous than most other people" (social comparison), "I am afraid of losing my mind" (fear), and "I am a damaged person by my illness" (self-esteem)] (McCay \& Seeman, 1998). Although some aspects of the self-concept are measured by engulfment, the items are spread across many different constructs and appear not to measure a single or unified process. Illness self-concept, by contrast, is clearly defined in terms of three interrelated constructs which are relatively homogeneous and distinct from other constructs, such as optimism, illness intrusiveness, and self-esteem. 
Other research (Charmaz, 1999, 2002; Levine, 1999) appears to be relevant to illness self-concept; however, upon careful examination, this research is not related to the current conceptualization of self in illness. As discussed in the introduction, Charmaz $(1999 ; 2002)$ relates the experience of illness to acquiring a sick role and describes a need to restructure the self through discarding old habits and forming new ones that conform to the parameters of a given illness. Charmaz uses narrative of chronically ill individuals to speculate about how chronic illness is experienced but does not systematically quantify illness self-concept. Levine (1999) relates the concept of identity salience to the evaluation of symptoms. Specifically, this work examines how social identities in healthy individuals (e.g., rugby players and secretaries) can be made salient, which then determines how specific symptoms are interpreted. This research does not address persons who are diagnosed with a chronic illness or how that chronic illness comes to permeate the self.

\section{Illness Self-Concept in Fibromyalgia}

The results of the current study demonstrate that illness self-concept in fibromyalgia patients is an important predictor of adjustment. The nature of fibromyalgia is such that there is not a singular effective treatment. Fibromyalgia patients experience chronic widespread pain, severe fatigue, and a number of related symptoms and disorders, including irritable bowel syndrome, restless legs, vertigo, insomnia, and depression. Although there is a body of research providing evidence that fibromyalgia is a disorder of the central nervous system (Bendtsen, Norregaard, Jensen, \& Olesen, 1997; Bennett, 1999), whereby patients become hypersensitive to 
sensory input (e.g., touch, smell), there is still a sense of lingering debate over the etiology of the condition (Bennett, 2002, 2004).

The fact that fibromyalgia is not a well established condition in comparison to other chronic illnesses may make fibromyalgia patients more vulnerable to having a self-concept that is consumed by illness, particularly with regard to the illness selfconsciousness construct. There is also a stereotype of fibromyalgia patients as consumed by victimization and depression. However, it is clear from the current study that many fibromyalgia patients were able to withstand feelings of depression and victimization and were able to preserve a sense of non-illness self. Illness self-concept predicted quality of life at all levels of depression and victimization. This result is important because the present sample contained substantial numbers of individuals who were considerably more depressed, and even more clinically depressed, than many other chronic conditions (Symister and Friend, 1996, 2003). This demonstrates that illness self-concept goes beyond the degree of depression and victimization in characterizing how the self experiences illness.

\section{Illness Self-Concept and Denial}

It could be said that the extreme case of illness as peripheral to the self is a form of denial. However, in the current study, it was found that the more illness was peripheral to the self, the better the outcomes in terms of quality of life and depression. According to the current theory, the only situation where illness as central to the self would possibly be beneficial is in the case of a life-threatening illness. Participants in the current study were all diagnosed with fibromyalgia by a physician, and the nature 
of participating in this study required that they acknowledge their illness. Additionally, there is no significant relationship between social desirability and functional status $(\mathrm{r}=$ -.07), demonstrating that participants offered unbiased evaluations of their disease status and were not denying or downplaying their illness.

\section{Illness Self-Concept Across Illnesses and Treatment}

It is likely that illness self-concept will vary across different chronic illnesses and as a function of treatment. There may be aspects of fibromyalgia (i.e., lack of treatment, skepticism) which make these patients more vulnerable to incorporating illness as central to the self-concept. Similarly, unique aspects of other chronic illnesses may present other vulnerabilities or protections. For example, end-stage renal disease requires either a kidney transplant or dialysis treatment, which replaces the function of the kidneys. Dialysis can take place in a clinic, performed by nurses, or it can be done at home, by the patient. The type of treatment that an individual receives may impact the processes (directionality, pervasiveness, and illness selfconsciousness) which determine illness self-concept.

If patients receive kidney transplants, they may have the opportunity to return to the life and functioning they experienced prior to kidney failure. As a result, illness may no longer occupy a central region of the life space. Illness self-consciousness will decrease since they no longer have to undergo treatment and pervasiveness will decrease as they resume activities. Kidney patients who receive dialysis treatment at a center may report greater pervasiveness because of the duration of treatment (up to four hours three times a week with commute time), but less illness self-conscious 
because it is performed by a nurse. Those patients who perform dialysis at home may report less pervasiveness because they can treat themselves on their own time and without travel, but may report increased illness self-consciousness due to the responsibility of managing their own treatment. The nature, course, and treatment associated with an illness are likely to impact illness self-concept and the three underlying processes.

\section{Demographic Characteristics, Illness Self-Concept and Adjustment}

Two issues were raised with regards to the demographic characteristics of the current sample. One concerns the generalizability of the study, which is based in part on how well the study sample represents the typical fibromyalgia population. The second concerns some interesting findings with respect to this study's sample. The demographic characteristics of the current sample are similar to other studies with fibromyalgia patients. The mean age in the current sample was $53(\mathrm{SD}=10)$, demonstrating a skew toward older individuals, which is similar to other studies with fibromyalgia patients where the mean age was $48(\mathrm{SD}=10.32$; Thieme, Turk, \& Flor, $2004)$ and 60 ( $\mathrm{SD}=10.2$; Oliver \& Cronan, 2005). Mean length of diagnosis in the current study was 9.7 years $(\mathrm{SD}=7.45)$, with other studies reporting similar duration of symptoms $(\mathrm{M}=8.9, \mathrm{SD}=8.3$; Burckhardt, et al., $1994 ; \mathrm{M}=9, \mathrm{SD}=9.23$; Thieme, Turk \& Flor, 2004). Sixty-three percent of the current sample were married, compared with $74 \%$ and $72 \%$ in other studies. Thirty-seven percent were employed in the current sample, versus $66 \%$ and $31 \%$ in other studies with fibromyalgia patients (Burckhardt 
et al., 1994; Oliver \& Cronan, 2005). Eighty-three percent of the current sample had at least some college compared with $81 \%$ in another study (Oliver \& Cronan, 2005).

The current sample was $95 \%$ female and $97 \%$ Caucasian. Epidemiologic studies indicate that fibromyalgia is significantly more common in women than in men, with prevalence rates for women in the general population being reported around $4.9 \%$ versus $1.6 \%$ in men (White et al., 1999). One study indicated that the female to male ratio for fibromyalgia cases reported in the clinic was 9:1 (Miedema et al., 1988). The ethnic breakdown reported in the current study is in part a reflection of the ethnic breakdown in the general population in Portland, Oregon and the surrounding areas, which is predominantly Caucasian, and may in part be skewed because of the method of recruitment (indirectly through the internet).

Consequently, it is important to think about the ways in which the demographic characteristics of the current sample may have influenced responses to study questions or the study results. Because the level of education in the current sample is fairly high ( $83 \%$ had some college), depression may be lower than what would be found in a sample of less educated subjects since education and depression are correlated $(r=-.31)$. In the current study, there was a significant correlation between gender and the outcome variables, with men $(n=5)$ reporting more depression, poorer quality of life, and illness as more central to the self. This correlation should be considered cautiously because of the small number of male subjects, but could suggest that males who have fibromyalgia experience or report worse outcomes than women. However, one study that compared psychological 
factors (stress, anxiety, depression and hassles) in men and women with fibromyalgia reported no significant differences between gender (Yunus, Celiker \& Aldag, 2004).

\section{Limitations and Strengths}

The current study is limited by the self-report and cross-sectional nature of the data. Data that are strictly self-report bear some difficulty in interpretation, and may increase measurement error. The nature of self-report is such that only the participant presents perceptions of psychological adjustment, disease status, and other study variables. Because information is only gleamed from one person, it is not possible to rule out biases in the data that result from the state or traits specific to an individual. For example, if a subject is depressed, there may be biases in how they perceive their social support network and their functional status. However, it should be noted that some of these effects can be controlled statistically. In the current study, after controlling for depression, illness self-concept contributed significant variance to quality of life, indicating that depression did not explain this relationship.

Social support data can be collected from the social network themselves, with family and friends reporting their own perceptions of support and how they interact with subjects or reinforce illness. In a similar way, physicians can provide measures of functional status and disease severity that may be more objective than participant reports. In the current study, I found it more meaningful to examine participants' perceptions of their social network since perceptions of social support and objective reports of social support may not be related and provide different types of information. Perceptions of social support address the question of how people view their social 
network, whereas object measures of social support address the influence of received support. In a follow-up study, it may be helpful to obtain a measure of both perceived and received support to examine the relationship between the two types of support and how each impacts illness self-concept and adjustment.

The current study collected reports of functional status only from the perspective of participants, which may be influenced by pain, fatigue, and depression, among other factors. Obtaining an objective measure of disease severity from a physician may provide a way to determine if psychological variables and illness selfconcept influence physiological functioning and processes. In the case of fibromyalgia, illness stems from central nervous system dysfunction where the body becomes hypersensitive to sensory signals. Changes in psychological well-being and illness self-concept (i.e., minimizing illness in the self) may influence this process, such that the body responds less to pain and other sensory input.

Cross-sectional data, collected at only one point in time, provides a snapshot of the relationships between illness self-concept, psychological adjustment, and determinants of illness self-concept (e.g., optimism and illness intrusiveness). Although the current study provided an illustration of the proposed relationships between variables (see Figure 1), it is possible that the variables interact in other ways. For example, it is possible that depression influences illness self-concept, or that depression influences optimism, which then influences illness self-concept. With only cross-sectional data, it is impossible to disentangle these relationships. 
Transactional oriented research (Werner, Brown \& Altman, 2002) suggests that various aspects of a given phenomenon fit together in a variety of ways, rather than in a specific, unidirectional way. In the current study, it is possible that the determinants of illness self-concept (ISC support, optimism, illness intrusiveness and functional status) do not work in isolation, but interact with each other in important ways to influence illness self-concept. Optimism may influence perceptions of support and the extent of illness intrusiveness; perceptions of intrusiveness may be influenced by the degree of support, and perceptions of support may influence functional status.

Transactional models also emphasize that relationships between variables may change depending on circumstances. The current study describes such a scenario in the introduction of this paper, proposing that changes in treatment (i.e., introduction of new efficacious treatments) or the course of illness may signify changes in illness selfconcept and presumably psychological adjustment. Although the current study cannot test alternative, more complex models of the study variables, data collected at a second time point (which is currently underway) will be able to address some of these issues. For example, with a second time point, I can test whether illness self-concept contributes to changes in depression over time or the reverse.

Since the current conceptualization and measurement of illness self-concept has only been tested with fibromyalgia patients, it is possible that the results found in this study apply only to people with this condition. Although the concepts presented in this study were developed with all chronic illnesses in mind, until they are tested in other populations, it is premature to assume that they are generalizable outside of 
fibromyalgia. If illness self-concept is identified in other chronically ill populations, the processes underlying illness self-concept (directionality, pervasiveness and illness self-consciousness) may be differentially salient, affecting the parameters of illness self-concept or the strength of the relationship between illness self-concept and adjustment. As previously discussed, illnesses that require extensive treatment may increase the pervasive impact of illness, whereas illnesses that are highly stigmatizing may increase illness self-consciousness.

\section{Strengths}

The current study has several strengths, including support for all study hypotheses, an excellent return rate in data collection, scale development and high internal consistency for two new scales, and development of a theory in a difficult area of research. This study collected data from fibromyalgia patients through a mailed questionnaire. As reflected in the data, many of these patients were severely depressed and all of them experience chronic widespread pain and fatigue. Of 171 eligible participants, 109 completed and returned the questionnaire, yielding a $64 \%$ return rate. This is impressive considering the physical and psychological symptoms experienced by these participants and that the requirement was to complete a 16-page questionnaire.

Two scales were developed explicitly for the purposes of the current study in accordance with the theory of illness self-concept. The scales demonstrated high internal consistency ( $\alpha=.94$ and .89$)$ and all items contributed to the overall scales. In addition, each scale contained items that addressed the three sub-constructs 
(directionality, pervasiveness and illness self-consciousness) and presented items that reflected illness as both central and peripheral to the self. The data provided construct validity for the scales as they correlated substantially with other variables that they are assumed to be related to, but demonstrated discriminant validity by predicting adjustment controlling for these variables. Time two data will help establish further validity and test-retest reliability for the scales.

One of the most important strengths of this study was the development of a theory and measurement tool to examine how the self is influenced by illness. While the self in illness has been discussed at length in the literature (Ashmore \& Contrada, 1999; Charmaz, 1999; Leventhal, Idler, \& Leventhal, 1999; Ouellette, 1999), only two studies have attempted to empirically test this relationship, presumably because it is a difficult and complex issue. Devins, who has conducted numerous studies in chronic illness (Beanlands, et al., 2003; Devins, Armstrong, et al., 1990; Devins, Beanlands, et al., 1997; Devins, Edworthy, Seland et al., 1993; Devins, Mandin, et al., 1990; Devins, Mann, et al., 1990; Devins, Seland, et al., 1993), was not able to identify a characterization of the self in illness that adequately predicted adjustment. It is a notable accomplishment that this study developed a theory that sufficiently describes the experience of the self in illness, and that the conceptualization was strongly related to adjustment. Additionally, this study identified four determinants of illness selfconcept and established that the construct is independent of optimism, illness intrusiveness, social support, functional status, self-esteem, victimization, and depression. 


\section{Implications}

Results of the current study have significant implications for the field of research and practice in chronic illness. Based on the findings of this study, illness self-concept appears to be an important variable in adjustment to illness. The nature of chronic illness is such that it is enduring and does not have a cure, and many conditions do not have effective treatments. As a result, it is increasingly important to examine the psychological aspects of illness in order to improve quality of life and disease management. If illness self-concept is an important variable in determining adjustment to illness, it can be targeted for change by physicians, psychologists and patients.

Results of the current study indicate that when illness is central to the selfconcept, adjustment is poor. Accordingly, minimizing illness in the self-concept and life space may lead to improvements in adjustment. One way this could be accomplished is through expanding the life space. The extent to which illness is central to the self may be a function of the expansiveness of an individual's life space, such that illness self-concept is the ratio of illness to life space. When the life space is extensive, illness occupies a smaller portion, compared to the situation where the life space is constricted. An intervention could focus on expanding the life space in people whose illness is central to the self. This could be accomplished by asking participants to designate areas of their life that can be expanded (e.g., work, social life, passive recreation), and proposing ways to extend them. 
Summary

The current study was successful in conceptualizing and measuring how the self is influenced by chronic illness. The data support the theory posited, which identifies three processes that determine whether illness is central or peripheral to the self. The theory and concepts described in the current study introduce a psychological construct which may be extremely valuable in predicting adjustment to chronic illness. Future studies should examine illness self-concept in relation to various chronic illnesses, specifically examining the three underlying constructs of directionality, pervasiveness, and illness self-consciousness. Future studies should also identify strategies to minimize illness in the self and life space in order to improve quality of life and adjustment. 
Table 1

Illness Self-Concept Scale: Item-Total Correlations and Item Correlations with Social Desirability

Item

1. My illness is with me most of the time.

2. I am preoccupied with my illness.

3. I have a positive view of life, in spite of my illness.

4. I try not to let my illness control how I feel.

5. My illness is at the center of who I am.

6. My illness is often on my mind.

7. I do not allow my illness to affect too many parts of my life.

8. I feel consumed by my illness.

9. I only think of my illness when I have to.

10. My illness has undermined my confidence in myself and what I can do.

11. At times, it seems like my illness runs my life.

12. I have preserved my sense of self, in spite of my illness.

13. It seems like almost everything I do is influenced by my illness.

14. I do many of the same things as healthy others, despite my illness.

15. My illness has affected nearly all aspects of my life.

16. My illness prevents me from doing things I need to do.

17. I do not let my illness take over my life.

18. I am dominated by my illness.

19. My illness has not kept me from doing the things I enjoy doing.

20. My illness prevents me from being the kind of person I wish to be.

21. I see myself as a healthy person, in spite of my illness.

22. I rarely feel trapped by my illness.

23. My illness dictates nearly everything I do.

Item-Total

Correlation

$.54 * *$

$.73 * *$

$.67 * *$

$.52 * *$

$.55 * *$

$.65^{* *}$

$.74 * *$

$.78 * *$

$.56 * *$

$.58^{* *}$

$.59 * *$

$.59 * *$

$.55^{* *}$

$.63^{* *}$

$.58 * *$

$.64 * *$

$.68^{* *}$

$.72 * *$

$.60 * *$

$.65^{* *}$

$.60 * *$

$.64^{* *}$

$.80^{* *}$

$.63^{* *}$
Item

Correlation with Social

Desirability

$-.04$

$-.26 * *$

$-.26^{* *}$

$-.16$

$-.25 * *$

$-.28 * *$

$-.25 * *$

$-.25^{* *}$

$-.19$

$-.30 * *$

$-.21 *$

$-.16$

$-.06$

$-.03$

$-.04$

$-.15$

$-.18$

$-.16$

$-.04$

$-.30 * *$

$-.24 *$

$-.17$

$-.24 *$

Average Item-Total Correlation

.18

Note: ${ }^{* *}$ Correlation significant at $\mathrm{p}<.01,{ }^{*}$ Correlation significant at $\mathrm{p}<.05$ 
Table 2

Illness Self-Concept Subscale:

Items worded such that if endorsed, they reflect illness as central to the self.

13 Subscale Items

Item Mean $=3.69 \mathrm{SD}=1.07$

My illness is at the center of who I am.

I feel consumed by my illness.

My illness has undermined my confidence in myself and what I can do.

At times, it seems like my illness runs my life.

I am dominated by my illness.

My illness prevents me from being the kind of person I wish to be.

My illness dictates nearly everything I do.

My illness is with me most of the time.

It seems like almost everything I do is influenced by my illness.

My illness has affected nearly all aspects of my life.

My illness prevents me from doing things I need to do.

I am preoccupied with my illness.

My illness is often on my mind. 
Table 3

Illness Self-Concept Subscale:

Items worded such that if endorsed, they reflect illness as peripheral to the self.

Ten Subscale Items

Item Mean $=3.11 \mathrm{SD}=1.03$

I have a positive view of life, in spite of my illness.

I try not to let my illness control how I feel.

I have preserved my sense of self, in spite of my illness.

I do not let my illness take over my life.

I see myself as a healthy person, in spite of my illness.

I rarely feel trapped by my illness.

I do not allow my illness to affect too many parts of my life.

I do many of the same things as healthy others, despite my illness.

My illness has not kept me from doing the things I enjoy doing.

I only think of my illness when I have to. 


\section{Illness Self-Concept Subscales}

\section{Directionality Subscale Items}

Item Mean $=3.09 \quad \mathrm{SD}=1.04$

I have a positive view of life, in spite of my illness.

I try not to let my illness control how I feel.

My illness is at the center of who I am.

I feel consumed by my illness.

My illness has undermined my confidence in myself and what I can do.

At times, it seems like my illness runs my life.

I have preserved my sense of self, in spite of my illness.

I do not let my illness take over my life.

I am dominated by my illness.

My illness prevents me from being the kind of person I wish to be.

I see myself as a healthy person, in spite of my illness.

I rarely feel trapped by my illness.

My illness dictates nearly everything I do.

\section{Pervasiveness Subscale Items}

Item Mean $=4.08 \quad \mathrm{SD}=1.04$

My illness is with me most of the time.

I do not allow my illness to affect too many parts of my life.

It seems like almost everything I do is influenced by my illness.

I do many of the same things as healthy others, despite my illness.

My illness has affected nearly all aspects of my life.

My illness prevents me from doing things I need to do.

My illness has not kept me from doing the things I enjoy doing.

\section{Illness Self-Consciousness Subscale Items}

Item Mean $=3.38 \quad \mathrm{SD}=1.21$

I am preoccupied with my illness.

My illness is often on my mind.

I only think of my illness when I have to. 
Table 5

Correlation Between Illness Self-Concept Subscales and Study Variables

\begin{tabular}{|c|c|c|c|c|c|c|}
\hline & Optimism & $\begin{array}{c}\text { ISC } \\
\text { Support }\end{array}$ & $\begin{array}{c}\text { Illness } \\
\text { Intrusive- } \\
\text { ness }\end{array}$ & $\begin{array}{c}\text { Functional } \\
\text { Status }\end{array}$ & Depression & $\begin{array}{l}\text { Quality } \\
\text { of Life }\end{array}$ \\
\hline Directionality & $-.66^{* *}$ & $.55^{* *}$ & $.64^{* *}$ & $.39^{* *}$ & $.70^{* *}$ & $-.78^{* *}$ \\
\hline Pervasiveness & $-.51 * *$ & $.50 * *$ & $.71^{* *}$ & $.49^{* *}$ & $.53 * *$ & $-.64 * *$ \\
\hline $\begin{array}{l}\text { Illness Self- } \\
\text { Consciousness }\end{array}$ & $-.48 * *$ & $.40^{* *}$ & $.50 * *$ & $.33 * *$ & $.49 * *$ & $-.55^{* *}$ \\
\hline
\end{tabular}

Note: ${ }^{* *}$ Correlation significant at $\mathrm{p}<.01,{ }^{*}$ Correlation significant at $\mathrm{p}<.05$ 
Table 6

ISC Support Scale: Item-Total Correlations and Item Correlations with Social Desirability

Item

Item Correlation Item-Total with Social Correlation Desirability

1. Points out things I can do in spite of my illness.

2. Helps me focus on life apart from my illness.

3. Sometimes makes me conscious of my physical limitations.

4. Makes me feel that I am a capable person.

5. Encourages me to be involved in activities that are important to me.

6. Makes it seem as though my illness runs my life.

7. Treats me differently than healthy others in a way that makes me feel incompetent.

8. Helps me take my mind off of my illness.

9. Underestimates my ability to do things.

.41

.58

.46

$-.01$

$-.08$

$-.34 * *$

.71

$-.13$

.65

$-.02$

.69

$-.19$

10. Reminds me that my illness does not define me.

11. Undermines my confidence in myself and what I can do.

12. Makes me feel like I cannot to do much now that I am ill.

13. Sometimes views me as a "sick" person in a way that makes me feel helpless.

14. Helps me keep my illness in perspective.

Average Item-Total Correlation
.44

.53

.38

.57

.69

.65

$-.14$

$-.01$

.03

$-.09$

$-.13$

$-.11$

.58

$-.20 *$

.63

$-.10$

Note: ${ }^{* *}$ Correlation significant at $\mathrm{p}<.01,{ }^{*}$ Correlation significant at $\mathrm{p}<.05$ 
Table 7

$\underline{\text { ISC Support Subscales }}$

Directionality Subscale Items

Item Mean $=2.28 \quad \mathrm{SD}=.92$

Makes me feel that Ii am a capable person.

Makes it seem as though my illness runs my life.

Treats me differently than healthy others in a way that makes me feel incompetent.

Underestimates my ability to do things.

Undermines my confidence in myself and what I can do.

Sometimes views me as a "sick" person in a way that makes me feel helpless.

Pervasiveness Subscale Items

Item Mean $=2.45 \quad \mathrm{SD}=.92$

Points out the things I can do in spite of my illness.

Encourages me to be involved in activities that are important to me.

Makes me feel like I cannot do much now that I am ill.

\section{Illness Self-Consciousness Subscale Items}

Item Mean $=2.75 \quad \mathrm{SD}=.85$

Helps me focus on life apart from my illness.

Sometimes makes me conscious of my physical limitations.

Helps me take my mind off of my illness.

Reminds me that my illness does not define me.

Helps me keep my illness in perspective.

Note: ${ }^{* *}$ Correlation significant at $\mathrm{p}<.01,{ }^{*}$ Correlation significant at $\mathrm{p}<.05$ 
Table 8

Correlation Between ISC Support Subscales and Study Variables

\begin{tabular}{|c|c|c|c|c|c|c|}
\hline & Optimism & $\begin{array}{c}\text { Illness } \\
\text { Intrusive- } \\
\text { ness }\end{array}$ & $\begin{array}{l}\text { Illness } \\
\text { Self- } \\
\text { Concept }\end{array}$ & $\begin{array}{c}\text { Functional } \\
\text { Status } \\
\end{array}$ & Depression & $\begin{array}{l}\text { Quality } \\
\text { of Life }\end{array}$ \\
\hline Directionality & $-.35^{* *}$ & $.46^{* *}$ & $.50^{* *}$ & $.29^{* *}$ & $.47^{* *}$ & $-.38 * *$ \\
\hline Pervasiveness & $-.39 * *$ & $.32 * *$ & $.50^{* *}$ & $.24^{*}$ & $.43^{* *}$ & $-.47 * *$ \\
\hline $\begin{array}{l}\text { Illness Self- } \\
\text { Consciousness }\end{array}$ & $-.44 * *$ & $.42 * *$ & $.46^{* *}$ & $.20^{*}$ & $.43^{* *}$ & $-.45^{* *}$ \\
\hline
\end{tabular}

Note: ${ }^{* *}$ Correlation significant at $\mathrm{p}<.01,{ }^{*}$ Correlation significant at $\mathrm{p}<.05$ 
Table 9

Correlation Between Study and Demographic Variables

\begin{tabular}{lccccccc} 
& Education & $\begin{array}{c}\text { Marital } \\
\text { Status }\end{array}$ & $\begin{array}{c}\text { Employ- } \\
\text { ment } \\
\text { Status }\end{array}$ & $\begin{array}{c}\text { Stopped } \\
\text { Work }\end{array}$ & $\begin{array}{c}\text { Length } \\
\text { of } \\
\text { Diagnosis }\end{array}$ & Ethnicity & Age \\
\hline Illness Self-Concept & $-.28^{* *}$ & .13 & .19 & $-.31^{* *}$ & .04 & .17 & -.06 \\
ISC Support & $-.26^{* *}$ & .09 & .14 & $-.24^{*}$ & .03 & .13 & -.04 \\
Optimism & $.26^{* *}$ & -.14 & .04 & .15 & .07 & -.16 & .11 \\
Illness Intrusiveness & -.12 & .02 & .11 & $-.34^{* *}$ & -.04 & .14 & -.11 \\
Functional Status & $-.28^{* *}$ & $.21^{*}$ & $.33^{* *}$ & $.31^{* *}$ & .06 & .01 & .04 \\
Depression & $-.31^{* *}$ & $.25^{* *}$ & .04 & $-.23^{*}$ & -.06 & $.25^{* *}$ & -.09 \\
Quality of Life & $.25^{* *}$ & $32^{* *}$ & -.12 & $.23^{*}$ & .12 & -.18 & .03 \\
\hline
\end{tabular}

Note: Sample sizes for correlations range from 98 to 109 , depending on the variable.

${ }^{* *}$ Correlation significant at $\mathrm{p}<.01,{ }^{*}$ Correlation significant at $\mathrm{p}<.05$ 
Table 10

Correlations and Descriptive Statistics of Study Variables

\begin{tabular}{|c|c|c|c|c|c|c|c|c|}
\hline & $\underline{1}$ & $\underline{2}$ & $\underline{3}$ & $\underline{4}$ & $\underline{5}$ & $\underline{6}$ & $\underline{7}$ & $\underline{8}$ \\
\hline 1. Illness Self-Concept & $*$ & & & & & & & \\
\hline 2. ISC Support & $.55^{* *}$ & * & & & & & & \\
\hline 3. Optimism & $-.63^{* *}$ & $-.45^{* *}$ & $*$ & & & & & \\
\hline 4. Illness Intrusiveness & $.69 * *$ & $.47 * *$ & $-.39 * *$ & * & & & & \\
\hline 5. Functional Status & $.44 * *$ & $.28^{* *}$ & $-.23^{*}$ & $.48^{* *}$ & * & & & \\
\hline 6. Depression (BDI-A) & $.67 * *$ & $.51^{* *}$ & $-.66^{* *}$ & $.44^{* *}$ & $.31^{* *}$ & * & & \\
\hline 7. Quality of Life & $-.76^{* *}$ & $-.48^{* *}$ & $.69^{* *}$ & $-.52 * *$ & $-.42 * *$ & $-.78 * *$ & $*$ & \\
\hline 8. Social Desirability & $-.28 * *$ & -.19 & $.33^{* *}$ & $-.24 *$ & -.07 & $-.39 * *$ & $.29 * *$ & * \\
\hline Means & 79.04 & 34.78 & 21.26 & 53.21 & 46.11 & 16.54 & 14.23 & 7.58 \\
\hline Standard Deviation & 22.53 & 10.97 & 5.03 & 16.59 & 12.81 & 9.35 & 4.62 & 2.99 \\
\hline Possible Range & $23-138$ & $14-84$ & $6-30$ & $13-91$ & $\begin{array}{c}5.71- \\
80.01\end{array}$ & $0-63$ & $4-23$ & $0-13$ \\
\hline Observed Range & $28-130$ & $14-68$ & $6-29$ & $12-91$ & $\begin{array}{c}16.43- \\
77.10\end{array}$ & $2-43$ & $4-23$ & $0-13$ \\
\hline Alpha & .94 & .89 & .89 & .87 & .90 & .87 & .88 & - \\
\hline
\end{tabular}

Note: ${ }^{* *}$ Correlation significant at $\mathrm{p}<.01,{ }^{*}$ Correlation significant at $\mathrm{p}<.05$ 
Table 11a

Results for Hypothesis 1a: Illness Self-Concept Predicting Quality of Life

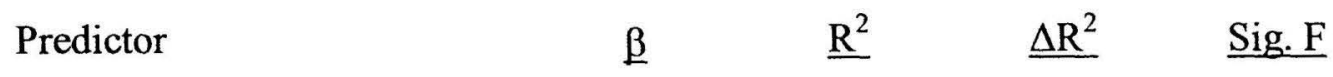

Step 1:

Education $.22^{*}$

Marital Status $\quad-.28 * *$

Stopped Work $\quad .18^{*}$

$\begin{array}{llll}\text { Social Desirability } & .27^{* *} & .28 & 9.40^{* * *}\end{array}$

Step 2:

Education

.06

Marital Status $\quad-.21^{* *}$

Stopped Work $\quad-.02$

Social Desirability $\quad .09$

$\begin{array}{lllll}\text { Illness Self-Concept } & -.71^{* * *} & .67 & .39 & 113.85^{* * *}\end{array}$

Multiple $\mathrm{R}=.82$

Note. ${ }^{*} \mathrm{p}<.05 .{ }^{* *} \mathrm{p}<.01 .{ }^{* * *} \mathrm{p}<.001$. 
Table 11b

Results for Hypothesis 1b: Illness Self-Concept Predicting Depression

Predictor

$\underline{B} \quad \underline{R}^{2} \quad \underline{\Delta R^{2}} \quad \underline{\text { Sig. } F}$

Step 1:

Education

Marital Status

$-.29 * *$

Stopped Work

$.18 *$

Social Desirability

$-.17 *$

$-.40 * * *$

.36

$13.58 * * *$

Step 2:

Education

$-.16 *$

Marital Status

.13

Stopped Work

$-.02$

Social Desirability

$-.26 * * *$

Illness Self-Concept

$.56 * * *$

.59

.24

$56.60 * * *$

Multiple $\mathrm{R}=.77$

Note. ${ }^{*} \mathrm{p}<.05 . \quad * * \mathrm{p}<.01 . \quad * * * \mathrm{p}<.001$. 
Table 12a

Results for Hypothesis 2a: ISC Support Predicting Illness Self-Concept

Predictor

B

$\underline{\mathrm{R}^{2}}$

$\underline{\Delta \mathrm{R}^{2}}$

$\underline{\text { Sig. F }}$

Step 1:

Education

$-.23 *$

Stopped Work

$-.28 * *$

Social Desirability

$-.25 * *$

.23

$9.65^{* * *}$

Step 2:

Education

$-.13$

Stopped Work

$-.19 *$

Social Desirability

$-.17 *$

ISC Support

$.43 * * *$

.39

.16

$25.47^{* * *}$

Multiple $\mathrm{R}=.62$

Note. ${ }^{*} \mathrm{p}<.05 .{ }^{* *} \mathrm{p}<.01 . \quad{ }^{* * *} \mathrm{p}<.001$. 
Table $12 b$

Results for Hypothesis 2b: Optimism Predicting Illness Self-Concept

$\begin{array}{lllll}\text { Predictor } & \underline{R^{2}} & \underline{\Delta \mathrm{R}^{2}} & \underline{\text { Sig. F }}\end{array}$

Step 1:

Education $\quad-.23 *$

Stopped Work $\quad-.28^{* *}$

Social Desirability $\quad-.25^{* *}$

$.239 .65^{* * *}$

Step 2:

\begin{tabular}{lllll} 
Education & -.11 & & & \\
Stopped Work & $-.22^{* *}$ & & & \\
Social Desirability & -.07 & & & \\
Optimism & $-.54^{* * *}$ & .46 & .23 & $41.45^{* * *}$ \\
& & & & \\
Multiple R $=.68$ & & & & \\
\hline
\end{tabular}

Note. ${ }^{*} \mathrm{p}<.05 .{ }^{* *} \mathrm{p}<.01 .{ }^{* * *} \mathrm{p}<.001$. 
Table 12c

Results for Hypothesis 2c: Illness Intrusiveness Predicting Illness Self-Concept

Predictor

B

$\underline{\mathrm{R}^{2}}$

$\underline{\Delta \mathrm{R}^{2}}$

$\underline{\text { Sig. F }}$

Step 1:

Education

Stopped Work

$-.23 *$

Social Desirability

$-.28 * *$

$-.25 * *$

.23

$9.65^{* * *}$

Step 2:

Education

$-.19 * *$

Stopped Work

$-.07$

Social Desirability

$-.12$

Illness Intrusiveness

$.63 * * *$

.55

.32

$69.28 * * *$

Multiple $\mathrm{R}=.74$

Note. ${ }^{*} \mathrm{p}<.05 .{ }^{* *} \mathrm{p}<.01 .{ }^{* * *} \mathrm{p}<.001$. 
Table 12d

Results for Hypothesis 2d: Functional Status (FIQ) Predicting Illness

Self-Concept

$\begin{array}{lllll}\text { Predictor } & \underline{R^{2}} & \underline{\mathrm{R}^{2}} & \underline{\mathrm{Sig}} \mathrm{F}\end{array}$

Step 1:

Education $\quad-.22 *$

Stopped Work $\quad-.24^{*}$

Marital Status $\quad .09$

Employment $\quad .07$

Status

Social $-26 * *$

Desirability

Step 2:

Education $\quad-.16$

Stopped Work $\quad-.17$

Marital Stats $\quad .04$

Employment $\quad .01$

Status

Social $\quad-.24^{* *}$

Desirability

Functional $\quad .32 * *$

Status

Multiple $\mathrm{R}=.56$

Note. ${ }^{*} \mathrm{p}<.05 .{ }^{* *} \mathrm{p}<.01 .{ }^{* * *} \mathrm{p}<.001$. 
Table 13

Additional Analysis For Hypothesis 2: Multiple Regression with ISC Support, Optimism, Illness Intrusiveness, and Functional Status Predicting Illness SelfConcept

Predictor

$\underline{B} \quad \underline{R^{2}} \quad \underline{\Delta R^{2}} \quad \underline{\text { Sig. } F}$

Step 1:

Education $\quad-.22 *$

Stopped Work $\quad-.24 *$

Marital Status $\quad .09$

Employment Status $\quad .07$

Social Desirability $\quad-.26^{* *}$

Step 2:

Education $\quad-.05$

Stopped Work $\quad .00$

Marital Status $\quad .04$

Employment Status $\quad .11$

Social Desirability $\quad-.03$

ISC Support $\quad .14$

Optimism $-.35^{* * *}$

Illness Intrusiveness $\quad .43^{* * *}$

$\begin{array}{llllll}\text { Functional Status } & .05 & .68 & .44 & 30.88^{* * *}\end{array}$

Multiple $\mathrm{R}=.82$

Note. ${ }^{*} \mathrm{p}<.05 .{ }^{* *} \mathrm{p}<.01 .{ }^{* * *} \mathrm{p}<.001$. 
Table 14

Summary Table for Hypothesis 3: Illness Self-Concept Predicting Additional Variance in Quality of Life and Depression Controlling for ISC Support, Optimism, Illness Intrusiveness, and Functional Status

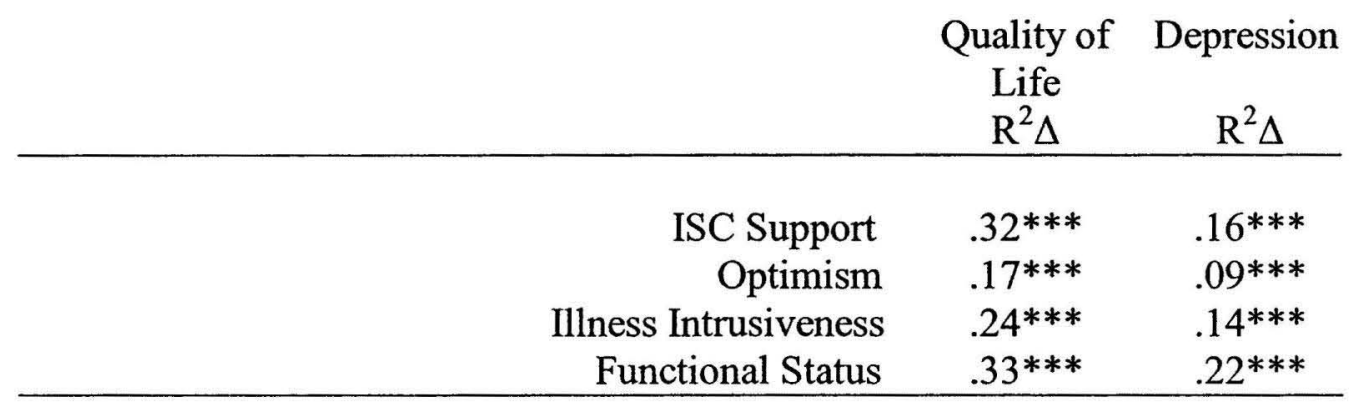

Note: All analyses controlled for education, stopped work and social desirability. Marital status and employment status were controlled for in analyses with functional status.

***All change statistics are significant at $\mathrm{p}<.001$. 
Table $15 \mathrm{a}$

Results for Hypothesis 3a: Illness Self-Concept Predicting Quality of Life Controlling for ISC Support

Predictor

$\underline{B} \quad \underline{R^{2}} \quad \underline{\Delta R^{2}} \quad \underline{\text { Sig. } F}$

Step 1:

Education $.23 *$

Stopped Work $.20^{*}$

Social Desirability $\quad .29 * *$

.20

$8.42^{* * *}$

Step 2:

Education $\quad .15$

Stopped Work $\quad .13$

Social Desirability $\quad .23 *$

$\begin{array}{lllll}\text { ISC Support } & -.35^{* * *} & .31 & .11 & 15.10^{* * *}\end{array}$

Step 3:

Education $\quad .06$

Stopped Work $\quad-.01$

Social Desirability $\quad .10$

ISC Support $\quad-.04$

$\begin{array}{lllll}\text { Illness Self-Concept } & -.72 * * * & .63 & .32 & 82.20^{* * *}\end{array}$

Multiple $\mathrm{R}=.79$

Note. ${ }^{*} \mathrm{p}<.05 .{ }^{* *} \mathrm{p}<.01 .{ }^{* * *} \mathrm{p}<.001$. 
Table $15 b$

Results for Hypothesis 3b: Illness Self-Concept Predicting Depression Controlling for ISC Support

Predictor

$\underline{\beta}$

$\underline{\mathrm{R}^{2}}$

$\underline{\Delta \mathrm{R}^{2}}$

$\underline{\text { Sig. F }}$

Step 1:

Education $.29 * *$

Stopped Work

$-.19 *$

Social Desirability

$-.41 * * *$

.33

$15.96^{* * *}$

Step 2:

Education

Stopped Work

$-.21 * *$

Social Desirability

$-.11$

ISC Support

$-.35^{* * *}$

$.35^{* * *}$

.43

.10

$17.63^{* * *}$

Step 3:

Education

$-.15^{*}$

Stopped Work

$-.02$

Social Desirability

$-.26^{* * *}$

ISC Support

.13

Illness Self-Concept

$.51^{* * *}$

.59

.16

$37.86^{* * *}$

Multiple $\mathrm{R}=.77$

Note. ${ }^{*} \mathrm{p}<.05 .{ }^{* *} \mathrm{p}<.01 .{ }^{* * *} \mathrm{p}<.001$. 
Table $15 \mathrm{c}$

Results for Hypothesis 3c: Illness Self-Concept Predicting Quality of Life Controlling for Optimism

$\begin{array}{lllll}\text { Predictor } & \underline{\mathrm{R}^{2}} & \underline{\Delta \mathrm{R}^{2}} \quad \underline{\text { Sig. } \mathrm{F}}\end{array}$

Step 1:

Education

$.23 *$

Stopped Work

$.20 *$

Social Desirability

$.29 * *$

.20

$8.42 * * *$

Step 2:

Education

.09

Stopped Work

Social Desirability

Optimism

Step 3:

Education

.03

Stopped Work

.01

Social Desirability

.04

Optimism

Illness Self-Concept

$-.56 * * *$

.68

.17

$52.38 * * *$

Multiple $\mathrm{R}=.83$

Note. ${ }^{*} \mathrm{p}<.05 . \quad{ }^{* *} \mathrm{p}<.01 . \quad * * * \mathrm{p}<.001$. 
Table 15d

Results for Hypothesis 3d: Illness Self-Concept Predicting Depression Controlling for Optimism

Predictor

$\underline{B} \quad \underline{R^{2}} \quad \underline{\Delta R^{2}} \quad \underline{\text { Sig. } F}$

Step 1:

Education $.29 * *$

Stopped Work

$-.19^{*}$

Social Desirability

$15.96^{* * *}$

Step 2:

Education

Stopped Work

Social Desirability

Optimism

Step 3:

Education

Stopped Work

Social Desirability

Optimism

Illness Self-Concept

Multiple $\mathrm{R}=.79$

Note. ${ }^{*} \mathrm{p}<.05 .{ }^{* *} \mathrm{p}<.01 . \quad{ }^{* * *} \mathrm{p}<.001$.
$-.18^{*}$

$-.13$

$-.24 * *$

$\begin{array}{llll}-.51 * * * & .53 & .20 & 42.25 * * *\end{array}$

$-.13^{*}$

$-.04$

$-.21 * *$

$-.28 * *$

$.42 * * *$

.62

$.09 \quad 24.12^{* * *}$ 
Table 15e

Results for Hypothesis 3e: Illness Self-Concept Predicting Quality of Life Controlling for Illness Intrusiveness

Predictor

B

$\underline{\mathrm{R}^{2}}$

$\underline{\Delta R^{2}}$

$\underline{\text { Sig. F }}$

Step 1:

Education $.23^{*}$

Stopped Work $.20 *$

Social Desirability

Step 2:

Education $.20 *$

Stopped Work

.04

Social Desirability

$.19^{*}$

Illness Intrusiveness

$$
-.48 * * *
$$

.39

.19

$29.67 * * *$

Step 3:

Education

.07

Stopped Work $\quad-.01$

Social Desirability $\quad .10$

Illness Intrusiveness $\quad-.02$

Illness Self-Concept

$-.72 * * *$

.63

.24

$61.33^{* * *}$

Multiple $\mathrm{R}=.79$

Note. ${ }^{*} \mathrm{p}<.05 .{ }^{* *} \mathrm{p}<.01 .{ }^{* * *} \mathrm{p}<.001$. 
Table $15 f$

Results for Hypothesis 3f: Illness Self-Concept Predicting Depression Controlling for Illness Intrusiveness

Predictor

$\underline{\underline{R^{2}}} \quad \underline{\Delta R^{2}} \quad \underline{\text { Sig. } F}$

Step 1:

Education

Stopped Work

$-.19 *$

Social Desirability

Step 2:

Education

Stopped Work

Social Desirability

Illness Intrusiveness
$-.27^{* *}$

$-.06$

$-.33^{* * *}$

$.37 * * *$

.44

.11

$19.84^{* * *}$

Step 3:

Education

Stopped Work

Social Desirability

Illness Intrusiveness

Illness Self-Concept
$-.17 *$

$-.02$

$-.27 * * *$

.03

Multiple $\mathrm{R}=.76$

Note. ${ }^{*} \mathrm{p}<.05 .{ }^{* *} \mathrm{p}<.01 .{ }^{* * *} \mathrm{p}<.001$. 
Table 15g

Results for Hypothesis 3g: Illness Self-Concept Predicting Quality of Life Controlling for Functional Status

Predictor

$\underline{\beta} \quad \underline{R^{2}} \quad \underline{\Delta R^{2}} \quad \underline{\text { Sig. } F}$

Step 1:

Education $.22 *$

Stopped Work

Marital Status

Employment Status

$-.01$

Social Desirability

$.27 *$

Step 2:

Education

Stopped Work

Marital Status

Employment Status

Social Desirability

Functional Status
.17

.10

$-.23 * *$

.04

$.25 * *$

$-.29 * *$

.35

.07

$9.8^{* *}$

Step 3:

Education

Stopped Work

Marital Status

Employment Status

Social Desirability

Functional Status

Illness Self-Concept
.06

$-.02$

$-.20 * *$

.05

.09

$-.08$

$-.69^{* * *}$

.67

.33

$93.53^{* * *}$

Multiple $\mathrm{R}=.82$

Note. ${ }^{*} \mathrm{p}<.05 .{ }^{* *} \mathrm{p}<.01 . \quad{ }^{* * *} \mathrm{p}<.001$. 
Table $15 \mathrm{~h}$

Results for Hypothesis 3h: Illness Self-Concept Predicts Depression Controlling for Functional Status

Predictor

$\underline{B} \quad \underline{\mathrm{R}^{2}} \quad \underline{\Delta \mathrm{R}^{2}} \quad \underline{\text { Sig. } \mathrm{F}}$

Step 1:

Education

Stopped Work

Marital Status

Employment Status

Social Desirability

$$
\begin{aligned}
& -.31 * * * \\
& -.19^{*} \\
& .19^{*} \\
& -.09 \\
& -.38 * * *
\end{aligned}
$$

Step 2:

Education

Stopped Work

Marital Status

$-.27 * *$

Employment Status

$-.16$

.16

Social Desirability

$-.12$

Functional Status

$-.37 * * *$

Step 3:

Education

Stopped Work

Marital Status

Employment Status

Social Desirability

Functional Status

Illness Self-Concept
$-.18 *$

$-.06$

$.14 *$

$-.13$

$-.24 * *$

$-.01$

$.57 * * *$

.22

Multiple $\mathrm{R}=.78$

Note. ${ }^{*} \mathrm{p}<.05 .{ }^{* *} \mathrm{p}<.01 .{ }^{* * *} \mathrm{p}<.001$. 
Table 16a

Additional Analysis For Hypothesis 3: Illness Self-Concept Predicting Quality of Life, Controlling for ISC Support, Optimism, Illness Intrusiveness, and Functional Status

Predictor

$\underline{\beta}$

$\underline{\mathrm{R}^{2}}$

$\underline{\Delta \mathrm{R}^{2}}$

$\underline{\text { Sig. F }}$

Step 1:

Education $.22 *$

Stopped Work

.16

Marital Status

$-.28 * *$

Employment Status

$-.01$

Social Desirability

$-.27^{* *}$

.28

$7.46^{* * *}$

Step 2:

Education

.04

Stopped Work

$-.03$

Marital Status

$.20 * *$

Employment Status

$-.01$

Social Desirability

.05

ISC Support

$-.07$

Optimism

Illness Intrusiveness

Functional Status

$-.11$

.65

Step 3:

Education

.02

Stopped Work

$-.03$

Marital Status

$-.19 * *$

Employment Status

.00

Social Desirability

.03

ISC Support

$-.01$

Optimism

$.32 *$

Illness Intrusiveness

$-.03$

Functional Status

$-.08$

Illness Self-Concept

$-.49$

.73

.08

Multiple $\mathrm{R}=.82$

Note. ${ }^{*} \mathrm{p}<.05 .{ }^{* *} \mathrm{p}<.01 .{ }^{* * *} \mathrm{p}<.001$. 
Table $16 \mathrm{~b}$

Additional Analysis For Hypothesis 3: Illness Self-Concept Predicting Depression Controlling for ISC Support, Optimism, Illness Intrusiveness, and Functional Status

Predictor

$\underline{\beta}$

$\underline{\mathrm{R}^{2}}$

$\underline{\Delta \mathrm{R}^{2}}$

$\underline{\text { Sig. F }}$

Step 1:

Education

Stopped Work

Marital Status

$-.19 *$

Employment Status

$-.19 *$

Social Desirability

$-.07$

$-.38 * * *$

Step 2:

Education

Stopped Work

Marital Status

$-.16^{*}$

$-.04$

$.14^{*}$

Employment Status

$-.04$

Social Desirability

$-.20 * *$

ISC Support

.15

Optimism

$-.37 * * *$

Illness Intrusiveness

$.18 *$

Functional Status

.02

.61

.24

$13.93 * * *$

Step 3:

Education

Stopped Work

$-.14^{*}$

$-.04$

Marital Status

.12

Employment Status

$-.08$

Social Desirability

$-.19 * *$

ISC Support

.10

Optimism

$-.24 * *$

Illness Intrusiveness

.02

Functional Status

.00

Illness Self-Concept

$.37 * *$

.65

.04

$11.16^{* *}$

Multiple $\mathrm{R}=.82$

Note. ${ }^{*} \mathrm{p}<.05 .{ }^{* *} \mathrm{p}<.01 . \quad * * * \mathrm{p}<.001$. 
Table 17a

Additional Analysis: Illness Self-Concept Predicting Quality of Life Controlling for Control of Symptoms

Predictor

$\underline{B} \quad \underline{\mathrm{R}^{2}} \quad \underline{\Delta \mathrm{R}^{2}} \quad \underline{\text { Sig. } \mathrm{F}}$

Step 1:

Education

Stopped Work

$.23 *$

Social Desirability

Step 2:

Education

Stopped Work

Social Desirability

$.19 *$

Control Over Pain

Control Over Fatigue

.08

Step 3:

Education

Stopped Work

.06

Social Desirability

$-.00$

Control Over Pain

Control Over Fatigue

.04

Illness Self-Concept

$-.04$

$-.74 * * *$

.63

.35

$88.60 * * *$

Multiple $\mathrm{R}=.79$

Note. ${ }^{*} \mathrm{p}<.05 .{ }^{* *} \mathrm{p}<.01 . \quad{ }^{* * *} \mathrm{p}<.001$. 
Table $17 \mathrm{~b}$

Additional Analysis: Illness Self-Concept Predicting Depression Controlling for Control of Symptoms

Predictor

$\underline{B} \quad \underline{\mathrm{R}^{2}} \quad \underline{\Delta \mathrm{R}^{2}} \quad \underline{\text { Sig. } \mathrm{F}}$

Step 1:

Education

Stopped Work

Social Desirability

Step 2:

Education

$-.26 * *$

Stopped Work

$-.18$

Social Desirability

$-.38^{* * *}$

Control Over Pain

$-.15$

.38

.05

$3.58^{*}$

Control Over Fatigue

$-.10$

Step 3:

Education

$-.16^{*}$

Stopped Work

$-.03$

Social Desirability

$-.27$

Control Over Pain

$-.03$

Control Over Fatigue

.04

Illness Self-Concept

$.57 * * *$

.59

.21

$47.25 * * *$

Multiple $\mathrm{R}=.76$

Note. ${ }^{*} \mathrm{p}<.05 .{ }^{* *} \mathrm{p}<.01 .{ }^{* * *} \mathrm{p}<.001$. 
Table 18

Additional Analysis: Illness Self-Concept Predicting Quality of Life Controlling for Depression

Predictor

$\underline{B} \quad \underline{R^{2}} \quad \underline{\Delta R^{2}} \quad \underline{\text { Sig. } F}$

Step 1:

Education

Stopped Work

$.23 *$

Social Desirability

Step 2:

Education .01

Stopped Work

.06

Social Desirability

$-.02$

Depression

$-.76^{* * *}$

.58

.38

$91.16^{* * *}$

Step 3:

Education

$-.01$

Stopped Work

$-.02$

Social Desirability

$-.02$

Depression

$-.43 * * *$

Illness Self-Concept

$-.49 * * *$

.70

.12

$38.27 * * *$

Multiple $\mathrm{R}=.84$

Note. ${ }^{*} \mathrm{p}<.05 .{ }^{* *} \mathrm{p}<.01 .{ }^{* * *} \mathrm{p}<.001$. 
Table 19a

Additional Analysis: Illness Self-Concept Predicting Quality of Life Controlling for $\underline{\text { Self-Esteem }}$

Predictor

$\underline{B} \quad \underline{\mathrm{R}^{2}} \quad \underline{\Delta \mathrm{R}^{2}} \quad \underline{\text { Sig. } \mathrm{F}}$

Step 1:

Education $.23 *$

Stopped Work $.20^{*}$

Social Desirability $.28 * *$ .20 $8.43^{* * *}$

Step 2:

Education .06

Stopped Work

.14

Social Desirability .05

Self-Esteem

.48

.28

$52.56^{* * *}$

Step 3:

Education .02

Stopped Work

.01

Social Desirability

.03

Self-Esteem $.27 * *$

Illness Self-Concept $-.59 * * *$ .67 .19 $54.00^{* * *}$

Multiple $\mathrm{R}=.82$

Note. ${ }^{*} \mathrm{p}<.05 .{ }^{* *} \mathrm{p}<.01 .{ }^{* * *} \mathrm{p}<.001$. 
Table 19b

Additional Analysis: Illness Self-Concept Predicting Depression Controlling for SelfEsteem

$\begin{array}{lllll}\text { Predictor } & \underline{R^{2}} & \underline{\mathrm{R}}^{2} & \underline{\mathrm{R}^{2}} & \underline{\text { Sig. } \mathrm{F}}\end{array}$

Step 1:

Education $\quad-.29^{* *}$

Stopped Work $\quad-.19 *$

Social Desirability $\quad-.41^{* * *} \quad .33 \quad 15.96^{* * *}$

Step 2:

Education $\quad-.12$

Stopped Work $\quad-.12$

Social Desirability $\quad-.17 *$

Self-Esteem - $-.62^{* * *}$

$\begin{array}{lll}.61 & .28 & 68.95^{* * *}\end{array}$

Step 3:

Education $\quad-.09$

Stopped Work $\quad-.05$

Social Desirability $\quad-.16^{*}$

Self-Esteem $\quad-.42^{* * *}$

$\begin{array}{lllll}\text { Illness Self-Concept } & .35^{* * *} & .68 & .07 & 19.00^{* * *}\end{array}$

Multiple $\mathrm{R}=.82$

Note. ${ }^{*} \mathrm{p}<.05 .{ }^{* *} \mathrm{p}<.01 .{ }^{* * *} \mathrm{p}<.001$. 
Table 20a

Additional Analysis: Illness Self-Concept Predicting Quality of Life Controlling for Victimization

Predictor

$\underline{\beta}$

$\underline{\mathrm{R}^{2}}$

$\underline{\Delta R^{2}}$

$\underline{\text { Sig. F }}$

Step 1:

Education $.22 *$

Stopped Work

Marital Status

$-.26 * *$

Social Desirability

.28

$9.40^{* * *}$

Step 2:

Education

$.16^{*}$

Stopped Work

.12

Marital Status

$-.27 * *$

Social Desirability

$.16^{*}$

Victimization

Step 3:

Education .06

Stopped Work

$-.01$

Marital Status

Social Desirability

$-.22 * * *$

Victimization

.09

Illness Self-Concept

$-.12$

$-.63 * * *$

.68

.19

$54.95^{* * *}$

Multiple $\mathrm{R}=.82$

Note. ${ }^{*} \mathrm{p}<.05 .{ }^{* *} \mathrm{p}<.01 .{ }^{* * *} \mathrm{p}<.001$. 
Table 20b

Additional Analysis: Illness Self-Concept Predicting Depression Controlling for Victimization

Predictor

$\underline{\beta}$

$\underline{\mathrm{R}^{2}}$

$\underline{\Delta \mathrm{R}^{2}}$

$\underline{\text { Sig. F }}$

Step 1:

Education $-.29 * *$

Stopped Work

$-.17 *$

Marital Status

$.18^{*}$

Social Desirability

Step 2:

Education $-.24 * *$

Stopped Work

$-.12$

Marital Status

$.17 *$

Social Desirability

$-.30^{* * *}$

Victimization

Step 3:

Education

Stopped Work

Marital Status

Social Desirability

Victimization

Illness Self-Concept
$-.17 *$

$-.03$

$.14^{*}$

$-.25^{* * *}$

$.19 *$

$.43 * * *$

Multiple $\mathrm{R}=.78$

Note. ${ }^{*} \mathrm{p}<.05 .{ }^{* *} \mathrm{p}<.01 .{ }^{* * *} \mathrm{p}<.001$. 


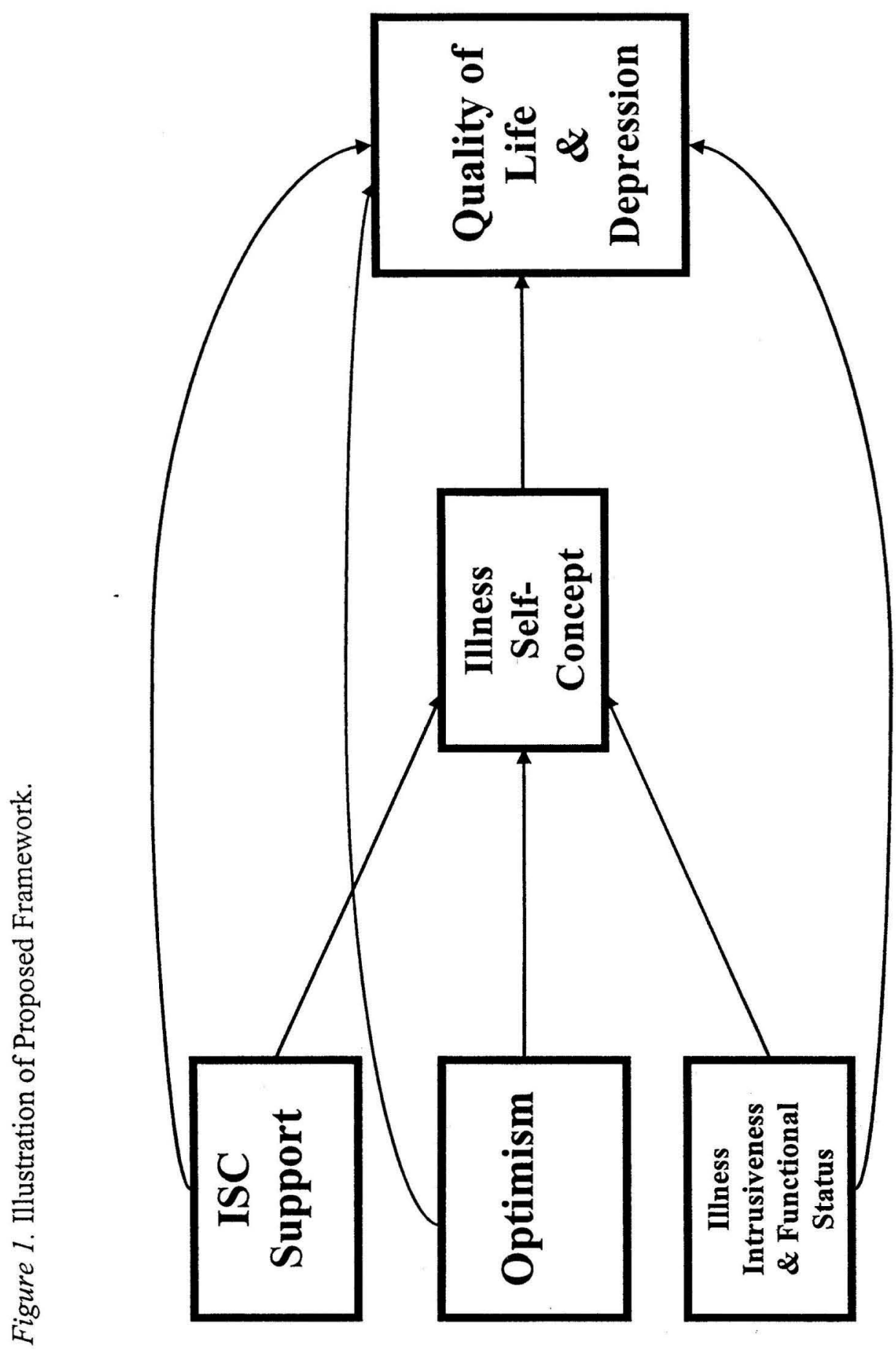


Figure 2. Box and Whisker Plot of the Illness Self-Concept Scale.
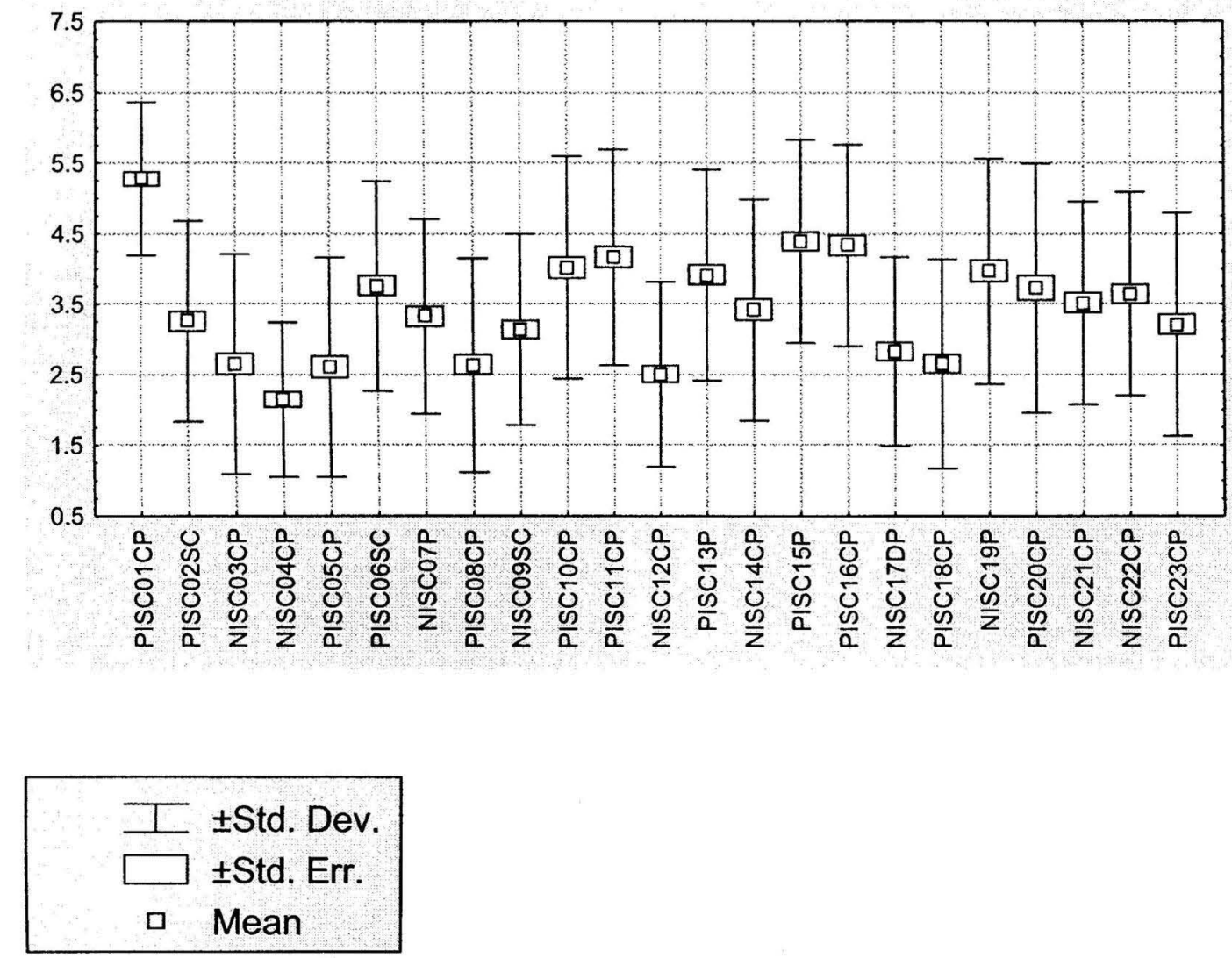

$\mathrm{P}=$ Items worded to represent illness as central to the self

$\mathrm{N}=$ Items worded to represent the ability to preserve the self 
Figure 3. Distribution of the Illness Self-Concept Scale.

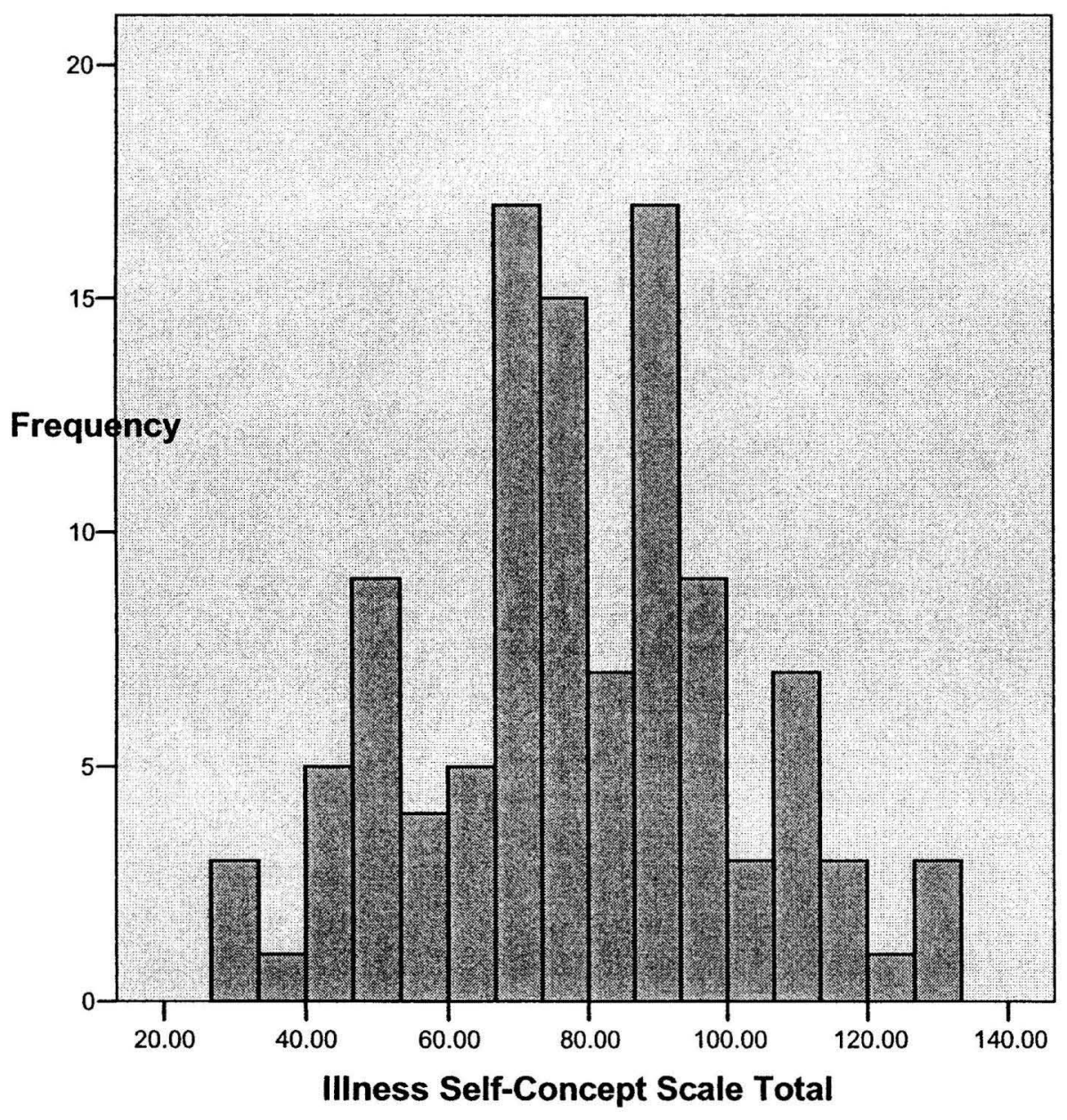

Mean $=79.04$

Std. Dev. $=22.53$

$N=109$ 
Figure 4. Box \& Whisker Plot of the ISC Support Scale.
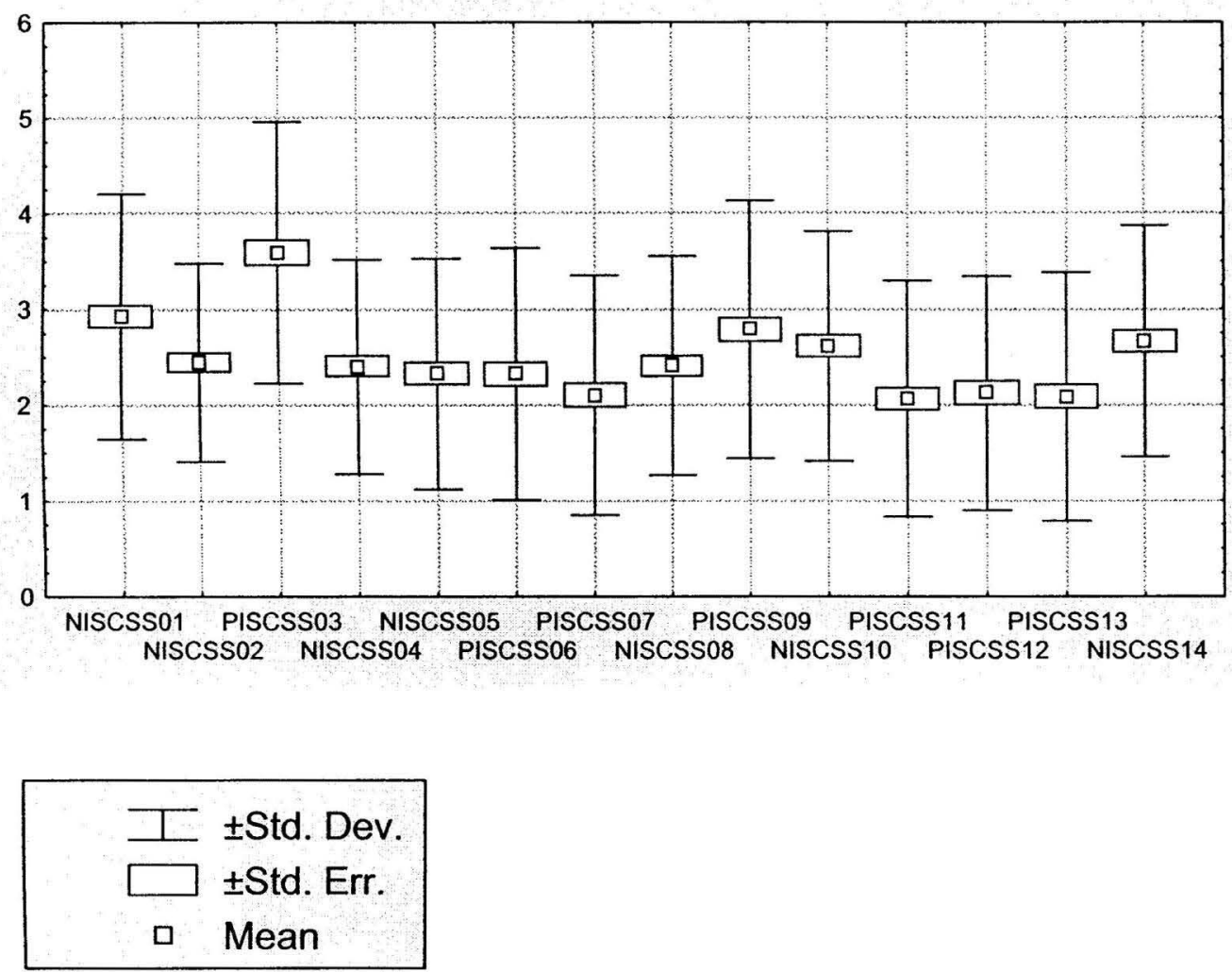

$\mathrm{P}=$ Items worded to represent a social network that reinforces illness as central to the self $\mathrm{N}=$ Items worded to represent a social network that reinforces illness as peripheral to the self 
Figure 5. Distribution of the ISC Support Scale.

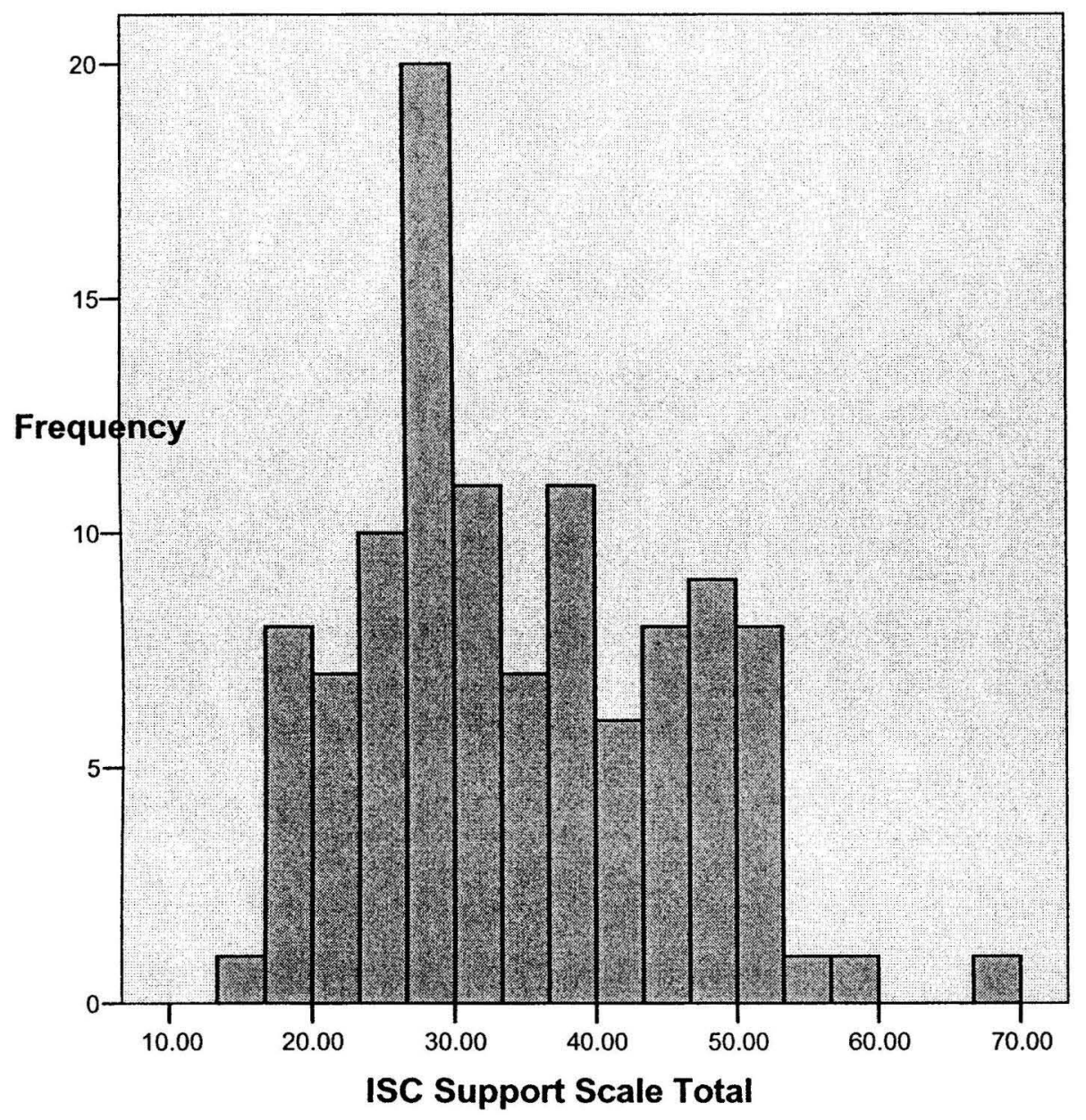

Mean $=34.7798$

Std. Dev. $=10.96742$

$N=109$ 


\section{References}

Asch, S.E. (1952). Social Psychology. Englewood Cliffs, NJ: Prentice-Hall, Inc..

Ashmore, R.D., \& Contrada, R.J. (1999). Behavioral aspects of physical health and disease. In R.J. Contrada \& R.D. Ashmore (Eds.), Self, social identity and physical health (pp. 240-255). New York: Oxford University Press.

Ashmore, R.D., \& Jussim, L. (Eds.). (1997). Self and identity: Fundamental issues. New York: Oxford.

Aspinwall, L.G., \& Taylor, S.E. (1992). Modeling cognitive adaptation: A longitudinal investigation of the impact of individual differences and coping on college adjustment and performance. Journal of Personality and Social Psychology, 63, 989-1003.

Bachman, J., Kahn, R., Davidson, T., \& Johnston, L. (1967). Youth in transition (Vol. 1). Ann Arbor, MI: Institute for Social Research.

Beanlands, H.J., Lipton, J.H., McCay, E.A., Schimmer, A.D., Elliott, M.E., Messner, H.A., \& Devins, G.M. (2003). Self-concept as a "BMT patient", illness intrusiveness, and engulfment in allogeneic bone marrow transplant recipients. Journal of Psychosomatic Research, 55, 419-425.

Beck, A.T., Ward, C.H., Mendelson, M., Mock, J., \& Erbaugh, J. (1961). An inventory for measuring depression. Archives of General Psychiatry, 4, 561571. 
Bediako, S.M., \& Friend, R. (2004). Illness-specific and general perceptions of social relationships in adjustment to rheumatoid arthritis: The role of interpersonal expectations. Annals of Behavioral Medicine, 28, 3, 203-210.

Bendtsen, Nooregaard, Jensen, \& Olesen (1997). Evidence of qualitatively altered nociception in patients with fibromyalgia. Arthritis \& Rheumatism, 40, 98-102.

Bennett, R.M. (1999). Emerging concepts in the neurobiology of chronic pain: evidence of abnormal sensory processing in fibromyalgia. Mayo Clinic Proc, 74, 385-398.

Bennett, R.M. (2002). The rational management of fibromyagia patients. Rheumatic Disease Clinics of North America, 28, 181-199.

Bennett, R.M. (2004). Fibromyalgia: Present to future. Current Pain and Headache Reports, 8, 379-384.

Bennett, R.M., Jones, J., Turk, D.C., Russell, I.J., \& Matallana, L. (2006). An internet based survey of 2,596 people with fibromyalgia. A description of symptoms, impact, and health care. Unpublished manuscript, Oregon Health \& Science University, Portland.

Bloom, J.R., Stewart, S.L., Johnston, M., \& Banks, P. (1998). Intrusiveness of illness and quality of life in young women with breast cancer. Psycho-Oncology, 7, 89-100.

Burckhardt, C.S., Clark, S.R., \& Bennett, R.M. (1991). The Fibromyalgia Impact Questionnaire: Development and validation. Journal of Rheumatology, 18, 728-734. 
Burckhardt, CS., O’Reilly, C.A., Wiens, A.N., Clark, S.R., Campbell, S.M., \& Bennett, R.M. (1994). Assessing depression in fibromyalgia patients. Arthritis Care \& Research, 7, 35-39.

Byrne, B.M. (1996). Measuring self-concept across the life span. Washington, DC: American Psychological Association.

Campbell, A., Converse, P., \& Rodgers, W. (1976). The qualify of American life. New York: Sage.

Cantril, H. (1965). The pattern of human concerns. New Brunswick, NJ: Rutgers University Press.

Carver, C.S., Pozo, C., Harris, S.D., Noriega, V., Scheier, M.F., Robinson, D.S., Ketcham, A.S., Moffat, F.L., \& Clark, K.C. (1993). How coping mediates the effect of optimism on distress: A study of women with early stage breast cancer. Journal of Personality and Social Psychology, 65, 375-390.

Carver, C.S., Reynolds, S.L., \& Scheier, M.F. (1994). The possible selves of optimists and pessimists. Journal of Research in Personality, 28, 133-141.

Charmaz, K. (1999). From the "sick role" to stories of self. In R.J. Contrada \& R.D. Ashmore (Eds.), Self, social identity, and physical health (pp.209-239). New York: Oxford University Press.

Charmaz, K. (2002). The self as habit: The reconstruction of self in chronic illness. The Occupational Therapy Journal of Research, 22, Supplement, 31S-41S. 
Chiaramonte, G.R., \& Friend, R. (2006). Medical students' and residents' gender bias in the diagnosis, treatment, and interpretation of coronary heart disease symptoms. Health Psychology, 25, 255-266.

Crowne, D.P., \& Marlowe, D. (1960). A new scale of social desirability independent of psychopathology. Journal of Consulting Psychology, 24, 349-354.

Dancey, C.P., Hutton-Young, S.A., Moye, S., \& Devins, G.M. (2002). Perceived stigma, illness intrusiveness and quality of life in men and women with irritable bowel syndrome. Psychology, Health \& Medicine, 7, 381-395.

Devins, G.M., Yitzchak, B.M, Hutchinson, T.A., Hollomby, D.J., Barre, P.E., \& Guttmann, R.D. (1983-84). The emotional impact of end-stage renal disease: Importance of patient's perceptions of intrusiveness and control. International Journal of Psychiatry in Medicine, 13, 327-343.

Devins, G.M., Armstrong, S.J., Mandin, H., Paul, L.C., Hons, R.B., Burgess, E.D., Taub, K., Schorr, S., Letourneau, P.K., \& Buckle, S. (1990). Recurrent pain, illness intrusiveness, and quality of life in end-stage renal disease. Pain, 42, 279-285.

Devins, G.M., Beanlands, H., Mandin, H., \& Leendert, P.C. (1997). Psychosocial impact of illness intrusiveness moderated by self-concept and age in end-stage renal disease. Health Psychology, 16, 529-538.

Devins, G.M, Dion, R., Pelletier, L.G., Shapiro, C.M., Abbey, S., Raiz, L.R., Binik, Y.M., McGowan, P., Kutner, N.G., Beanlands, H., \& Edworthy, S.M. (2001). 
Structure of lifestyle disruptions in chronic disease. Medical Care, 39, 10971104.

Devins, G.M., Edworthy, S.M., Paul, L.C., Mandin, H., Seland, P., Klein, G., Costello, C.G., \& Shapiro, C.M. (1993). Restless sleep, illness intrusiveness, and depressive symptoms in three chronic illness conditions: Rheumatoid arthritis, end-stage renal disease and multiple sclerosis. Journal of Psychosomatic Research, 37, 2, 163-170.

Devins, G.M., Edworthy, S.M., Seland, T.P., Klein, G.M., Paul, L.C., \& Mandin, H. (1993). Differences in illness intrusiveness across rheumatoid arthritis, endstage renal disease, and multiple sclerosis. Journal of Nervous and Mental Disease, 181, 6, 377-381.

Devins, G.M., Mandin, H., Hons, R.B., Burgess, E.D., Klassen, J., Taub, K., Schorr, S., Letourneau, P.K., \& Buckle, S. (1990). Illness intrusiveness and quality of life in end-stage renal disease: Comparison and stability across treatment modalities. Health Psychology, 9, 117-142.

Devins, G.M., Mann, J., Mandin, H., Paul, L.C., Hons, R.B., Burgess, E.D., Taub, K., Schorr, S., Letourneau, P.K., \& Buckle, S. (1990). Psychosocial predictors of survival in end-stage renal disease. The Journal of Nervous and Mental Disease, 178, 2, 127-133.

Devins, G.M., Seland, T.P., Klein, G., Edworthy, S.M, \& Saary, M.J. (1993).

Stability and determinants of psychosocial well-being in multiple sclerosis. Rehabilitation Psychology, 38, 1, 11-26. 
Doeglas, D., Suurmeijer, T., Krol, B., Sanderman, R., van Rijswijk, M., \& van Leeuwen, M. (1994). Social support, social disability, and psychological wellbeing in rheumatoid arthritis. Arthritic Care and Research, 7, 10-15.

Eitel, P., Hatchett, L., Friend, R., Griffin, K.W., \& Wadhwa, N.K. (1995). Burden of self-care in seriously ill patients: Impact on adjustment. Health Psychology, 14, 457-463.

Epstein, S. (1973). The self-concept revisited. American Psychologist, 28, 404-416.

Fontaine, K.R., \& Seal, A. (1997). Optimism, social support, and premenstrual dysphoria. Journal of Clinical Psychology, 53, 243-247.

Giltay, E.J., Geleijnse, J.M., Zitman, F.G., Hoekstra, T., Schouten, E.G. (2004). Dispositional optimism and all-cause and cardiovascular mortality in a prospective cohort of elderly Dutch men and women. Archives of General Psychiatry, 61, 1126-1135.

Goodenow, C., Reisine, S.T., \& Grady, K.E. (1990). Quality of social support and associated social and psychological functioning in women with rheumatoid arthritis. Health Psychology, 9, 266-284.

Greenberg, G.D., \& Peterson, R.A. (1997). Illness Effects Questionnaire. In C.P. Zalaquett \& R.J. Wood (Eds.), Evaluating stress: A book of resource (pp.141164). Lanham, MD: Scarecrow Press, Inc.

Griffin, K.W., Friend, R., Kaell, A.T., \& Bennett, R.S. (2001). Distress and disease status among patients with rheumatoid arthritis: Roles of coping styles and 
perceived responses from support providers. Annals of Behavioral Medicine, 23, 133-138.

Griffin, K.W., Friend, R., Kaell, A.T., Bennett, R.S., \& Wadhwa, N.K. (1999). Negative affect and physical symptom reporting: A test of explanatory models in two chronically ill populations. Psychology and Health, 14, 295-307.

Hatchett, L., Friend, R., Symister, \& Wadhwa, N. (1997). Interpersonal expectations, social support, and adjustment to chronic illness. Journal of Personality and Social Psychology, 73, 560-573.

Inanici, F., \& Yunus, M.B. (2004). History of fibromyalgia: Past to present. Current Pain and Headache Reports, 8, 1369-378.

Kraaimaat, F.W., van Dam-Baggen, R.M.J., \& Bijlsma, J.W.J. (1995). Association of social support and spouse's reaction with psychological distress. Journal of Rheumatology, 22, 644-648.

Lally, S.J. (1989). "Does being in here mean there is something wrong with me"? Schizophrenia Bulletin, 15, 253-265.

Leventhal, H., Idler, E., \& Leventhal, E.A. (1999). The impact of chronic illness on the self system. In R.J. Contrada \& R.D. Ashmore (Eds.) Self, social identity and physical health (pp.2185-208). New York: Oxford University Press.

Levine, R.M. (1999). Identity and illness: The effects of identity salience and frame of reference on evaluation of illness and injury. British Journal of Health Psychology, 4, 63-80.

Lewin, K. (1951). Field Theory in Social Science. Chicago: Harper \& Row. 
Littlefield, C., Abbey, S., Fiducia, D., Cardella, C., Greig, P., Levy, G., Maurer, J., \& Winton, T. (1996). Quality of life following transplantation of the heart, liver, and lungs. General Hospital Psychiatry, 18, 36S-47S.

Markus, H., \& Nurius, P. (1986). Possible Selves. American Psychologist, 41, 954969.

Markus, H., \& Wurf, E. (1987). The dynamic self-concept: A social psychological perspective. Annual Review of Psychology, 38, 299-337.

McCay, E.A., \& Seeman, M.V. (1998). A scale to measure the impact of a schizophrenic illness of an individual's self-concept. Archives of Psychiatric Nursing, XII, 41-49.

Miedema, H.S., Van der Linden, S.M., Rasker, J.J., \& Valkenburg, H.A. (1988). National database of patients visiting rheumatologists in the Netherlands: The standard diagnosis register of rheumatic diseases. A report and preliminary analysis. British Journal of Rheumatology, 37, 555-561.

Mullens, L.L., Chaney, J.M., Balderson, B., \& Hommel, K.A. (2000). The relationship of illness uncertainty, illness intrusiveness, and asthma severity to depression in young adults with long-standing asthma. International Journal of Rehabilitation and Health, 5, 3, 177-185.

Oliver, K. \& Cronan, T.A. (2005). Correlates of physical activity among women with fibromyalgia syndrome. Annals of Behavioral Medicine, 29, 44-53.

Osgood, C.E., Suci, G.J., \& Tannenbaum, P.H. (1957). The measurement of meaning. Urbana, IL: University of Illinois Press. 
Ouellette, S.C. (1999) The relationship between personality and health: What self and identity have to do with it. In R.J. Contrada \& R.D. Ashmore (Eds.), Self, social identity and physical health (pp. 125-154). New York: Oxford University Press.

Oyserman, D. (2004). Self-concept and identity. In M.B. Brewer \& M. Hewstone (Eds.), Self and social identity (pp.5-24). Malden, MA: Blackwell.

Peterson, R.A., Kimmel, P.L, Sacks, C.R., Mesquita, M.L., Simmens, S.J., \& Reiss, D. (1991). Depression, perception of illness and mortality in patients with endstage renal disease. International Journal of Psychiatry in Medicine, 21, 343354.

Revenson, T.A., Schiaffino, K.M., Majerovitz, D., \& Gibofsky, A. (1991). Social support as a double-edged sword: The relation of positive and problematic support to depression among rheumatoid arthritis patients. Social Science and Medicine, 33, 807-813.

Riemsma, R.P, Taal, E., Wiegman, O., Rasker, J.J., Bruyn, G.A.W., \& Van Paassen, H.C. (2000). Problematic and positive support in relation to depression in people with rheumatoid arthritis. Journal of Health Psychology, 5, 221-230.

Roberts, J.E., \& Monroe, S.M. (1999). Vulnerable self-esteem and social processes in depression: Toward an interpersonal model of self-esteem. In T. Joiner \& J.C. Coyne (Eds.), The interactional nature of depression: advances in interpersonal approaches (Ch.7). Washington D.C.: American Psychological Association. 
Rosenberg, M. (1979). Conceiving the self. New York: Basic Books.

Scheier, M.F., \& Carver, C.S. (1985). Optimism, coping, and health: Assessment and implications of generalized outcome expectancies. Health Psychology, 4, 219247.

Scheier, M.F., Magovern, G.J., Abbott, R.A., Matthews, K.A., Owens, J.F., Lefebvre, R.C., \& Carver, C.S. (1989). Dispositional optimism and recovery from coronary artery bypass surgery: The beneficial effects on physical and psychological well-being. Journal of Personality and Social Psychology, 57, 1024-1040.

Scheier, M.F. \& Carver, C.S. (1992). Effects of optimism on psychological and physical well-being: Theoretic overview and empirical update. Cognitive Therapy and Research, 16, 208-228.

Scheier, M.F., Carver, C.S., \& Bridges, M.W. (1994). Distinguishing optimism from neuroticism (ant trait anxiety, self-mastery, and self-esteem): A reevaluation of the Life Orientation Test. Journal of Personality and Social Psychology, 67, 1063-1078.

Schur, E. (1971). Labeling deviant behavior: Its sociological implications. New York: Harper \& Row.

Symister, P., \& Friend, R. (1996). Quality of life and adjustment in renal disease: A health psychology perspective. In R.J. Resnick \& R.H. Rozensky (Eds.), Health psychology through the life span (pp. 265-287). Washington, D.C.: American Psychological Association. 
Symister, P. \& Friend, R. (2003). The influence of social support and problematic support on optimism and depression in chronic illness: A prospective study evaluating self-esteem as a mediator. Health Psychology, 22, 123-129.

Talbot, F., Nouwen, A., \& Gingras, J. (1999). Relations of diabetes intrusiveness and personal control to symptoms of depression among adults with diabetes. Health Psychology, 18, 537-542.

Thieme, K., Turk, D.C., Flor, H. (2004). Comorbid depression and anxiety in fibromyalgia syndrome: Relationship to somatic and psychosocial variables. Psychosomatic Medicine, 66, 837-844.

Werner, C.M., Brown, B.B., \& Altman, I. (2002). Transactionally oriented research: Examples and strategies. In R.B. Bechtel \& A. Churchman (Eds.), Handbook of Environmental Psychology (pp.203-221). Hoboken, NJ: Wiley \& Sons, Inc.

White, P., Harth, M., Speechley, M., \& Ostbye, T. (1999). The London fibromyalgia epidemiology study: The prevalence of fibromyalgia syndrome in London, Ontario. Journal of Rheumatology, 26, 1570-1576.

Wolfe, F., Smythe, H.A., Yunus, M.B., Bennett, R.M., Bombardier, C., Goldenberg, D.L., et al. (1990). The American College of Rheumatology 1990 Criteria for the classification of fibromyalgia: report of the Multicenter Criteria Committee, Arthritis \& Rheumatism, 33, 160-72.

Wolfe, F., Anderson, J., Harkness, D., Bennett, R.M., Caro, X.J., Goldenberg, D.L., et al. (1997). Health status and disease severity in fibromyalgia. Arthritis \& Rheumatism, 40, 1571-1579. 
Wright, B.A. (1983). Physical disability-a psychosocial approach. New York: Harper Collins.

Yunus, M.B., Celiker, R., \& Aldag, J.C. (2004). Fibromyalgia in men: Comparison of psychological features with women. Journal of Rheumatology, 31, 2464-2467.

Zook, A., \& Sipps, G.J. (1985). Cross-validation of a short form of the marlowecrowne social desirability scale. Journal of Clinical Psychology, 41, 236-238. 
Appendix A

Illness Self-Concept Scale

The following items ask about how fibromyalgia affects you. CIRCLE the number that corresponds to how you feel. Please use the following scale:

\begin{tabular}{|c|c|c|c|c|c|}
\hline $\begin{array}{l}\text { Strongly } \\
\text { Disagree }\end{array}$ & Disagree & $\begin{array}{l}\text { Somewhat } \\
\text { Disagree }\end{array}$ & $\begin{array}{c}\text { Somewhat } \\
\text { Agree }\end{array}$ & Agree & $\begin{array}{c}\text { Strongly } \\
\text { Agree }\end{array}$ \\
\hline 1 & 2 & 3 & 4 & 5 & 6 \\
\hline 1 & 2 & 3 & 4 & 5 & 6 \\
\hline 1 & 2 & 3 & 4 & 5 & 6 \\
\hline 1 & 2 & 3 & 4 & 5 & 6 \\
\hline 1 & 2 & 3 & 4 & 5 & 6 \\
\hline 1 & 2 & 3 & 4 & 5 & 6 \\
\hline 1 & 2 & 3 & 4 & 5 & 6 \\
\hline 1 & 2 & 3 & 4 & 5 & 6 \\
\hline 1 & 2 & 3 & 4 & 5 & 6 \\
\hline 1 & 2 & 3 & 4 & 5 & 6 \\
\hline 1 & 2 & 3 & 4 & 5 & 6 \\
\hline 1 & 2 & 3 & 4 & 5 & 6 \\
\hline 1 & 2 & 3 & 4 & 5 & 6 \\
\hline 1 & 2 & 3 & 4 & 5 & 6 \\
\hline 1 & 2 & 3 & 4 & 5 & 6 \\
\hline 1 & 2 & 3 & 4 & 5 & 6 \\
\hline 1 & 2 & 3 & 4 & 5 & 6 \\
\hline 1 & 2 & 3 & 4 & 5 & 6 \\
\hline 1 & 2 & 3 & 4 & 5 & 6 \\
\hline 1 & 2 & 3 & 4 & 5 & 6 \\
\hline 1 & 2 & 3 & 4 & 5 & 6 \\
\hline 1 & 2 & 3 & 4 & 5 & 6 \\
\hline 1 & 2 & 3 & 4 & 5 & 6 \\
\hline
\end{tabular}

8. I feel consumed by my illness.

9. I only think of my illness when I have to.

10. My illness has undermined my confidence in myself and what I can do.

11. At times, it seems like my illness runs my life.

12. I have preserved my sense of self, in spite of my illness.

13. It seems like almost everything I do is influenced by my illness.

14. I do many of the same things as healthy others, despite my illness.

15. My illness has affected nearly all aspects of my life.

16. My illness prevents me from doing things I need to do.

17. I do not let my illness take over my life.

18. I am dominated by my illness.

19. My illness has not kept me from doing the things I enjoy doing.

20. My illness prevents me from being the kind of person that I wish to be.

21. I see myself as a healthy person, in spite of my illness.

22. I rarely feel trapped by my illness.

23. My illness dictates nearly everything I do.

2 
Appendix B

ISC Support Scale

The following items refer to your social support network (your spouse or partner, family, and close friends). CIRCLE the number that corresponds to how you feel. Please respond to the questions below using this scale:

My social support network...

$\begin{array}{lcccc}\text { Strongly Disagree } & \begin{array}{c}\text { Somewhat } \\ \text { Disagree }\end{array} & \begin{array}{c}\text { Somewhat } \\ \text { Agree }\end{array} & \text { Agree } & \begin{array}{c}\text { Strongly } \\ \text { Agree }\end{array}\end{array}$

1. Points out the things I can do in spite of my

$$
1
$$

2

3

4

5

6

2. Helps me focus on life apart from my illness.

1

3. Sometimes makes me conscious of my physical limitations.

4. Makes me feel that I am a capable person.

5. Encourages me to be involved in activities that are important to me.

6. Makes it seem as though my illness runs my life.

7. Treats me differently than healthy others in a way that makes me feel incompetent.

8. Helps me take my mind off of my illness.

9. Underestimates my ability to do things.

10. Reminds me that my illness does not define me.

11. Undermines my confidence in myself and what I can do.

1

2

3

4

5

6

2

3

4

5

6

1

2

3

$\begin{array}{lll}4 & 5 & 6 \\ 4 & 5 & 6\end{array}$

1

2

3

1

2

3

$\begin{array}{lll}4 & 5 & 6 \\ 4 & 5 & 6\end{array}$

12. Makes me feel like I cannot do much now that I am ill.

13. Sometimes views me as a "sick" person in a way that makes me feel helpless.

14. Helps me keep my illness in perspective.

$\begin{array}{lll}4 & 5 & 6\end{array}$

$\begin{array}{lll}4 & 5 & 6\end{array}$


Appendix C

Illness Intrusiveness Ratings Scale

The following items ask about how much your illness and/or its treatment interfere with different aspects of your life. Please CIRCLE the number that best describes your current life situation. If an item is not applicable, please circle the number one (1) to indicate that this aspect of your life is not affected very much. Please do not leave any item unanswered.

How much does your illness and/or Not very

Very its treatment interfere with your:

Much

Much

1. Health

1

2

3

4

5

7

2. Diet (i.e., the things you eat and drink)

3. Work

4. Active recreation (e.g., sports)

1

1

2

3

5

6

7

5. Passive recreation (e.g., reading,

1

2

3

4

5

6

7

listening to music)

6. Financial situation

7. Relationship with your spouse (girlfriend or boyfriend if not married)

8. Sex life

9. Family relationships

10. Other social relationships

1

1

2

2

3

4

5

6

7

11. Self-expression/Selfimprovement

12. Religious expression

13. Community and civic involvement 
Appendix D

Fibromyalgia Impact Questionnaire (FIQ)

Directions: For questions 1 through 11, please CIRCLE the number that best describes how you did overall for the past week. If you don't normally do something that is asked, cross the question out.

Were you able to...

1. Do shopping?

2. Do laundry with a washer/dryer?

3. Prepare meals?

4. Wash dishes/cooking utensils by hand?

5. Vacuum a rug?

6. Make beds?

7. Walk several blocks?

8. Visit friends or relatives?

9. Do yard work?

10. Drive a car?

11. Climb stairs?

\section{Always Most Occasionally Never Times}

0

$0 \quad 1$

2

3

$0 \quad 1$

2

3

$0 \quad 1$

$\begin{array}{ll}0 & 1\end{array}$

0

1

0

1

$\begin{array}{ll}0 & 1\end{array}$

0

1

0

1

0

1

2

2

2

2

23

2

3

3

3

12. Of the 7 days in the past week, how many days did you feel good?

0 1

2

3

4

5

6

7

13. How many days last week did you miss work, including housework, because of fibromyalgia?

o

1

2

3

4

5

6

7 
Directions: For the remaining items, place a mark like this / at the point on the line that best indicates how you felt overall for the past week.

14. When you worked, how much did pain or other symptoms of your fibromyalgia interfere with your ability to do your work, including housework?

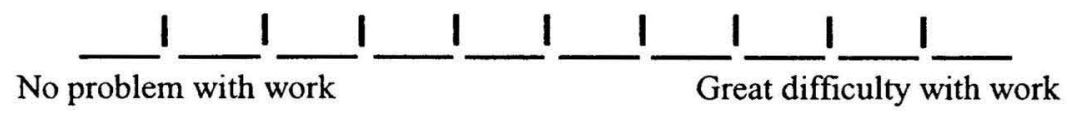

15. How bad has your pain been?

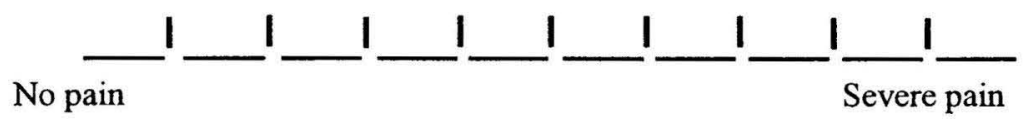

16. How tired have you been?

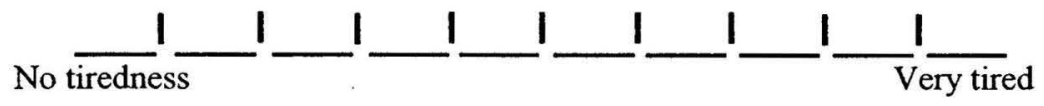

17. How have you felt when you get up in the morning?

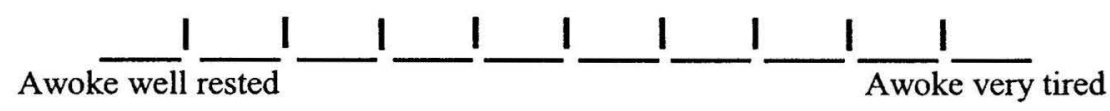

18. How bad has your stiffness been?

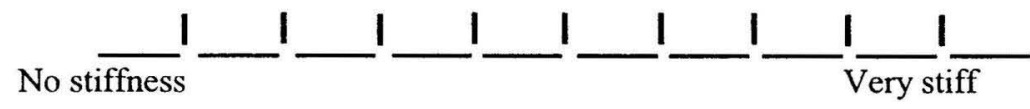

19. How nervous or anxious have you felt?

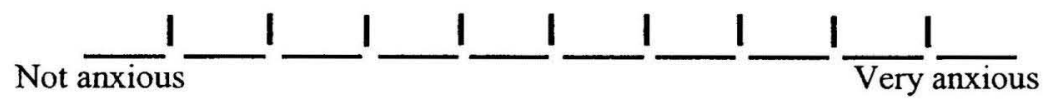

20. How depressed or blue have you felt?

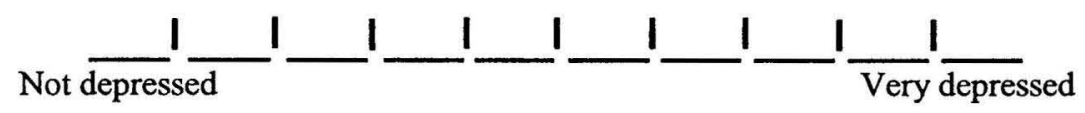

21. How victimized do you feel by your illness?

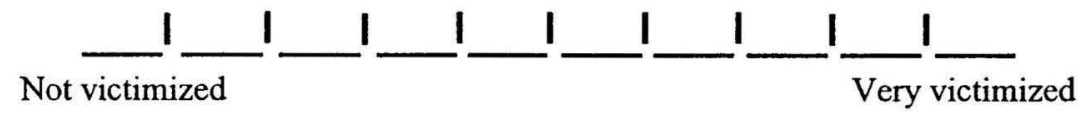

22. How much control do you have over your pain?

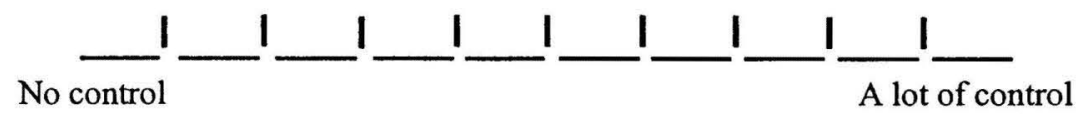

23. How much control do you have over your fatigue?

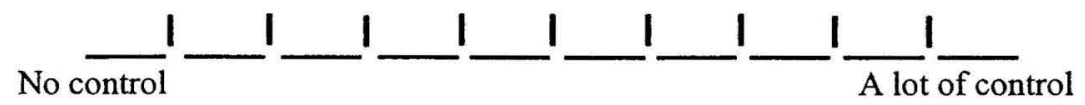


Appendix E

Life Orientation Test- Revised (LOT-R)

Please indicate the extent to which you agree with each of the following statements. CIRCLE the number that corresponds to how you feel.

\begin{tabular}{|c|c|c|c|c|c|}
\hline & $\begin{array}{l}\text { Strongly } \\
\text { Disagree }\end{array}$ & Disagree & Neutral & Agree & $\begin{array}{l}\text { Strongly } \\
\text { Agree }\end{array}$ \\
\hline $\begin{array}{l}\text { 1. In uncertain times, I usually expect the } \\
\text { best. }\end{array}$ & 1 & 2 & 3 & 4 & 5 \\
\hline 2. It's easy for me to relax. & 1 & 2 & 3 & 4 & 5 \\
\hline 3. If something can go wrong for me, it will. & 1 & 2 & 3 & 4 & 5 \\
\hline 4. I'm always optimistic about the future. & 1 & 2 & 3 & 4 & 5 \\
\hline 5. I enjoy friends a lot. & 1 & 2 & 3 & 4 & 5 \\
\hline 6. It's important for me to keep busy. & 1 & 2 & 3 & 4 & 5 \\
\hline 7. I hardly ever expect things to go my way. & 1 & 2 & 3 & 4 & 5 \\
\hline 8. I don't get upset too easily. & 1 & 2 & 3 & 4 & 5 \\
\hline $\begin{array}{l}\text { 9. Overall, I expect more good things to } \\
\text { happen to me than bad. }\end{array}$ & 1 & 2 & 3 & 4 & 5 \\
\hline $\begin{array}{l}\text { 10. I rarely count on good things happening to } \\
\text { me. }\end{array}$ & 1 & 2 & 3 & 4 & 5 \\
\hline
\end{tabular}


Appendix F

\section{Marlowe-Crowne Social Desirability Scale}

Read each statement carefully, then CIRCLE TRUE or FALSE for each item:

1. It is sometimes hard for me to go on with my work if I am not encouraged.

2. I sometimes feel resentful when I don't get my way.

True False

True False

3. On a few occasions, I have given up doing something because I thought too little of my ability.

True False

4. There have been times when I felt like rebelling against people in authority even though I knew they were right.

True False

5. No matter who I'm talking to, I'm always a good listener.

True False

6. There have been occasions when I took advantage of someone.

True False

7. I'm always willing to admit it when I make a mistake.

True False

8. I sometimes try to get even, rather than forgive and forget.

True False

9. I am always courteous, even to people who are disagreeable.

True False

10. I have never been irked when people expressed ideas very different

True False from my own.

11. There have been times when I was quite jealous of the good fortune

True False of others.

12. I sometimes get irritated by people who ask favors of me.

True False

13. I have never deliberately said something that hurt someone else's feelings.

True False 
Appendix G

Quality of Life

CIRCLE the number that corresponds to how you feel:

1. I generally feel in good spirits.

2

Always true
Often true
3

Sometimes

true
4

Seldom

true
5

Never true

2. I find a good deal of happiness in life.

1

Always true
2

Often true
3

Sometimes

true
4
Seldom
true

5

Never

true

3. Everything considered, how satisfied or dissatisfied would you say you are with your life these days?

$\begin{array}{ccccccc}\mathbf{1} & \mathbf{2} & \mathbf{3} & \mathbf{4} & \mathbf{5} & \mathbf{6} & \mathbf{7} \\ \begin{array}{c}\text { Very } \\ \text { satisfied }\end{array} & \text { Satisfied } & \begin{array}{c}\text { Somewhat } \\ \text { satisfied }\end{array} & \text { Neutral } & \begin{array}{c}\text { Somewhat } \\ \text { dissatisfied }\end{array} & \text { Dissatisfied } & \begin{array}{c}\text { Very } \\ \text { dissatisfied }\end{array}\end{array}$

4. Everything considered, how would you rate your present life?

$\begin{array}{cccccc}1 & \mathbf{2} & \mathbf{3} & \mathbf{4} & \mathbf{5} & \mathbf{6} \\ \begin{array}{c}\text { Not } \\ \text { satisfactory }\end{array} & \begin{array}{c}\text { Clearly below } \\ \text { average }\end{array} & \begin{array}{c}\text { A little below } \\ \text { average }\end{array} & \begin{array}{c}\text { A little above } \\ \text { average }\end{array} & \begin{array}{c}\text { Clearly above } \\ \text { average }\end{array} & \begin{array}{c}\text { Very good } \\ \end{array}\end{array}$




\title{
Appendix $\mathrm{H}$ \\ Beck Depression Inventory (BDI)
}

\begin{abstract}
Please read each group of statements carefully. Then pick out the one statement in each group which best describes the way you have been feeling the past month, including today. CIRCLE the number beside the statement you picked. If several statements in the group seem to apply equally well, circle each one. Be sure to read all the statements in each group before making your choice.
\end{abstract}

0 I do not feel sad.

1 I feel sad.

2 I am sad all the time and I can't snap out of it.

3 I am so sad or unhappy that I can't stand it.

0 I am not particularly discouraged about the future.

1 I feel discouraged about the future.

2 I feel I have nothing to look forward to.

3 I feel that the future is hopeless and that things cannot improve.

- I do not feel like a failure.

1 I feel I have failed more than the average person.

2 As I look back on my life, all I can see is a lot of failures.

3 I feel I am a complete failure as a person.

0 I get as much satisfaction out of things as I used to.

1 I don't enjoy things the way I used to.

2 I don't get real satisfaction out of anything anymore.

3 I am dissatisfied or bored with everything.

0 I don't feel particularly guilty.

1 I feel guilty a good part of the time.

2 I feel quite guilty most of the time.

3 I feel guilty all of the time.

0 I don't feel I am being punished.

1 I feel I may be punished.

2 I expect to be punished.

3 I feel I am being punished.

0 I don't feel disappointed in myself.

1 I am disappointed in myself.

2 I am disgusted with myself.

3 I hate myself.

- I don't feel I am any worse than anybody else.

1 I am critical of myself for my weaknesses or mistakes.

2 I blame myself all the time for my faults.

3 I blame myself for everything bad that happens.

- I don't cry any more than usual.

1 I cry more now than I used to.

2 I cry all the time now.

3 I used to be able to cry, but now I can't cry even though I want to.

0 I am no more irritated now than I ever am.

1 I get annoyed or irritated more easily than I used to.

2 I feel irritated all the time now.

3 I don't get irritated at all by the things that used to irritate me. 


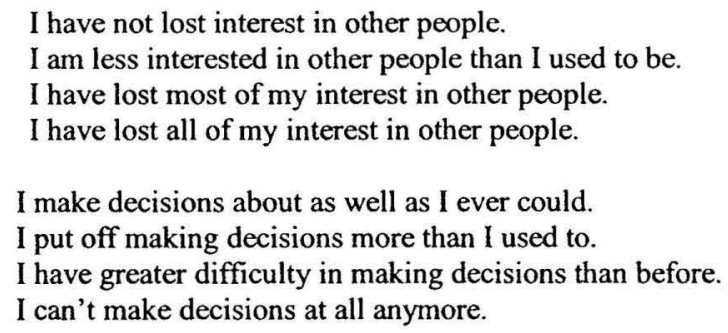

0 I can sleep as well as usual.

1 I don't sleep as well as I used to.

2 I wake up one to two hours earlier than usual and find it hard to get back to sleep.

3 I wake up several hours earlier than I used to and cannot get back to sleep.

$0 \quad$ I don't get more tired than usual.

1 I get tired more easily than I used to.

2 I get tired from doing almost anything.

3 I am too tired to do anything.

$0 \quad$ My appetite is no worse than usual.

1 My appetite is not as good as it used to be.

2 My appetite is much worse now.

$3 \quad$ I have no appetite at all anymore.

0 I haven't lost much weight, if any lately.

1 I have lost more than 5 pounds.

2 I have lost more than 10 pounds.

3 I have lost more than 15 pounds.

I am purposely trying to lose weight by eating less (Circle one).

$1 \quad$ Yes

2 No

0 I am no more worried about my health than usual.

1 I am worried about physical problems such as aches and pains, or upset stomach, or constipation.

2 I am very worried about physical problems and it's hard to think or do much else.

3 I am so worried about my physical problems that I cannot think about anything else.

0 I have not noticed any recent change in my interest in sex.

1 I am less interested in sex than I used to be.

$2 \quad$ I am much less interested in sex now.

$3 \quad$ I have lost interest in sex completely. 